\title{
DIE NEUERE ENTWICKLUNG \\ DES LANDSCHAFTSBEGRIFFES
}

\author{
Otto Wernli
}

Mit 11 Abbildungen

\section{VORWORT}

Im Jahre 1935 hat Kurt BürgER eine Auslegung des Landschaftsbegriffes vorgenommen und damit in bedeutsamer Art zur Entfaltung der geographischen Wissenschaft beigetragen. Unter Berücksichtigung der seitherigen Entwicklung der Kenntnisse drängt sich jedoch schon heute eine weitere Klärung dieses wichtigen Begriffes auf.

Der Titel verspricht eine geschichtliche Untersuchung. Dazu sind zwei Bemerkungen unerläßlich: Zunächst einmal ist der betrachtete Zeitraum kurz; trotzdem bildeten sich gegenüber der Vergangenheit verschiedene neue Auffassungen heraus. Er ist indessen zu kurz, als daß sich darin eine selektive Kraft hätte bemerkbar machen können, welche Bewährtes aus Unbewährtem auszulesen imstande gewesen wäre, und darum stehen die Meinungen und Vorschläge für den nicht speziell methodologisch geschulten Geographen als mehr oder weniger gleichberechtigt nebeneinander. Die gewählte Zeitspanne läßt also nicht ohne weiteres ein allgemein annehmbares und für die Zukunft wegweisendes Ergebnis hervortreten. Verlangt man nun gleichwohl darnach, denn die Arbeit befriedigt nur, wenn sie weiterführt, dann ist man zu werten gezwungen. Innerhalb eines gewissen Rahmens ist dieses Vorgehen erlaubt; es sind ihm jedoch enge Grenzen gesteckt. Aus diesem Grunde darf hier nicht etwa eine neue und alles Bisherige souverän überbauende Landschaftsauffassung oder Landschaftsmethodik gesucht werden. Eher handelt es sich um eine sinngemäße Gegenüberstellung bestehender Lösungen und um deren Deutung von einem grundsätzlichen Standpunkte her.

Die Arbeit weist dementsprechend auch nicht ein letztes und alles umfassendes Schlußresultat auf. Ein solches muß in der Summe der verschiedenenorts ermittelten Teilresultate gesehen werden. Über manche Einzelfragen sind wohl noch spezielle Darstellungen erforderlich.

Die gesamte Untersuchung gründet auf den Ergebnissen von mehreren verschiedenartigen Arbeiten, von Quellen, die tiefer erfaßt und ausgewertet wurden, und anderen, aus denen ich bei Gelegenheit eine Anregung schöpfte, die mir aber als solche kaum mehr gegenwärtig sind. Die breiteste Grundlage ergab die Verarbeitung der geographisch-methodologischen Literatur der letzten Jahrzehnte, wovon in erster Linie Werke aus dem deutschsprachigen Kulturbereich ausgewählt wurden.

$\mathrm{Da} \beta$ die Untersuchung durchgeführt werden konnte, verdanke ich hauptsächlich den unzähligen wertvollen Anregungen, welche mir Herr Privatdozent Dr. H. CAROL seit Jahren in unseren gemeinsamen Diskussionen geboten hat, und der bereitwilligen Unterstützung von Herrn Prof. Dr. H. Boesch, dem Direktor des Geographischen Institutes an der Universität Zürich. Ferner ist Herr Prof. Dr. E. WinkLER von der Eidgenössischen Technischen Hochschule durch seine Hinweise in Vorlesungen und früheren Aussprachen nicht unmaßgeblich beteiligt an meiner Einstellung $\mathrm{zu}$ den behandelten Problemen. 


\section{A. PROBLEMSTELLUNG}

a) Der Landschaftsbegriff und die Geographie - b) Methodologische Bemerkungen -

c) Die Verwendbarkeit des Landschaftsbegriffes - d) Die Aufgabe

a) «Es entspricht dem Geist der Zeit, daß seit etwa drei Jahrzehnten in der geographischen Wissenschaft ein starker Zug zur Synthese zu verspüren ist» ${ }^{1}$. Unter der geographischen Synthese wird der Zusammenklang der Einzelerscheinungen in der Erdhülle verstanden, und dieser Zusammenklang wieder manifestiert sich im Objekt, das heute allgemein als Landschaft bezeichnet wird. «In der deutschen geographischen Literatur prägte S. PASSARge 1913 den Ausdruck ,Landschaftsgeographie' und propagierte von $1919 \mathrm{ab}$ in mehreren bekannten Werken den schon zweimal 1884 und 1885 verwendeten Begriff der ,Landschaftskunde', den er als einen neuen $Z$ weig der Erdkunde vorstellte» ${ }^{2}$.

Wenn die Landschaft als geographisches Untersuchungsobjekt anerkannt wurde, so hängt diese Tatsache bestimmt mit dem wissenschaftlichen Zeitgeschehen zusammen; sicher spielte aber eine ebenso wesentliche Rolle, da $\beta$ die Geographie in der Landschaft das Objekt gefunden hat, das ihr zur Selbständigkeit und zu einem einheitlichen Charakter verhelfen sollte. Gerade aus diesem Grunde erlangte die Landschaft mehr und mehr zentrale Bedeutung. ( $\mathrm{Da} \beta$ der Grund als solcher einem persönlichen Anliegen der Geographen entsprang, ist nicht entscheidend; wichtig bleibt der erzielte Fortschritt.) Wohl hielt es HetTnER noch im Jahre 1919 für nötig, die Frage der Einheit der Geographie an den Anfang jeder geographischen Diskussion zu stellen ${ }^{3}$. Doch schon 1935 kam BürgER in seiner Dissertation ${ }^{4}$ zum Schluß: «Die Geographie ist in der Tat eine einheitliche Wissenschaft, steht doch ihr ganzes Schaffen unter einem einzigen Begriffe, dem Begriffe der Landschaft.» Und inzwischen sind wir dahin gelangt, da es wenige geographische Arbeiten mehr gibt, die nicht von der Voraussetzung ausgehen, daß die Landschaft das Untersuchungsobjekt der Geographie ist. «Die Landschaft ist der Gegenstand geographischer Forschung. Darüber besteht, wie ein Überblick über die neuere methodologische, geographische Literatur zeigt, kaum eine Verschiedenheit der Auffassungen», sagt beispielsweise BoEsch ${ }^{5}$. LAUTENSACH und andere sprechen von den «geographischen Zentralbegriffen Land und Landschaft $\gg^{6}$, und in dem eben herausgekommenen Handbuch der Mittelschulpädagogik findet man die Formulierung: «Als Wissenschaft ist sie (die Geographie) eine selbständige Disziplin, denn die Selbständigkeit einer Wissenschaft wird bedingt durch den Forschungsgegenstand, in unserem Falle die Landschaft der Erde, und durch die Fragestellungen, nach denen der Forschungsgegenstand untersucht und dargestellt wird. Die Geographie hat ihren eigenen Problemkreis, wenn sie sich auch mit vielen anderen Wissenschaften berührt und mehrere Hilfswissenschaften besitzt ${ }^{7}$.

Im Verlauf von etwa vierzig Jahren ist Tatsache geworden, was sich von den ersten konkreten Vorstellungen an über ein Jahrhundert hinweg vorbereitete: Die Landschaft ist zum anerkannten Untersuchungsobjekt, sogar, wie sich WINKLER ${ }^{8}$ ausdrückt, zum «Inbegriff» der Geographie geworden, und auf ihr wissenschaftliches Erfassen konzentriert sich dementsprechend die Aufgabe der heutigen Geographen. An dieser Feststellung ändert nicht, daß führende Forscher sich nicht binden lassen und der Geographie weiterhin auch noch andere Ziele stecken.

1 Troll, Die geogr. Landschaft und ihre Erforschung, S. 163.

2 Troll, ebd.

${ }^{3}$ Hettner, Die Einheit der Geographie, S. 3.

+ Bürger, Der Landschaftsbegriff, S. 114.

${ }^{5}$ BoEsCh, Amerikanische Landschaft, S. 5.

${ }^{6}$ Lautensach, Der Geographische Formenwandel, S. 2.

7 W AGNER, Der erdkundliche Unterricht, S. 12-13.

${ }^{8}$ WINKLER, Landschaft als Inbegriff der Geographie, S. 137. 
Wieviel mit der allgemeinen Anerkennung des Landschaftsobjektes inbezug auf die erwünschte Einheitlichkeit und Selbständigkeit der Geographie tatsächlich erreicht ist, kann allerdings heute noch nicht eindeutig beurteilt werden. Wenn auch «die Gegenstandsfixierung in eine recht erfreuliche Phase der Abklärung getreten ist», betont WINKLER, «so bestehen doch nach wie vor Differenzen über Umfang und Inhalt des Begriffs Landschaft und vor allem auch über die Art und Weise, wie das Gebilde, das er bezeichnet, objektgemäß zu erfassen ist ${ }^{9}$. Aus dieser Feststellung erwächst als dringende gegenwärtige Forderung die systematische Klärung des Landschaftsbegriffes und die Herleitung einer ihm entsprechenden Methodik. Das praktisch-geographische Arbeiten vermag dieser Forderung offensichtlich nicht zu genügen.

b) Friedrich Sch NeIDeR sagt in «Philosophie der Gegenwart» 1953: «Das wissenschaftliche Erkennen ist am Anfang bestimmt durch das, was man eigentlich will» 10. Und Paul NigGLI (1945) ausführlicher: «Es ist nicht so, daß beschreibende Naturwissenschaft durch bloße Registrierung des Beobachteten entsteht, daß es genügt, in der Darstellung wahr zu sein. Wie der Künstler darf man sich der Natur nicht passiv hingeben, man muß das, was sich dem Auge darbietet, in seinen ureigensten Besitz bringen, neu gestalten.» «Gerade (aber natürlich nicht nur) für die sogenannte beschreibende Naturwissenschaft gilt, daß sie nur Wissenschaft ist, wenn sie mit königlicher Souveränität, innerhalb der ihr gegebenen Freiheiten, gliedert, gestaltet, hervorhebt und mit wohlerwogenen Gründen auf die Seite schiebt, damit sich, frei von Arabesken, eine Grunderkenntnis entschleiert»11. Im selben Sinne äußert sich HettNer schon 1927 vom Standpunkt der Geographie aus: «Die glückliche Idee entspringt allerdings aus der Versenkung in den Gegenstand; aber sie muß durch systematische Klärung der Begriffe vorbereitet und durch systematischen Vergleich bestätigt werden》12. Und LAUTENSACH in jüngster Gegenwart: «Die wissenschaftliche Geographie befindet sich zur Zeit in einer Entwicklungsphase, die von großer Bedeutung für die Zukunft werden kann, wenn sie die Schärfung ihrer Grundbegriffe als eine notwendige Voraussetzung erfolgreicher Arbeit betrachtet» 13 .

$\mathrm{Da} ß$ eine den heutigen Ansprüchen genügende Klärung des geographischen Landschaftsbegriffes noch aussteht und darum die gesamte Methodik des Faches als wenig gefestigt erscheint, findet verschiedene Deutungen. Die hauptsächliche ist die, daß das geographische eines der komplexesten wissenschaftlichen Untersuchungsobjekte darstellt und eine dementsprechend differenzierte Methode verlangt, die nur allmählich und durch stetige Überprüfung gewonnen werden kann. Dann muß die Konzeption der geographischen Forschung seit der Einführung des Landschaftsbegriffes von Grund auf neu durchdacht und gestaltet werden, wobei traditionsgebundene Auffassungen nicht leicht zu überwinden sind. Und schließlich ist nicht zu übersehen, daß man innerhalb der Geographie die Bedeutung des methodologischen Arbeitens unterschätzt und deshalb auch vernachlässigt hat.

Die bisherigen Bemerkungen führen an die eigentliche Problemstellung heran. Fragen wir uns zunächst, was wir unter dem «Begriff» der Landschaft verstehen, so zeigen sich im Hinblick auf unsere Aufgabe folgende Merkmale: Zum Wesen des Begriffes gehört, daß er ein abgerundetes, durch deutliche Grenzen umschlossenes Ganzes bezeichnet, das sich von anderen Ganzheiten allseitig unterscheidet. Wohl setzt sich diese Ganzheit in mannigfacher Weise aus Einzelnem zusammen, die Teile sind jedoch miteinander verbunden und ergeben einen einheitlich geformten Inhalt. Bei einer Erörterung des Landschaftsbegriffes wird es folglich in erster Linie darum gehen müssen, diesen komplexen und begrenzten Inhalt zu erkennen und möglichst

\footnotetext{
${ }^{9}$ WinkLER, Landschaft als Inbegriff der Geographie, S. 137.

10 Schneider, Philosophie der Gegenwart, S. 60.

11 Niggli, Schulung und Naturerkenntnis, S. 184-185.

12 Hettner, Die Geographie, ihre Geschichte..., S. 294.

13 Lautensach, Über die Begriffe Typus und Individuum, S. 28 (Zitat gekürzt).
} 
klar hervortreten zu lassen. Indem wir ferner denkend die Einzelvorstellungen zueinander in Beziehung bringen, sehen wir sie auch in ihrem inneren Zusammenhang, in der besonderen Form der Zusammengehörigkeit. Es resultiert aus diesem denkenden Durchdringen des Landschaftsbegriffes die Art seines inneren Aufbaues oder das logische Gesetz in der Verknüpfung seiner Bestandteile. Aus dem Wesen des Begriffes Landschaft leiten sich somit Aufgabe und Weg unserer Untersuchung ab.

c) Über die skizzierte Problemstellung hinaus stellt sich auch die Frage nach der Verwendbarkeit des noch umstrittenen Landschaftsbegriffes. Vorläufig stehen nämlich konkrete Ergebnisse noch aus, und die gegenwärtige Situation, wie sie neulich (1955) E. NEEF zusammenfaßte, ist wenig zukunftweisend: «Die laufenden Bemühungen um Landschaftsbegriff und Landschaftsgliederung haben $\mathrm{zu}$ keinem endgültigen und allgemein anerkannten Ergebnis geführt. Man muß sich ernstlich fragen, ob sie überhaupt zu dem gewünschten Ergebnis führen können... Damit ist aber die Frage der Brauchbarkeit des Landschaftsbegriffes angeschnitten oder, besser, die Frage, welche Bedeutung der Landschaftsvorstellung für die Geographie theoretisch zukommt ${ }^{\mathbf{1 4}}$.

Der vorliegende Versuch zur Beurteilung der Verwendbarkeit des Landschaftsbegriffes geht von der negativen Kritik aus, der er immer wieder ausgesetzt ist. Bekanntlich werden drei Vorwürfe erhoben: Ein erster liegt darin, daß zu große Vielfalt in seiner Inhaltgebung bestehe, da $\beta$ er beinahe von Wissenschafter zu Wissenschafter in neuer Bedeutung oder zum mindesten mit einer anderen und nicht immer klar durchschaubaren Nuancierung Verwendung finde. Die beiden weiteren Vorwürfe beziehen sich auf Nachteile, welche aus der Komplexität der Landschaft erwachsen. Die Landschaft sei als Ganzes einer wissenschaftlichen Durchdringung unzugänglich, und sie verliere andererseits, wenn sie in ihre Teile zerlegt werde, den ursprünglichen, nur ihr eigenen Charakter. Tatsächlich scheint es keine geographische Arbeit zu geben, die auf die Landschaft in einer umfassenden Art einzugehen vermöchte, und umgekehrt erweckt jedes gliedernde Vorgehen bald den Eindruck einer spezialwissenschaftlichen und nicht mehr einer landschaftlich-geographischen Untersuchung.

Der erste Vorwurf stellt die Brauchbarkeit des Landschaftsbegriffes überhaupt in Frage; die beiden andern bedeuten zum mindesten eine Einschränkung, und zwar von der synthetisierenden wie von der analysierenden Seite her. Wie weit diese Einschränkung reicht, oder, umgekehrt, wie groß die uneingeschränkte Gültigkeit bleibt, ist die offene Frage.

d) Wie aus der vorausgehenden Darstellung zu ersehen ist, sind es drei Einzelthemen, welche zur Behandlung kommen sollen: 1. Die Vorstellung vom Landschaftsinhalt, 2. die landschaftliche Struktur und 3. die Verwendbarkeit des Landschaftsbegriffes. Alle haben sich dem Hauptthema unterzuordnen. Das heißt hier, daß sie jeweilen auf die neuere Entwicklung bezogen werden müssen. Es wird richtig sein, in einem ersten Abschnitt die Ausgangssituation zu bestimmen und zu charakterisieren. Von ihr ausgehend und auf sie bezogen werden sich die Linien der Entwicklung aufzeigen und beurteilen lassen.

\section{B. DIE AUSGANGSSITUATION}

\section{Begrenzung der berücksichtigten Zeitspanne}

a) Die sachlichen Gründe für die vorgenommene zeitliche Abgrenzung - b) Die praktischen Gründe - c) Die Verwertung der Gestalttheorie - d) Aus dem allgemeinen geistigen Zeitgeschehen hergeleitete Gründe.

a) Im Bereiche der geographischen Forschung hat es, wie wir rückblickend feststellen, eine Reihe von Jahren gegeben, die mehrere gemeinsame Merkmale aufweisen und darum sinnvoll als eine zeitliche Einheit für diese Untersuchung angenommen

${ }^{14}$ in: SieberT, Wort, Begriff und Wesen der Landschaft, S. 6. 
werden können. $\mathrm{Zu}$ diesen Merkmalen gehört vorab die bei den meisten Geographen erkennbare Tendenz, die Landschaft als ihr zentrales Untersuchungsobjekt aufzufassen. Wenn sie auch früher schon vereinzelt zur Darstellung gelangte, so geschah es doch nicht so eindringlich, wie sich in neuerer Zeit das geographische Arbeiten in voller Erkenntnis ihrer Bedeutung um ihre wissenschaftliche Betrachtung bemüht. Hinzu kommt die Einsicht in die Kompliziertheit des landschaftlichen Objektes, eine Erkenntnis, welche imstande ist, die früher undifferenzierte und falsche Auffassung zu ersetzen, wonach mit der Einführung des Landschaftsbegriffes schon alle Probleme aufgezeigt und ein ungerichtetes Weiterwachsen der Geographie verhindert sei. Die letzten Jahre lehren im Gegenteil - und das ist ihr weiterer gemeinsamer Zug -, daß mit der Anerkennung des Landschaftsobjektes die Besinnung auf die eigentlichen Grundlagen der Geographie erst begonnen hat und daß die am tiefsten liegenden Unklarheiten damit Gegenstand der Untersuchung werden.

Die Zeitspanne, die so durch eine relative Einheitlichkeit in der Auffassung von der Aufgabe der Geographie und durch eine große Vielfalt der auftretenden Probleme und ihrer Lösungen gekennzeichnet ist, umfaßt ungefähr die letzten drei Jahrzehnte.

b) Die Gegenwart bedeutet sicher nicht das Ende dieser Periode, sondern sie ist eher der Brennpunkt aufeinandertreffender Auffassungen mitten in der intensivsten Auseinandersetzung. Der Ausgangspunkt hingegen ist als solcher klar gekennzeichnet; ihm kommt die Eigenschaft einer deutlichen Wende und damit auch eines neuen Beginnes zu. Er manifestiert sich in der Haltung und in den Anschauungen des führenden Geographen Hettner. Seine zusammenfassende Methodik aus dem Jahre 192715 enthält gerafft Rückschau, Gegenwart und Ausblick, und sie ist unseren $Z$ wecken darum in besonderem Maße dienlich.

Neben der Möglichkeit, die Arbeit Hettners zu verwerten, gehört zur Gruppe der praktischen Gründe für die Abgrenzung des Stoffbereiches auch die Tatsache, daß die Literatur aus dem letzten Vierteljahrhundert überblickt werden kann, ohne daß dabei wichtige Einzelzüge vernachlässigt werden müssen. Im übrigen hat derselbe Zeitabschnitt für eine Bearbeitung den Vorteil, daß die geographisch-methodische Thematik in mehreren Kulturbereichen gleichartig und darum auch vergleichbar ist. Schließlich steht am Beginn dieser Periode - sozusagen als Vorläufer meiner Untersuchung - die von Kurt Bürger verfaßte Arbeit über den Landschaftsbegriff der vergangenen Zeit ${ }^{16}$.

c) Und eine weitere Feststellung charakterisiert die erwähnte Zeitspanne: Die wissenschaftliche Denkweise hat in der Gestalttheorie eine Möglichkeit geschaffen, die Eigenart von komplex aufgebauten Untersuchungsobjekten zu erfassen. Sie auch auf die Landschaft anzuwenden, wurde in den letzten Jahren das Bemühen der Geographie. Die Geographie erfuhr dadurch ihre bedeutsame Entwicklung, da die Gestalttheorie ihr zu einem eigenen, markanteren Gepräge verhalf und ihr gegenüber anderen Wissenschaften eine größere Selbständigkeit verlieh. Eine Wahrnehmung ist vor allem wirksam geworden: Landschaft, als Gestalt gesehen, ist aus der summativen Betrachtungsweise nicht zu verstehen. Neben Art, Zahl und Größe der Einzelteile haben vor allem die zwischen diesen bestehenden Beziehungen Bedeutung. Die Beziehungen konstituieren die Gesamtheit, als welche die Gestalt erscheint.

d) Der Landschaftsbegriff ist für die heutige geographische Forschung zum repräsentativen Begriff geworden. Er ist das Kennzeichen einer neuen Situation, und șeine wissenschaftliche Verwendung vermöchte schon für sich allein die Wahl und Abgrenzung des Zeitraumes zu rechtfertigen, die für diese Untersuchung getroffen wurde. Diese Zeit hat sich jedoch noch in anderer und ganz wesentlicher Weise als eine

15 Hetrtner, Die Geographie, ihre Geschichte..

16 Bürger, Der Landschaftsbegriff. 
solche erweiterter und tieferer Erkenntnis erwiesen. Seit dem Übergang vom 19. zum 20. Jahrhundert verflüchtigt sich der Anspruch auf unbedingten Wahrheitsbesitz mehr und mehr auch aus dem Wissenschaftsbereich. Das Denken über Zeit und Raum erschloß von neuem gegenüber einer einstmals allzu optimistischen Auffassung die überwunden geglaubte Ansicht, welche die Möglichkeit wissenschaftlicher Erkenntnis in die Grenzen des immer wieder nur Vorläufigen verweist. Was wir nachweislich erkennen, sind bloß Aspekte der Wahrheit. Das Absolute ist uns verborgen; es wird zwar in Teilwahrheiten sichtbar, erscheint aber in wandelbarer Gestalt. An ihm haften die vergänglichen Wesenszüge des Betrachters und die Bedingtheit der äußeren Umstände.

Auf der Grundlage dieser Anschauung ist der Vorbehalt zu verstehen, den Prof. BoEsch macht, wenn er schreibt: «Jede Definition der geographischen Landschaft entspricht dem jeweiligen Stand der Erkenntnis und wird somit früher oder später überholt sein. Gleichzeitig sind nebeneinander verschiedene Definitionen möglich, indem jede für eine verschiedene Auffassung steht» ${ }^{17}$. Was der Wissenschafter heute erkennt und in umfassender Definition festhält, ist wahr, wiewohl nicht endgültig wahr. Sie stellt eine in der Auffassung begründete und damit modifizierbare Wahrheit dar, auch wo sie einstweilen als unanfechtbare Erkenntnis erscheint.

Dem Geographen der Gegenwart bedeutet diese Feststellung, daß ihm die Landschaft immer nur in bedingter Form entgegentritt. Die Bedingung selbst ergibt sich durch die jeweilige Betrachtungsweise, die von unserem Interesse, unserem Standpunkt und letztlich auch von unseren technischen Möglichkeiten abhängig ist. Es bleibt vor allem das Verdienst von Hans CAROL, diese Einsicht systematisch gefördert zu haben, indem er die «Betrachtungssysteme» in die Landschaftskunde einführte. Er leistet damit an die Wissenschaft einen entscheidenden Beitrag. ( $\mathrm{Zu}$ den Betrachtungssystemen ist er, wie seine Arbeiten zeigen, von unten aufbauend über die heute als sekundär zu wertenden «Betrachtungsrichtungen» vorgestoßen.) Unter den Betrachtungssystemen versteht er das Herantreten an die Landschaft von bestimmten Gesichtspunkten her, und er erreicht damit, daß auf einmal je ein wesentlicher Aspekt klar erfaßt werden kann.

\section{Die Vorstellung vom Landschaftsinhalt vor einem Vierteljahrhundert}

\section{Einführung}

Den Landschaftsbegriff dadurch erhellen zu wollen, daß man alle bestehenden Deutungs- und Anwendungsmöglichkeiten nennt und nebeneinander stellt, scheint wenig erfolgversprechend zu sein. Man tappt, wenn man so vorgeht, in einem grenzenlosen Raum und entbehrt des Maßstabes, um die nötigen Beziehungen herstellen zu können. Günstiger ist es, wenn von außen her, und zwar immer wieder neu, an die Aufgabe herangetreten und die Bezugsebene nicht in der zu betrachtenden Materie selbst gesucht wird. Bei der vorliegenden Arbeit sei, soweit möglich, dieser zweite Weg begangen; was in den Kapiteln A und BI dargestellt wurde, bildet dazu die allgemeine geistige Grundlage.

Im Augenblick steht als konkrete Aufgabe im Vordergrund, den Landschaftsbegriff, wie er vor einem Vierteljahrhundert üblich war, zu erfassen. Die Lösung ist deshalb nicht einfach, weil geographische Darstellungen in den Anfängen der Landschaftskunde häufig vage, gefühlsbetont und widerspruchsvoll waren. Umsomehr ist es jedenfalls notwendig, daß einmal jede Aussage zergliedert und einzeln untersucht wird. Der Weg mag als mühsam empfunden werden. Eine Zusammenfassung am Schluß des Kapitels B soll dann die Einheit wieder herstellen.

${ }^{17}$ BoEsch, Amerikanische Landschaft, S. 6. 
«Unter einer geographischen Landschaft versteht die heutige Geographie einen Teil der Erdoberfläche, der nach seinem äußeren Bilde und dem Zusammenwirken seiner Erscheinungen sowie den inneren und äußeren Lagebeziehungen eine Raumeinheit von bestimmtem Charakter bildet, der diesen Erdraum von seiner Umgebung unterscheidet», stellt BüRGER in seiner Arbeit «Der Landschaftsbegriff» 18 im Jahre 1935 fest. Diese Definition ist für die damalige Zeit repräsentativ, und es sei nun inbezug auf die inhaltgebende Substanz herausgehoben, was sie festhält.

Es sind drei Tatsachen:

1. Die Landschaft bildet einen Teil der Erdoberfläche.

2. $\mathrm{Zu}$ einer Landschaft gehört, was sie in vierfacher Hinsicht einheitlich macht: - einheitlich nach dem visuellen Eindruck,

- nach der Art des Verbundenseins ihrer Elemente, dem «Zusammenwirken der Erscheinungen »,

- von den inneren und

- von den äußeren Lagebeziehungen her.

3. Der Inhalt verleiht der Landschaft einen bestimmten Charakter und unterscheidet sie dadurch von ihrer Umgebung.

Diese Art Landschaft ist, wie BüRGER weiterfährt, «objektiv gegeben ». Sie stellt eine «natürliche Einheit»dar, und vom geographischen Gesichtspunkt aus ist ihr mit einer möglichst naturwahren Darstellung Genüge getan. - Was nun die drei genannten Tatsachen im einzelnen betrifft, so werden sie, wie folgt, weiter charakterisiert. (Zitate und Meinungen ohne weitere Quellenangabe stammen aus der genannten Bürgerschen Arbeit.)

\section{Die Landschaft als Raumeinheit innerhalb der Erdoberfläche}

Die Gesamtheit aller Landschaften macht die Erdoberfläche aus. Dabei stehen die Landschaften nicht «in vollständiger Einsamkeit» einfach nebeneinander, sondern sie sind durch Wechselbeziehungen miteinander verbunden und bilden somit ein «einziges großes System »19.

Durch die Wechselbeziehungen wird, über die Landschaften hinaus, auch die gesamte Erdoberfläche zu einer «individuellen Einheit» geformt. Aber es scheint mir, daß bei dieser um 1935 typischen Betrachtungsweise nur den einzelnen Landschaften die Bedeutung von konkreten Objekten bleibt und ihnen gegenüber der umfassende Erdoberflächenbegriff beinahe zu einem Abstraktum verblaßt. Praktisch wird ihm nämlich nicht mehr zugedacht als die Rolle, der Systematik zuliebe über den Landschaften zu stehen und diese zu sammeln. Der Begriff der Erdoberfläche büßt gegenüber jenem der Landschaft noch mehr an wissenschaftlich verwertbarem Gehalt ein als beispielsweise der Vegetationsbegriff dem Pflanzenbegriff gegenüber. Das Gesagte wird übrigens dadurch bestätigt, daß der Ausdruck «Erdoberfläche» ungenau geprägt ist, bedeutet er doch in jeder geographischen Interpretation einen Raum.

Hettner macht scheinbar eine Ausnahme: er verleiht dem Erdoberflächenbegriff, im Gegensatz zu anderen Autoren, einen spezifischen Wert. Genau besehen verwendet allerdings auch er ihn nicht in der Meinung, damit ein eigentliches Untersuchungsobjekt zu bezeichnen. Für ihn hat er ebenfalls in erster Linie systematische Geltung, wie ein Satz aus seinem Hauptwerk ${ }^{20}$ zeigt: «Ziel der chorologischen Auffassung ist die Erkenntnis des Charakters der Länder und Örtlichkeiten aus dem Verständnis des

18 BÜrger, Der Landschaftsbegriff, S. 29.

19 BÜRGER, Der Landschaftsbegriff, S. 39-41.

20 Hetrner, Die Geographie, ihre Geschichte...., S. 130. 
Zusammenseins und Zusammenwirkens der verschiedenen Naturreiche und ihrer verschiedenen Erscheinungsformen und die Auffassung der ganzen Erdoberfläche in ihrer natürlichen Gliederung in Erdteile, Länder, Landschaften und Örtlichkeiten.»

Für unsere Untersuchung ist nun wesentlich, welcher Inhalt dem damaligen Landschaftsbegriff zugesprochen wurde.

2. Der durch die vierfache Einheitlichkeit bestimmte Vorstellungsinhalt der Landschaft

a) Das Problem der landschaftlichen Einheit - b) Die visuelle und die assoziierende Komponente für die Inhaltsbestimmung - c) Die Bedeutung der Lagebeziehungen.

a) $\mathrm{Da}$ die Landschaft die in der Auslegung Bürgers genannte Einheitlichkeit aufweisen soll, ist eine nirgends begründete Tatsache; sie ist vielmehr eine zweckdienliche Forderung, und aus dieser Forderung werden die Auswahlprinzipien für alles Landschaftliche hergeleitet. Ausgewählt wird sehr wenig von allem, was nach heutigen Begriffen zur Landschaft zählen könnte, und der frühere Landschaftsbegriff muß dementsprechend als «substanzarm» bezeichnet werden.

Wenn Bürger im Anschluß an seine Definition von einer «objektiv gegebenen》 oder «natürlichen Landschaftseinheit» spricht, so ist auch diese Feststellung nicht unbesehen hinzunehmen. Sie muß zum mindesten ergänzt werden in dem Sinn, daß auch die «Objektivität» dem zeitbedingten Postulat der Einheitlichkeit untergeordnet bleibt. Bürgers Landschaftsbegriff deckt sich mit dem Einheitsbegriff. Was nicht einheitlich ist, ist für ihn und seine Zeit auch nicht landschaftlich; und «objektiv gegeben sein 》 bedeutet in diesem Zusammenhang nichts anderes als: vorhanden und für die Einheitstheorie verwendbar sein! - Bezeichnend ist, daß praktischen Arbeiten keineswegs mit der Theorie im Einklang stehen. Es zeigt sich schon zu jener Zeit, daß eine nur annähernd befriedigende Einheitlichkeit schwer zu erreichen ist, es sei denn, daß man ihr zuliebe den Inhalt sehr stark reduzierte - im Grunde genommen bis auf ein einzelnes Element. Falls man dies nicht tut oder vielmehr nicht tun kann, wenn man landschaftlich und nicht spezialwissenschaftlich arbeiten will, treten die schon häufig und fruchtlos erörterten Grenzprobleme auf 21.

b) Die zwei ersten und wohl wichtigsten Auswahlprinzipien sind der «Anteil am äußeren Bilde der Landschaft» und das «Zusammenwirken der Erscheinungen» oder - in kürzerer Form ausgesprochen - das visuelle und das assoziierende Prinzip. Was für das Auge sichtbar und was an verbindenden Kräften zwischen den Landschaftselementen vorhanden ist, hat landschaftliche Qualitäten. Berücksichtigt werden (nach einer Zusammenstellung Bürgers) die Oberflächenformen, der klimatische Erscheinungskreis, das Wasser, das Pflanzenkleid und Tier und Mensch.

"Der Wechsel von Hoch und Tief, von Flachland und Gebirge und die Abgrenzung des Landes gegenüber dem Wasser, das sind die auffallendsten $Z$ üge des Landschaftsbildes ”. Aus dieser Behauptung zieht Bürger den für unsere Ausgangssituation wesentlichen Schluß, daß die $\propto$ Morphologie die wichtigste Teilwissenschaft der Geographie und die genetische Betrachtung der Erdoberflächenformen das Kernstück von länderkundlichen Darstellungen» bilden. Eine gewisse Eigenständigkeit der Morphologie wird allerdings bereits herausgespürt und darum für sie eine zweifache Einengung vorgenommen: die Beschreibung dürfe gegenüber der Erklärung nicht zu kurz kommen, und die Ergebnisse müßten weniger für sich als in ihrer Wirkung auf die verschiedensten Landschaftselemente und diese wieder in ihrer Bedeutung für die Morphologie gesehen werden.

Beim Klima hat - merkwürdigerweise gerade umgekehrt wie bei der Morphologie - da Deskriptive in den Hintergrund zu treten. BÜRGER lehnt aber auch eine Klimaphysik innerhalb der Geographie ab, und darum verlangt er, daß jede geographische Klimabetrachtung mit Komplexbegriffen arbeite und im besonderen das Zusammenwirken der klimatischen Elemente betone.

Was weiter das Wasser in der Landschaft betrifft, so ist es ein Element, das "belebt", und dies in doppelter Hinsicht: es ist Grundbedingung für das Leben, und es entscheidet darüber, ob

${ }^{21}$ Siehe die Hinweise in : WINDLER, Zur Methodik der geographischen Grenzziehung, S. 130-133. 
eine Landschaft dem Betrachter als tot oder lebendig erscheint. «Das Wasser ist das , Auge " im Portrait der Landschaft und eines der wichtigsten Glieder der landschaftlichen Dynamik.”

Dem Pflanzenkleid wird eine mehrfache Bedeutung zugeschrieben. Es ist der wichtigste * Sonnenstrahlentransformator», das beste meteorologische Instrument, auf dem Weg über das Klima ein Höhen- und Oberflächenformenindikator und schließlich auch ein deutlicher Spiegel der edaphischen Verhältnisse. Fast überflüssig zu erwähnen, daß alle Pflanzen auch einen großen Anteil am äußeren Bilde der Landschaft haben, wobei weniger die Einzelpflanzen als vielmehr flächenhaft wirkende Bestände eine Rolle spielen.

Über die Tiere sagt Bürger, daß sie in ihrer Bedeutung für die Landschaft mit der Pflanzenwelt nicht zu vergleichen seien, weil sie nur punktweise auftreten und vielfach außerdem im Farbenund Blätterschutz der Vegetation stehen. "Immerhin - fährt er weiter - verdankt manche Landschaft diesen oder jenen eindrucksvollen Zug ihrer Tierwelt.»

Und der Mensch schließlich wirkt sowohl durch sein körperliches Dasein wie indirekt über seine * höheren geistigen Anlagen ", die es ihm ermöglichen, eine Kultur zu schaffen. *Weil der Mensch in der Kulturlandschaft ein hervorragender Landschaftsbildner ist, erwirbt er sich Heimatrecht in der geographischen Wissenschaft." Die Aufnahme des Menschen und seiner Schöpfungen erschwere zwar die Arbeit des Geographen, aber der Gerlandsche Versuch (Arbeit über die wissenschaftliche Aufgabe der Geographie aus dem Jahre 1887), den Menschen vollständig aus der Geographie hinauszuwerfen, müsse als ein verfehltes Unternehmen betrachtet werden.

Das von Bürger genannte erste Auswahlprinzip, welches als zur Landschaft gehörend gelten läßt, was Anteil an ihrem äußeren Bilde hat, ist enger gefaßt, als wie man es beispielsweise bei PASSARge 22 vorfindet. Dieser Autor läßt als landschaftlich alles sinnlich Wahrnehmbare zu, alles, was «mit dem Auge, dem Gehör, mit Gefühl, Geruch, Geschmack» aufgenommen werden kann. Der Auffassung Passarges braucht aber keine besondere Beachtung geschenkt zu werden, weil sie rein theoretischen Charakter hat. Für das praktische Arbeiten gilt nämlich auch bei ihm vornehmlich das visuelle Prinzip.

c) Landschaftliche Qualitäten haben außer den visuell in Erscheinung tretenden Gegebenheiten und den zwischen ihnen bestehenden Bindungen, wie vorne festgehalten: die inneren und die äußeren Lagebeziehungen.

Was mit den äußeren Lagebeziehungen gemeint ist, geht deutlich aus der Bürgerschen Arbeit hervor, hingegen läßt sich keine genaue Bestimmung der inneren Beziehungen finden; vor allem nicht, wenn diese noch etwas anderes sein sollten als das schon genannte «Zusammenwirken der Erscheinungen». (An dieser Stelle sei mir die Bemerkung erlaubt, daß die erwähnte Unklarheit keinen Einzelfall in der methodologisch-geographischen Literatur darstellt. Ich empfinde es vielmehr als verbreiteten Mangel, daß man sich nicht bestimmt und auch nicht widerspruchsfrei ausdrückt.)

Unter den äußeren Lagebeziehungen sind Bindungen von Landschaft zu Landschaft gemeint. Die äußeren Lagebeziehungen erklären jene Erscheinungen, welche aus ihrer eigenen Landschaft heraus nicht verstanden werden könnten; Fremdlingsformen, wie sich PASSARGE 23 ausdrückt. "Wir begegnen solchen Fremdlingserscheinungen auf Schritt und Tritt», bemerkt BüRgER. «Die großartigsten Beispiele sind die Lößmassen Chinas und der aus regenreichen Landschaften kommende Nil.»

\section{Landschaftsinhalt und Landschaftscharakter}

Ein letztes Kriterium, welches zwischen landschaftlichen und nicht-landschaftlichen Gegebenheiten entscheidet, liegt in der weiteren und alles Bisherige irgendwie zusammenfassenden Forderung, daß die Landschaft einen eigenen, von ihrer Umgebung unterschiedlichen Charakter haben soll. BüRGER schenkt diesem Kriterium keine große Beachtung mehr, und er äußert sich darum auch weniger ausführlich dazu als etwa Hetrner. Dieser Autor prägt die beiden, ihrem Sinne nach immer wiederkehrenden Sätze: «Geographisch sind die Erscheinungen nur insofern, als sie an verschie-

22 Passarge, Einführung in die Landschaftskunde, S. 1.

23 Passarge, Vergleichende Landschaftskunde, Heft 1, S. 12. 
denen Stellen der Erdoberfläche verschieden ausgebildet sind», und : «Erscheinungen, die überall gleich sind, gehen nicht in die Geographie ein » ${ }^{\mathbf{4}}$.

Die Bemerkung Hetrners hilft mit, den Landschaftsinhalt zu beschränken. Tatsächlich ist das Interesse des Geographen auf die Differenziertheit und die große Mannigfaltigkeit der landschaftlichen Phänomene gerichtet, doch schließt das nicht aus, daß auch in einem weiteren Bereiche gleichartige Erscheinungen berücksichtigt werden. Sogar der Erdmagnetismus, der die gesamte Erde umspannt, kann gegebenenfalls geographisch verwertet werden.

\section{Die Bürgersche Definition ergänzende Auffassungen}

a) Methodische, auf die Zeit bezogene und praktische Überlegungen bei der Bestimmung des Landschaftsinhaltes - b) Sachliche und unsachliche Kriterien für die Inhaltsbestimmung -

c) Hinweise auf wirklichkeitsnähere Landschaftsauffassungen.

a) Die Bürgersche Definition ist repräsentativ für die Landschaftsauffassung ihrer Zeit, aber sie ist doch bloß Definition, was heißt, daß mit ihr nur die wesentlichen Merkmale erfaßt sind. Für die Bestimmung des Landschaftsinhaltes kamen neben den fünf genannten sachlichen Prinzipien hie und da auch drei andere zur Anwendung, von denen hier noch kurz gesprochen sei. Das eine davon ist methodischer Art, das andere steht im Zusammenhang mit der Zeit, und das dritte ergab sich aus praktischen Überlegungen.

Unter den drei Prinzipien das wichtigste ist wohl das methodische. Wie dieses etwa zur Auswirkung kommen konnte, ist auf Seite 8 am Beispiel der Oberflächenformen bereits dargelegt worden. Man sah einerseits, daß die Oberflächenformen zu den «auffallendsten Zügen des Landschaftsbildes» gehören und eingehender betrachtet werden müssen, andererseits durfte ihre Behandlung nicht derart in den Mittelpunkt rücken, daß daraus eine selbständige Morphologie mit landschaftsunabhängigen Ergebnissen erwachsen konnte. Die Einsicht führte zu folgender methodischer Vorschrift: erstens müsse die Beschreibung gegenüber der Erklärung besonderes Gewicht bekommen, und zweitens sollten die Oberflächenformen weniger für sich als in ihrer Wirkung auf die verschiedensten Landschaftselemente zur Darstellung gelangen. Die zweite Einschränkung ist noch einigermaßen verständlich, die erste hingegen bedeutet eine unbegreifliche Entwertung und Einengung der Geographie. Die Absicht, Morphologie und Landschaftskunde voneinander zu trennen, wird selbstverständlich nicht beanstandet. Fraglich ist jedoch, ob das gesteckte Ziel über methodische Vorschriften erreicht werden müsse. Ich bin überzeugt, daß eine Wissenschaft, der man vorschreibt, auf das Erklären zu verzichten, keine echte Wissenschaft mehr ist. Die wegweisende Frage scheint mir die zu sein, inwiefern Erdoberflächenformen landschaftlich relevant seien.

Nun ist es seit Dilthey zwar allgemein üblich, daß erklärende und beschreibende Wissenschaften gelegentlich voneinander geschieden werden, und darum sei an dieser Stelle eine prinzipielle Erörterung eingeflochten.

Tatsächlich besteht die Möglichkeit, die Realwissenschaften zwei Gruppen zuzuordnen, deren Gegensätzlichkeit in den Begriffen «erklären》 und «beschreiben» aufzugehen scheint. Beide Begriffe dienen aber im vorliegenden Zusammenhang bestimmt nur als Hilfsbegriffe, welche die wirklich existierende Unterschiedlichkeit nicht wiederzugeben vermögen. «Erklärung» und «Beschreibung» sind zwei im Dienste der Wissenschaft stehende Methoden der Objektsbetrachtung, wobei die eine bei dieser und die zweite bei jener Wissenschaft im Vordergrund stehen mag, beide aber, um erfolgreich zu sein, kombiniert werden müssen, «und zwar nicht nur einmalig, sondern der Entwicklung der Erkenntnisse folgend, immer und immer wieder von

${ }^{24}$ Hettner, Die Geographie, ihre Geschichte..., S. $140^{\circ}$ und S. 217. 
neuem »25. (Selbst in Wissenschaften, welche nach allgemeinem Dafürhalten nur für die eine Methode prädestiniert erscheinen, war auf die Dauer ohne die ergänzende zweite Methode nicht auszukommen ${ }^{26}$.) Und das gilt auch für die Geographie. Die bisherigen geographischen Arbeiten lassen deutlich erkennen, daß die einseitig postulierte Beschreibung in der Praxis in keiner Weise ausreichte und daß eben auch die erklärende Methode herangezogen werden mußte... offenbar ganz nach der jeweils vorliegenden Situation. Beispielsweise sollte bei der Betrachtung des klimatischen Erscheinungskreises - gerade umgekehrt wie bei den Erdoberflächenformen - die Beschreibung der Erklärung weichen, wie folgender Satz aus der Bürgerschen Arbeit zeigt: "Eine Klimabetrachtung im Rahmen einer landeskundlichen Darstellung wird dann nicht befriedigen, wenn sie ausschließlich deskriptiv eingestellt ist ${ }^{27}$.

Die zutreffenden Bezeichnungen für den angedeuteten Gegensatz gibt NigGLI ${ }^{28}$. Auf die Seite des sogenannten «Erklärens»stellt er die Begriffspaare «abstrakt-generalisierend», «atektonisch-imperativ» und «ursächlich-erklärend». Die Seite des «Beschreibens» wird charakterisiert mit: «vergleichend-systematisch», «tektonischnormativ» und «urbildlich-erläuternd». Und richtig ist nun eben, daß auch die «vergleichend-systematische» oder «tektonisch-normative» Forschung erklärt. Diese Art des Erklärens hat allerdings nicht die Kausalität zum Gegenstand, sondern sie versucht, wie Niggli sagt, den Zusammenhang zwischen Idee, Urbild und Verwirklichung herzustellen, und anstatt nach Kausalgesetzen tendiert sie nach Strukturgesetzen ${ }^{29}$.

Und nun der Faktor Zeit? - Für die Inhaltsbestimmung der Landschaft kam er derart uneinheitlich zur Verwendung, daß er im Grunde genommen unwirksam bleiben mußte. Man prägte zuerst einmal die heute noch zu hörende Formulierung von der Geographie als Gegenwartswissenschaft. Weil sie aber nicht uneingeschränkt verwendbar war, traten bald da, bald dort Anpassungen verschiedenster Art auf. Bei Bürger liest man: «Will die Geographie zu einem wirklichen Verständnis der Landschaften gelangen, so kann sie weder von der wichtigen Erscheinung der Vorzeitformen absehen, noch an der Tatsache vorübergehen, daß auch die Jetztformen ihre Wurzeln in der Vergangenheit haben. Der Geograph betrachtet aber die Vergangenheit nicht um ihrer selbst willen, sondern lediglich als Schlüssel zum Verständnis der heutigen Landschaft.» Und an anderer Stelle: «Wir haben die Geographie eine Gegenwartswissenschaft genannt... Das soll natürlich nicht heissen, daß es den Geographen grundsätzlich verboten sein soll, sich führend auf dem Gebiete der Geschichte der Landschaft zu betätigen. Eine solche Fundierung ist im Gegenteil gerade bei der Kulturlandschaft sehr erwünscht.»- Eine Äußerung Hettners ${ }^{30}$ besagt, daß die Zeit auch in die Geographie gehöre, daß sie aber in den Hintergrund zu treten habe. Man verfolge nicht den Ablauf der Zeit als solchen, sondern lege zu verschiedenen Zeiten Querschnitte. Die Geographie bedürfe der genetischen Auffassung, sie soll aber nicht zur Geschichte werden. - Spethmann möchte aus der Vergangenheit noch alles heute Wirksame berücksichtigen, und A. PENCK endlich behilft sich so, daß er die geographische Gegenwart besonders definiert. Sie sei nicht dem Augenblick gleichzusetzen, sondern ihr entspreche für eine bestimmte Landschaftserscheinung derjenige von heute rückwärts gerechnete Zeitraum, in dem sich diese Erscheinung nicht oder nur wenig verändert habe.

Noch fragwürdiger als die Zeit bleibt das dritte Hilfsmittel zur Umgrenzung des Landschaftsinhaltes: die praktischen Überlegungen. Folgender Satz aus der Arbeit

${ }^{25}$ Niggli, Probleme der Naturwissenschaften, S. 37.

${ }^{26} \mathrm{Vgl}$. dazu die Ausführungen Nigglis in "Probleme der Naturwissenschaften ", S. $13 \mathrm{ff}$.

27 Vgl. S. 8 der vorliegenden Arbeit.

${ }^{28}$ NigGli, Probleme der Naturwissenschaften, S. 20.

${ }^{29}$ Vgl. dazu auch den Abschnitt D II.

${ }^{30}$ HeTrner, Die Geographie, ihre Geschichte..., S. 131-132. 
Bürgers mag als Beleg genügen: «Die Oberflächenformen werden in einer Landschaftsbetrachtung eine um so größere Rolle spielen, je größer der für die Darstellung zur Verfügung stehende Raum ist».

b) Sachliche Kriterien bilden in allen Wissenschaften eine notwendige Voraussetzung, um Untersuchungsgegenstände inhaltlich voneinander zu trennen. Sie sind auch in der Geographie unerläßlich, alle übrigen Kriterien dagegen nicht zulässig. Diese wirken denn auch, wie die drei oben genannten Beispiele zeigen, unnatürlich. In der Wahl der Methoden und Mittel muß der Wissenschafter frei bleiben; er darf nicht an willkürliche und widerspruchsvolle Vorschriften gebunden sein. Entscheidend bleibt das Objekt. Selbst die Vielgestaltigkeit der Landschaft kann ein Abweichen von der wissenschaftlichen Norm nicht rechtfertigen.

«Der Gegenstand der Forschung bestimmt den Charakter einer Wissenschaft», sagt Paul Niggli ${ }^{31}$. Nun hat zwar auch WINKLER mit seiner Einschränkung recht: «sofern Wissenschaft als Ganzes nicht selbst nur Methode ist»32. Mit dieser Art Methode ist aber die wissenschaftliche Haltung im Gegensatz zur unwissenschaftlichen Betrachtungsweise gemeint.

Es ist unverkennbar, daß der Landschaftsauffassung vor einem Vierteljahrhundert eine höhere, umfassendere und dem Gegenstand entsprechende Betrachtungsebene fehlte. Man war beeinflußt von bereits weiter entwickelten Wissenschaften und versuchte, die Geographie ihnen gleichzustellen. Dazu erachtete man in erster Linie ein einheitliches und klar umgrenztes Untersuchungsobjekt als notwendig. Da die Landschaft die erwünschten Eigenschaften nicht augenfällig zeigte, versuchte man ihr mit Vorschriften aller Art beizukommen. Zuerst wählte man aus der mannigfaltigen Wirklichkeit sachlich aus, was man sich als zur Landschaft gehörend denken konnte. Wie sich dieses Vorgehen aber als ungenügend erwies, um das postulierte eigenständige und klar umrissene Objekt inhaltlich zu bestimmen, nahm man Zuflucht zu den erwähnten methodischen, zeitlichen und praktischen Einschränkungen.

c) Daß schon zu Bürgers Zeit viele Geographen die Landschaft umfassender gesehen haben, als wie sie in der bisherigen Darstellung charakterisiert worden ist, beweisen die Versuche, den Inhalt, welcher mit der üblichen Auffassung vernachläßigt wurde, auch noch in irgend einer Art einzubeziehen.

Aus diesem Bestreben heraus erwuchsen beispielsweise - angeregt durch PASSARgE - eine vergleichende und eine räumliche Landschaftskunde: «Die vergleichende Landschaftskunde erforscht die Natur- und Kulturlandschaftstypen. Sie ist rein physiognomisch eingestellt und einheitlich aufgebaut, da sie auch aus dem anthropogeographischen Erscheinungskreis alles sinnlich Wahrnehmbare seiner landschaftlichen Bedeutung entsprechend berücksichtigt. Demgegenüber hat die räumliche Landschaftskunde von den wirklichen Landschaften mit allen ihren landschaftlich wirksamen individuellen Merkmalen auszugehen und eine für bestimmte Erdoberflächenräume kein Element prinzipiell auslassende Landschaftsgliederung vorzunehmen» (nach Bürger).

Nach einer andern Ansicht - deren Vertreter Schlüter war - sollte der Stoffkreis nur so weit eingeschränkt werden, als er das Wesen der Landschaft bestimme. Für die Landschaftserklärung allerdings, meinte ScHLürER, müsse dann oft sehr weit über diesen Stoffkreis hinausgegangen werden. Er unterscheidet darum zwischen «eigentlichen Gegenständen»der Geographie und den «gestaltenden Faktoren».

In der dynamischen Länderkunde Spethmanns schließlich kommt eine dritte Auffassung zur Darstellung. SpethmanN geht von der Überzeugung aus, daß kein allgemein gültiges Schema verwendet werden könne. Der Maßstab, nach dem man sich zu richten habe, sei die landschaftliche Auswirkung. Mit diesem Maßstab ge-

${ }^{31}$ Niggli, Probleme der Naturwissenschaften, S. $234 \mathrm{ff}$.

32 Winkler, Das System der Geographie und die Dezimalklassifikation, S. 6. 
lange man nicht zu einer Einengung des Stoffkreises, sondern zu einer für jeden Erdraum charakteristischen und individuellen Gruppierung (nach Bürger).

Die eben angedeuteten Landschaftsauffassungen kommen der Wirklichkeit bestimmt näher als alle früher dargestellten Theorien. Sie sind aus diesem Grunde in besonderem Maße der Anerkennung wert. Immerhin: auch von ihnen besitzt keine die nötige Prägnanz, um zur Grundlage der geographischen Wissenschaft zu werden. Was stört, ist das Fehlen einer einzigen, alles zusammenfassenden Konzeption. Gerade diese Konzeption zu finden, ist nun offensichtlich das Bestreben vieler Geographen der letzten Jahre, und es wird Aufgabe des nächsten Hauptabschnittes der vorliegenden Arbeit sein, die bis heute gewonnenen Ergebnisse aufzuzeigen.

Bevor nun aber auf die Weiterentwicklung eingegangen werden kann, muß auch die Vorstellung von der Landschaftsstruktur, nicht bloß jene über den Landschaftsinhalt, als Beitrag zu unserer Ausgangssituation herangezogen werden.

\section{Die Vorstellung von der Landschaftsstruktur vor einem Vierteljahrhundert}

a) Die verschiedenen Arten der Elementenbindungen - b) Die Vorstellung vom Wesen der Gesamtheit aller Elementenbindungen - c) Die Gesamtheit der Elementenbindungen im Lichte der landschaftlichen Grenzprobleme - d) Kurze Gesamtübersicht.

Daß die Elemente, die Bausteine oder Bildner der Landschaft, nicht einfach lose, ohne gegenseitige Bindungen und Wirkungen, nebeneinander gesehen werden, ist Grundbedingung jeder Landschaftsauffassung. Bestünde die Vorstellung des Unverbundenseins, dann gäbe es über den Elementen kein eigenständiges Objekt mehr. Eine bloße Anreihung von Einzelerscheinungen schafft in keinem Fall (auch außerhalb der Geographie nicht) ein neues Gebilde. Der von den Geographen häufig zitierte Satz, daß die Landschaft mehr sei als die Summe ihrer Teile, ist somit ein Axiom, wenn vorausgesetzt wird, daß es eine Landschaft gibt. Im Grunde genommen ist schon die Verwendung des Ausdruckes «Landschaft» ein Hinweis darauf, da $\beta$ an mehr als an ein bloßes Nebeneinander von Elementen gedacht wird. Bezeichnend für dieses Wort - und etymologisch auch leicht nachweisbar - ist sein «Hang zu kollektiver Bedeutung ${ }^{33}$, und ein Kollektiv ist eigenschaftsreicher als nur eine summative Ansammlung.

a) Wenn auch jeder Landschaftsauffassung ein auf höherer Ebene verbundener Inhalt gemeinsam ist, so bestehen doch von jeher verschiedene Ansichten über die Art des Verbundenseins. Zur Zeit Bürgers sind die Vorstellungen noch auffällig vage, und ihre Auswertung in der methodologischen Literatur muß man mehr gefühlsmäßig als über den Verstand zu erfassen suchen. Offenbar wurden die landschaftsbildenden $\mathrm{Zu}$ sammenhänge damals eher erahnt als klar gesehen.

Die Landschaftsdefinition aus dem Jahre 1935 sagt über das Problem des Landschaftsaufbaues wenig aus. Es gilt als selbstverständlich, daß es ein «Zusammenwirken der Erscheinungen» und «innere und äußere Lagebeziehungen» gebe; auf ihr Wesen und ihre spezifische Bedeutung jedoch wird nicht eingegangen. Nun können aber doch einige Einzelheiten den weiteren Ausführungen BürGERS ${ }^{34}$ entnommen werden, und es sei versucht, diese hier in Kürze wiederzugeben:

Grundlegend sind die kausalen Zusammenhänge zwischen den Landschaftselementen, beispielsweise die Abhängigkeit der Pflanze vom Boden, des Tieres von der Pflanze und des Menschen von der Pflanze oder vom Tier. Die Landschaft wird allerdings nicht allein durch diese einfachen Kausalreihen erklärt, sondern es ist notwendig, «die innige Verknüpfung aller Erscheinungen » zu berücksichtigen. Was darun-

33 Siebert, Wort, Begriff und Wesen der Landschaft, S. 8.

34 BURger, Der Landschaftsbegriff, S. $41 \mathrm{ff}$. 
ter verstanden wird und was nach damaliger Auffassung die landschaftliche Eigentümlichkeit im Kern trifft, kann in drei Punkte zusammengefaßt werden:

1. Außer den in einer Richtung von Element zu Element wirkenden Kausalreihen bestehen auch gegenseitige Abhängigkeiten und mehrfache Überschneidungen.

2. Die gegenseitige Beeinflussung ist nicht nur im Bereich der Elemente festzustellen, sondern auch auf der Stufe der Elementen-Komplexe.

3. Die Abhängigkeitsverhältnisse werden schließlich noch dadurch erweitert, «daß sich in der einen Wirkungsrichtung Mittelglieder einschieben, die in der umgekehrten fehlen. Dieses $Z$ wischenschalten von Mittelgliedern hat zur Folge, daß eine Landschaftserscheinung bei einer andern, je nach dem Charakter der Zwischenglieder, ganz verschiedene Wirkungen hervorrufen kann, so daß eine Verwickelung und eine Vieldeutigkeit der Beziehungen entsteht, die den Geographen bei seinen wissenschaftlichen Schlüssen $\mathrm{zu}$ außerordentlicher Vorsicht ermahnt» (nach Bürger).

b) Wenn schon die Vorstellung über die Art der Einzelbindungen als vage befunden worden ist, so gilt diese Feststellung noch viel mehr für die Synthese, für die Gesamtheit aller zwischen den Landschaftselementen bestehenden Beziehungen. (Diese Gesamtheit macht erst das Wesen einer Landschaft aus.)

Nach der Auffassung, die vor einem Vierteljahrhundert Gültigkeit hatte, ist das Netz der gegenseitigen Elementen-Bindungen - gleicherweise wie der schon besprochene Landschaftsinhalt - so beschaffen, daß daraus Raumeinheiten resultieren. Die in einem «Landschaftsraum vereinigten Erscheinungen bilden (in der Ausdrucksweise BürGERS) gewissermaßen eine Gemeinschaft des geringsten gegenseitigen Widerstandes. Sie sind einander angepaßt, in ihrer Wirkungsweise gegeneinander abgewogen. Sie stehen miteinander in einer Art Gleichgewicht, das kein Zustand, sondern immerwährendes Geschehen ist...» «Jeder anderen geographischen Landschaft entspricht eine andere typische Vergesellschaftung, eine andere Anpassungsweise der Erscheinungen und damit ein anderes Gleichgewicht, das in seiner Eigenschaft mit den zu seiner Erhaltung nötigen Vorgängen den Charakter der betrachteten Landschaft bestimmt und bewirkt, daß uns diese als innere Einheit erscheint ...»35.

Um die vermeintlich bestehenden Raumeinheiten zu kennzeichnen, wurden hauptsächlich die Begriffe «Individualität», «Gefüge», 《Struktur» und «Ganzheit» und auch bereits der Begriff der «Gestalt» verwendet. Diese synthetisierenden Bezeichnungen faßte man seinerzeit allerdings noch $z u$ starr auf und - wie es scheint - auch zu eng. Wohl wurde schon erkannt, daß es verschiedene Gestaltstufen gibt; im besonderen, daß die biologische Gestalt (der Organismus) anders geartet ist als die geographische (die Landschaft), aber wesentliche Unterschiede blieben doch übersehen. Gerade die oben von BüRGER genannten Behauptungen über die Raumeinheiten entsprechen nicht den realen Gegebenheiten, wie sie sich dem unvoreingenommenen Betrachter darbieten. Sie treffen den Aufbau eines Organismus, nicht aber denjenigen der Landschaft. Eine Landschaftscharakterisierung muß weiter gefaßt sein. Niemals sind die in einem Landschaftsraum vereinigten Erscheinungen eine «Gemeinschaft des geringsten gegenseitigen Widerstandes », und nie sind sie in ihrer Wirkungsweise derart «gegeneinander abgewogen» wie geglaubt wurde. Die landschaftliche Wirklichkeit setzt sich aus «Sphären》 zusammen, welche verschiedenen Gesetzlichkeiten unterliegen und gegenseitige Beziehungen oft nur auf dem Weg über wenige Kontaktpunkte haben.

Ein Hinweis auf die einzelnen Sphären mag klärend wirken: Ein Kristall ist eine Gestalt im Bereich des Anorganischen, der pflanzliche Organismus ist organisch, und die Gestalt der menschlichen Psyche gehört ihrerseits einer dritten Seinsstufe an, nämlich der Welt des Geistig-Seelischen. Die Landschaft umfaßt (in ihrer Art)

35 BÜrger, Der Landschaftsbegriff, S. 42-43. 
Anorganisches, Organisches und Geistig-Seelisches (den Menschen) zugleich, und sie muß schon aus diesem Grunde eine besondere Struktur aufweisen. Wären die drei genannten Seinsbereiche eng aufeinander angewiesen und würde einer den anderen kausal bedingen, dann könnte sich das von BüRGER erwähnte landschaftliche Gleichgewicht einstellen. Es bestehen aber zwischen den Seinsbereichen nur Berührungspunkte, welche bloß wenige wesensbestimmende gegenseitige Einflüsse ermöglichen. Viele Erscheinungen innerhalb eines Seinsbereiches sind von einem andern aus gesehen Zufälligkeiten, und demzufolge fehlt auch das Aufeinander-Abgestimmtsein. Es wird beispielsweise - um nur an eine konkrete Tatsache zu erinnern - nicht behauptet werden können, daß die menschlichen Siedlungen durchwegs zum genannten «Gleichgewicht»zwischen den Landschaftselementen beitragen. Schon allein die geschichtliche Feststellung, daß es zu verschiedenen Zeiten verschiedene Bauweisen gibt, müßte einer solchen Annahme widersprechen. BüRGER bekäme mit seiner Auffassung dann recht, wenn die Landschaft nur oberffächlich betrachtet würde, d.h., wenn eben allein die wenigen tatsächlich bestehenden Beziehungen zwischen unseren Bauten und ihrer Umwelt gesehen und alle Formen, die ihre Wurzeln in der menschlichen Eigengesetzlichkeit haben, vernachläßigt würden.

c) Vermutlich ging es den Geographen vor und zur Zeit Bürgers gar nicht in erster Linie darum, die nun besprochene «innige Verknüpfung》 und «gegenseitige Abhängigkeit» aller Landschaftselemente exakt festzustellen. Es lag ihnen bestimmt mehr daran, eine derartige Verknüpfung als Mittel zum Zweck benützen zu können, das heißt, um daraus Raumeinheiten (also konkrete, begrenzte und eigenständige Untersuchungsobjekte, wie sie beispielsweise die Kristalle und Organismen darstellen) abzuleiten. "Jede Gestalt ist nach innen eine Einheit bestimmten Charakters», sagt BürgER. «Jede Gestalt $m u \beta$ sich aber auch von ihrer Umgebung unterscheiden, damit sie als ein Ganzes, eine für sich bestehende Wesenheit, eben als eine selbständige Gestalt erscheint. Auch die geographische Gestalt, die geographische Landschaft!»36.

Interessant für uns ist der Umstand, daß keiner der ständig mißlungenen Versuche von praktischen landschaftlichen Grenzziehungen den Glauben an die Ganzheitstheorie zu zerstören vermochte. Man stellte unbekümmert einfach fest, daß die geographische Gestalt weniger scharf umrissen sei als etwa der Organismus, und man freute sich sogar darüber, durch diese Tatsache im Aufsuchen von Landschaftsgrenzen ein besonders «fesselndes Problem»zu besitzen ${ }^{37}$.

Die Grenzziehungsversuche blieben aber nicht nur ohne praktischen Erfolg; sie konnten offensichtlich nicht einmal der Theorie entsprechend durchgeführt werden. Es scheint selbstverständlich zu sein, daß man nicht mehr auf die Stufe der Landschaftselemente hinunter steigt, wenn man auf höherer Ebene innerlich straff gebundene Raumeinheiten abgrenzen will. Für die Geographen zur Zeit Bürgers bestand diese selbstverständliche Konsequenz auch, aber (wie angedeutet) nur im Bereich der Theorie. Es mutet merkwürdig an, einerseits lesen zu können, da $\beta$ es sich «heute nicht mehr wie bei Buache, Gatterer usw. um eine Abgrenzung von außen her, sondern um die Individualisierung von Räumen auf Grund ihres inneren Aufbaues, ihres Gestaltcharakters» handle ${ }^{38}$, und andererseits feststellen $\mathrm{zu}$ müssen, daß kein praktischer Grenzziehungsversuch auf diese Forderung Rücksicht nimmt. Man glaubte ihr vielleicht $z u$ entsprechen, indem man die früher verwendeten Grenzlinien zu Grenzsäumen erweiterte, doch auch Grenzsäume sind allein durch einzelne Elemente bedingt.

d) Mit den in den Kapiteln B II und B III wiedergegebenen Feststellungen ist der wissenschaftliche Landschaftsbegriff, dessen man sich in den $Z$ wanziger- und

\footnotetext{
${ }^{36}$ BÜrger, Der Landschaftsbegriff, S. 48.

37 BÜRger, S. 48.

38 BÚrger, S. 48.
} 
ersten Dreißigerjahren bediente, dem gesetzten Rahmen entsprechend dargestellt. Es ist nicht angestrebt worden, eine möglichts große $\mathrm{Zahl}$ bestehender Auffassungen ausfindig zu machen und nebeneinander zu stellen. Wer eine derartige Übersicht wünscht, findet sie bei BürGER ${ }^{39}$ oder in sehr umfassender Art im Werke HARTSHORnes über «Das Wesen der Geographie » 40. In der vorliegenden Arbeit geht es durchwegs darum, die wesentlichen und immer wiederkehrenden Grundzüge herauszuschälen und diese dann, soweit möglich, am allgemeinen Denken zu messen. Über das bisherige Resultat soll in der Folge (wie in der Einführung auf Seite 6 vorgesehen) eine Zusammenfassung versucht werden.

Das ursprüngliche Wort «Landschaft» bedeutet, wie Herbert LeHManN in interessanter Weise darlegt ${ }^{41}$, eine «werthaltige Totalität», welche «durch die Vereinheitlichungskraft unserer Seele, als eine durch kein mechanisches Gleichnis ausdrückbare Verschlingung des Gegebenen mit unserem Schöpfersinn » lebte. Diese Totalität «tritt bereits in dem Bewußtseinsakt auf, der überhaupt Landschaft erzeugt, das heißt in jedem bewußten Landschaftssehen ». Solange das menschliche Verhältnis zur Natur «magisch oder mythisch, jedenfalls unmittelbar» war, gab es keine Landschaft. «,Landschaft' setzt eine Individualisierung der inneren und äußeren Daseinsformen voraus. Erst die Auflösung der ursprünglichen Gebundenheiten und Verbundenheiten zu differenzierten Eigenbeständen - diese große Formel der nachmittelalterlichen Welt - hat uns aus der Natur auch die Landschaft heraussehen lassen.»

Diese Deutung des Wesens der Landschaft (der Landschaft als «psychische Reaktion des Menschen auf einen gegebenen Tatbestand ${ }^{42}$ ) mußte ihre Gültigkeit verlieren mit der Entwicklung der spezifisch modernen Wissenschaften. Die aus den Wissenschaften entsprungenen «Ideen haben die Vorstellung des Menschen von sich selbst und von der Welt verwandelt ${ }^{43}$, im besonderen das Schwergewicht vom betrachtenden Subjekt auf das zu betrachtende Objekt verlagert. Diese Tatsache bedeutete für die Geographie, daß nunmehr nach der «Objektseite des Phänomens Landschaft» gefragt wurde ${ }^{44}$. ( Schon für Humbold liegt der Schwerpunkt ziemlich eindeutig auf der Objektseite», sagt Herbert LeHManN.)

Vorübergehend drohte die genannte Umstellung den Landschaftsbegriff zu zerstören oder zum mindesten zu entwerten, denn es schien den modernen Wissenschaften zu gelingen, die Menschheit davon zu überzeugen, daß allein das Atomisierbare in der Natur entscheidend sei und nur in einer bis zum letzten Baustein zerlegten Welt die Lösung der unser Leben begleitenden Rätsel liege. Es waren dann aber doch die gleichen Wissenschaften, welche die Begriffe der «Ganzheit» und der «Gestalt»indizierten, und, bezugnehmend auf diese neu gesehenen Daseinsstufen, konnte nun auch der Landschaftsbegriff als objektive «werthaltige Totalität» Bedeutung erlangen. Die neue Geltung wurde gegenüber der früheren sogar insofern größer, als die Landschaft nicht mehr nur Gegenstand des gefühlsbestimmten Naturliebhabers und des Künstlers blieb, sondern ebenso deutlich als wissenschaftliches Untersuchungsobjekt Interesse $\mathrm{zu}$ wecken begann. Was aus der Umstellung also resultierte, war die Betonung des Objekts, und der Geograph hatte nun an Stelle der «Vereinheitlichungskraft unserer Seele» die Einheitlichkeit der Landschaft selbst aufzudecken. Damit eröffnete sich aber die große und heute noch bestehende Problematik der Landschaftskunde.

Es ist verständlich, daß man sich im Zuge der Umstellung zunächst noch an die psychisch bedingte Landschaftsvorstellung anlehnte. Diese wurde bestimmt durch das visuelle Bild, und darauf sollte nun auch die wissenschaftliche und objektgebundene

\footnotetext{
39 BÜrger, Der Landschaftsbegriff.

*0 Hartshorne, The Nature of Geography.

41 Lehmann, Die Physiognomie der Landschaft, S. 185 und S. 188.

42 Lehmann, S. 188.

43 Oppenheimer, Wissenschaft und allgemeines Denken, S. 8.

44 Lehmann, Die Physiognomie der Landschaft, S. 188.
} 
Deutung in erster Linie Rücksicht nehmen. Das visuelle Landschaftsbild läßt die verwobene Wirklichkeit in mehr oder weniger kompakten Einheiten erscheinen, und das ist der Grund, warum auch die Landschaftskunde lange Zeit ihre Objekte speziell in solchen Einheiten sehen wollte. Die aus der Psychologie und der Biologie übernommenen Begriffe der «Ganzheit» und der «Gestalt» - beide immer wieder zu starr aufgefaßt - halfen zunächst mit, das Streben nach begrenzten und in sich geschlossenen Raumganzheiten zu unterstützen. Und dieses Streben schließlich führte seinerseits, weil es nämlich den tatsächlichen Gegebenheiten zuwiderläuft, zu erzwungenen und unnatürlich wirkenden Auffassungen, Formulierungen und Teillösungen.

\section{DIE NEUERE ENTWICKLUNG DES LANDSCHAFTSBEGRIFFES}

\section{Landschaftskundliches Begriffssystem}

\section{Einführung: Über die Möglichkeit der Erkenntnis}

Die nun folgende Untersuchung über die neuere Entwicklung des Landschaftsbegriffes macht es notwendig, ein Bezugssystem zu begründen, das erlaubt, die Entwicklung zuverlässig einzumessen und den jüngeren Landschaftsbegriff in vielem auch erst eigentlich verständlich zu machen. Bei der Beurteilung des früheren Landschaftsbegriffes bedurfte es eines präziseren Maßstabes deshalb noch nicht, weil jener grobzügiger gefaßt war als der neue. Erst in den letzten Jahren ging die Landschaftsauffassung tiefer und erwuchsen Nuancen gegen Nuancen.

Auf der Seite 6 unserer Darlegungen hat sich eine bestimmte und für die Fortführung der Untersuchung wesentliche Anschauungsweise des Seins (also auch des landschaftlichen Seins) mehrmals in verschiedener Form wiederholt: eigentliche Wirklichkeit und durch unsere Sinnes- und Geisteskräfte erfaßte Wirklichkeit weisen voneinander abweichende Inhalte auf. Diese Auffassung ist nun auch für die geschichtliche Untersuchung wegleitend. Im besonderen sind drei Gegebenheiten wesentlich:

Wir erfassen die Wirklichkeit als etwas, das uns als Gegenstand gegenübersteht, und alles, was uns gegenständlich entgegentritt, ist für das betrachtende Subjekt eine bestimmte Wirklichkeit, - nicht die eigentliche Wirklichkeit selbst, sondern die Weise, in der sie je und je erscheint. Das umfassende, absolute Sein bleibt unserem Bewußtsein verborgen. Je klarer uns jedoch die Gegenstände werden, desto unbedingter ist die Erkenntnis.

So wie sich unser Erkennen auf Erscheinungen, nicht unmittelbar auf das Wesen richtet, vollzieht es sich als Anschauung auch nur von je einem bestimmten Standpunkt aus. Jedem Standpunkt entspricht ein Aspekt, und jeder Aspekt vermag etwas Wesentliches zu erschließen; wenn wir ihn aber zum einzigen machen und alles durch eine Grundauffassung erklären wollen, wird die Wirklichkeit verfälscht. Uns entzieht sie sich, sofern wir sie forschend als Ganzes ergreifen wollen.

Indem wir, was wir als Wirklichkeit erkennen, aussagen, fassen wir sie in der Umgrenzung einer bestimmten Bedeutung. Sprache interpretiert, nennt wißbaren Gehalt. Dieser stellt die Auslegung dar, auf deren Grund als nie aussprechbare Wesenheit das absolute Sein gegenwärtig ist ${ }^{45}$.

Inbezug auf unser engeres Problem der naturwissenschaftlichen Erkenntnis wissen wir seit KANT, daß ihre Welt nicht gleichbedeutend ist mit der Welt vom «Ding an sich», das heißt mit der absoluten Wirklichkeit. Sie ist vielmehr die Welt, wie wir sie in Anbetracht unserer geistigen Veranlagung zu erkennen vermögen. Sie ist eine Welt der Erscheinungen. Demzufolge ist «die naturwissenschaftliche Erkenntnis im Hinblick auf die subjektive Beschaffenheit unseres Geistes eine relative, hingegen ist sie objektiv in dem Sinn, daß sie für alle, denkenden Geister' Gültigkeit besitzt, denn

${ }^{45}$ Vgl. K. Jaspers, Einführung in die Philosophie, S. 28 ff. und S. 76. 
alle Menschen sind geistig gleich beschaffen, und ihr Verstand betätigt sich in übereinstimmender Weise. Wenn die Welt der Naturwissenschaft eine solche der Erscheinungen ist, so sind die letzteren insofern fest begründet, als sie für alle denkenden Menschen die gleichen sind $\gg \mathbf{4 6}$.

Auf dem Boden der umschriebenen relativierenden Objektsbetrachtung läßt sich das gesuchte Bezugssystem aufbauen. Die genannte Relativierung ist unseres Erachtens sogar die einzige Betrachtungsweise, welche die gewünschten Dienste leisten kann, denn nur sie vermag den Wert jeder bisherigen Landschaftsauffassung richtig zu erkennen: sie allein steht außerhalb und über den zu beurteilenden Auffassungen und ist nicht selbst auch Partei. Daß die relativierende Betrachtung allgemeine Gültigkeit besitzt und auch für unsere $Z$ wecke verwendbar ist, wird als selbstverständlich vorausgesetzt. Es ist nicht etwa ein philosophisches System primär bevorzugt und auf die Geographie übertragen worden, vielmehr hat sich die gewählte Lösung von der geographischen Problemstellung her aufgedrängt.

\section{Die relativierende Objektsbetrachtung in der Geographie}

Nun ist es zwar unbestreitbar, daß auch die relativierende Objektsbetrachtung zu einer bestimmten Art von Landschaftsauffassung führt, und wir somit noch an einer eigenen Auffassung andern Landschaftsauffassungen messen. In der Tat zeigen wir die neuere Entwicklung des Landschaftsbegriffes im Lichte der relativierenden oder. wie wir später sagen werden, geomerischen Auffassung. Diese Feststellung bedeutet indessen keine Einschränkung, da die wesentliche Forderung erfüllt bleibt, daß das Bezugssystem die einzumessenden Landschaftsbegriffe überdache.

\section{Der Begriff der Substanz}

In der Geographie wird seit einigen Jahren unter Substanz der unbearbeitete Landschaftsinhalt verstanden ${ }^{47}$. Viele Fachvertreter unterscheiden jedoch nicht zwischen der landschaftlichen Wirklichkeit an sich und deren gegenständlicher Erscheinung, und von ihnen wird darum mit dem Substanzbegriff nur letzteres bezeichnet. Die allgemeine Bedeutung des Wortes Substanz verweist aber in den Bereich des Absoluten, auf das der Erscheinung «zugrunde liegende selbständige Sein, den beharrenden Träger der wechselnden Eigenschaften ${ }^{48}$. Soll der Substanzbegriff in der Geographie Verwendung finden, so kann er sich demnach - im Gegensatz etwa zur Auffassung LAUTENSACHS ${ }^{49}$ - sinngemäß nur auf das Absolute beziehen. Er hat alles zu umfassen, was letztlich mithilft, die gesamte Erdhülle aufzubauen und $\mathrm{zu}$ formen. Der interpretierte Gehalt des landschaftlichen Seins wird durch einen anderen und, wie wir soeben ausführen werden, neuen Begriff eindeutig benannt werden müssen.

Damit ist freilich auch gesagt, daß wir mit dem umfassenden Begriff der Substanz über die Grenzen der Erfahrungserkenntnis hinausgreifen. Im einzelnen läßt sich nicht aufführen, was alles zur Gestaltung der Erdhülle beiträgt; eine Darstellung wird immer auf eine Auswahl und eine unserem Sprachvermögen angepaßte lükkenhafte Zusammenstellung der Phänomene beschränkt bleiben. Dagegen kann sie in ihrer komplexen Vielgestaltigkeit wohl erahnt und als eine aus gemeinsamem Grunde erwachsene Einheit erlebt werden.

Wenn der Substanzbegriff in der Landschaftskunde einerseits zu vage angewendet wurde, weil er nicht Rücksicht nimmt auf die Unterscheidung von absolutem und ausgelegtem Sein, so ist er andererseits wieder zu eng: «Unter geographischer Sub-

${ }^{46}$ M. Gex, Einführung in die Philosophie, S. 159 und 160, vgl. bes. auch S. $145 \mathrm{ff}$.

47 Siehe: BoвeK und Schmithüsen, Die Landschaft im logischen System der Geographie, S. 112. Lautensach, Über die Begriffe Typus und Individuum..., S. 9-10. Carol, Zur Diskussion um Landschaft und Geographie, S. 114.

${ }^{48}$ A PeL, Philosophisches Wörterbuch, S. 228-230.

${ }^{49}$ Lautensach, Über die Begriffe Typus und Individuum..., S. 9-10. 
stanz verstehe ich - sagt beispielsweise LAUTENSACH ${ }^{50}$ - den gesamten physiognomisch erfaßbaren Stoffbereich der Erdhülle oder beliebiger Teile von ihr .... Sicher gehört nicht alles nur dem physiognomischen Kreise an, was landschaftlich irgendwie wirksam ist. Im übrigen ist es richtiger, statt von geographischer Substanz zu sprechen, den Ausdruck «Erdhüllensubstanz» zu gebrauchen oder, weil «Erdhülle» in neuerer Zeit auch mit «Geosphäre» ${ }^{51}$ gleichgesetzt wird, geosphärische Substanz.

In der Regel wird der Geograph beim landschaftlichen Arbeiten nicht gleichzeitig die ganze Erdhülle (Geosphäre) überblicken und berücksichtigen können; er wählt vielmehr einen seinen $Z$ wecken dienlichen Ausschnitt aus. Es gilt, auch für solche beliebig und von Fall zu Fall verschieden bemessene Teilstücke der Erdhülle eine Benennung $\mathrm{zu}$ finden, welche dem nun angewendeten Denken entspricht. Es soll ein Ausdruck sein, der die ganze substantielle Fülle jeder Erdhüllenstelle repräsentiert und womöglich nicht verschieden gedeutet und mißverstanden werden kann. CAROL spricht in diesem Zusammenhang von einem «Geomer», und es erweist sich als zweckmäßig, diese neue und treffende Bezeichnung weiterhin zu gebrauchen. Das griechische Substantiv «meros» hat unter anderem die Bedeutung von «Teil eines Ganzen», «Stück» oder «Landesteil, Bezirk, Gegend»52. Der umfassende Inhalt eines Geomers ist somit die geomerische Substanz.

Abbildung 1 stellt schematisch Geosphäre und Geomer dar. Wie ersichtlich, wird darauf der Landschaftsbegriff dem Anthroposphas Begriff des Geomers gleichgesetzt. Mit die- Biosphare ser Feststellung ist bereits ein Resultat der Lithosphare späteren Untersuchung vorweggenommen, und erst sie kann zeigen, warum sich die Parallelisierung aufdrängt und rechtfertigt. Unter Landschaft verstehen wir also einen beliebig begrenzbaren Ausschnitt aus der Geosphäre und unter landschaftlicher (oder geomerischer) Substanz «die ungeheure Fülle des irdischen Daseins innerhalb des Ausschnittes. Alles, was in der Erdhülle vorhanden ist, konstituiert die Landschaft: Berge, Ebenen, Meere, Seen, Luft, Pflanzen, Tiere, der Mensch als biologisches, soziales, wirtschaftendes und geistig tätiges Wesen, Felder, Gebäude, Verkehr all das in seinem gesamten Vorhandensein und seiner Interferenz macht die Landschaft aus $\gg \mathbf{5 3}$.

2. Die primäre Auslegung: Betrachtungssysteme

Aus der Darstellung des Substanzbegriffes geht hervor, daß sich Geosphäre (Erdhülle) und Geomer (Landschaft)

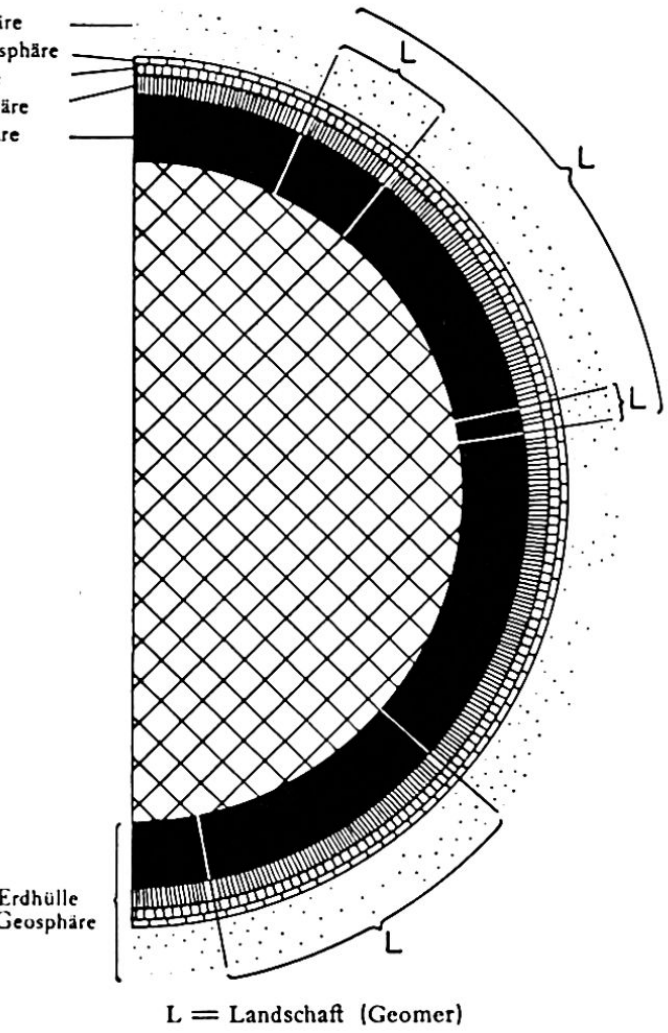

Abb. 1 Schematische Darstellung von Erdhülle (Geosphäre) und Landschaft (Geomer). (Aus: Carol, Zur Diskussion um Landschaft und Geographie, Figur 1. S. 114.)

50 Lautensach, Über die Begriffe Typus und Individuum..., S. 9-10.

51 Carol, Zur Diskussion um Landschaft und Geographie, S. 113.

52 Carol, S. 114. - Mit dem Begriff des * Geomers identisch ist der «Land „-Begriff LaUTENsACHS. Er definiert « Land» als « Raumindividuum, idiographisch als Gestalt erfaßt, in der Komplexität aller seiner geographischen Formen bzw. Erscheinungen und von beliebiger Größe (Der Geographische Formenwandel, S. 2).

53 Carol, Zur Diskussion um Landschaft und Geographie, S. 114. 
grundsätzlich nicht unterscheiden. Die Geosphäre ist als das größte mögliche Geomer zu betrachten, und beide Begriffe stehen für das volle und absolute, nicht interpretierte landschaftliche Sein. Selbstverständlich gibt es Geomere, die nicht an allen Sphären der Erdhülle Anteil haben. In einer Salzwüste sind bloß Lithosphäre, Hydrosphäre und Atmosphäre vereinigt. Im Urwald werden diese drei Sphären von der Biosphäre überlagert, und durch den Menschen erst wird die Anthroposphäre geschaffen. Die Salzwüste ist das Beispiel eines anorganischen, und der Urwald dasjenige eines organischen Geomers (anorganische und organische Landschaft). Alle Sphären zusammen ergeben das kulturlandschaftliche Geomer (die Kulturlandschaft). In jedem Fall ist aber unter einem Geomer die gesamte jeweils existierende landschaftliche Substanz zu verstehen.

Durch die wissenschaftliche Betrachtung wird das Geomer interpretiert. Jeder Betrachtungsweise entspricht ein bestimmter Aspekt, wie folgendes Beispiel zeigen soll:

In einer hügeligen Landschaft findet sich ein gegen Süden exponiertes, leicht geneigtes Hangstück. Wie seine weitere Umgebung trägt es Naturwiese, und es unterscheidet sich auch durch die pedologischen Verhältnisse nicht. Dem vorbeiwandernden Betrachter fällt dieser Geländeteil kaum als solcher auf, und auf einer Nutzungsoder einer Bodenkarte käme er nicht eigens zur Darstellung. Die Verhältnisse ändern sich jedoch beispielsweise bei der speziellen agrargeographischen Betrachtung. Von der «Welt» ${ }^{54}$ des Bauern aus kann das betreffende Hangstück gerade wegen seiner südlichen Exposition z. B. als Rebberg Bedeutung erlangen und aus dem Zusammenhang hervortreten. Erst vom agrargeographischen Gesichtspunkt aus fällt auch die angenehme und vorher nicht relevante Stetigkeit der Neigung auf und tritt zudem vielleicht eine pedologische Eigenschaft in Erscheinung, die zunächst als unwesentlich erkannt und vernachlässigt wurde. Das Hangstück wird nun aus den genannten Gründen als markante einzelne Gegebenheit erfaßt.

In entsprechender Art kann sich in den «Augen» des Industriegeographen eine selbständige Struktureinheit abheben, obwohl die dafür entscheidenden Merkmale teilweise andere sein werden. Die bis anhin nicht mitbestimmende günstige Zufahrtsmöglichkeit und Ebenheit treten eventuell in den Vordergrund. Der Maßstab für die pedologischen Verhältnisse muß den neuen Ansprüchen an den Boden gerecht werden, und er wird Eigenschaften aufzeigen (Festigkeit beispielsweise), die in der Agrargeographie, weil nicht relevant, nicht erkannt wurden. Der vom industriegeographischen Gesichtspunkt aus gesehene Gehalt wird auch zu einer neuen und von der agrargeographischen abweichenden Gliederung des Ausschnittes führen.

Jede Betrachtungsweise richtet sich auf die hügelige Landschaft mit dem vollen Inhalt, also auf die umfassende geomerische Substanz; diese wird aber in verschiedenem Lichte gesehen. Das jeweilige Heraustreten bestimmter Einheiten entspricht einer einseitigen «Beleuchtung» oder eben einer Interpretation. Das Geomer läßt sich folglich nicht schlechthin geographisch untersuchen; erst standpunktbedingte Einzeluntersuchungen schaffen den Zugang und ergeben Maßstab, Grenzen, Gruppierungen und Namen.

Selbstverständlich gilt die Forderung, daß die wissenschaftliche Auslegung der absoluten Wirklichkeit nicht zufällig sei. Die Auslegung ist dann richtig, wenn sie objektiven Charakter hat: sie soll für alle «denkenden Geister» Gültigkeit besitzen, indem sie jederzeit und von jedermann nachweisbar ist ${ }^{55}$. Für die zweckmäßigen Auslegungsweisen hat CAROL den Begriff des Betrachtungssystems in die Landschaftskunde eingeführt. Er ist treffend und soll im weiteren verwendet werden.

Abbildung 2 zeigt die von CAROL zusammengestellten Betrachtungssysteme zur Untersuchung der Kulturlandschaft. Die Landschaft, als beliebig großer Ausschnitt

${ }^{54} \mathrm{Vgl}$. Staiger, Versuch über den Begriff des Schönen.

55 Vgl. S. 17 der vorliegenden Arbeit. 


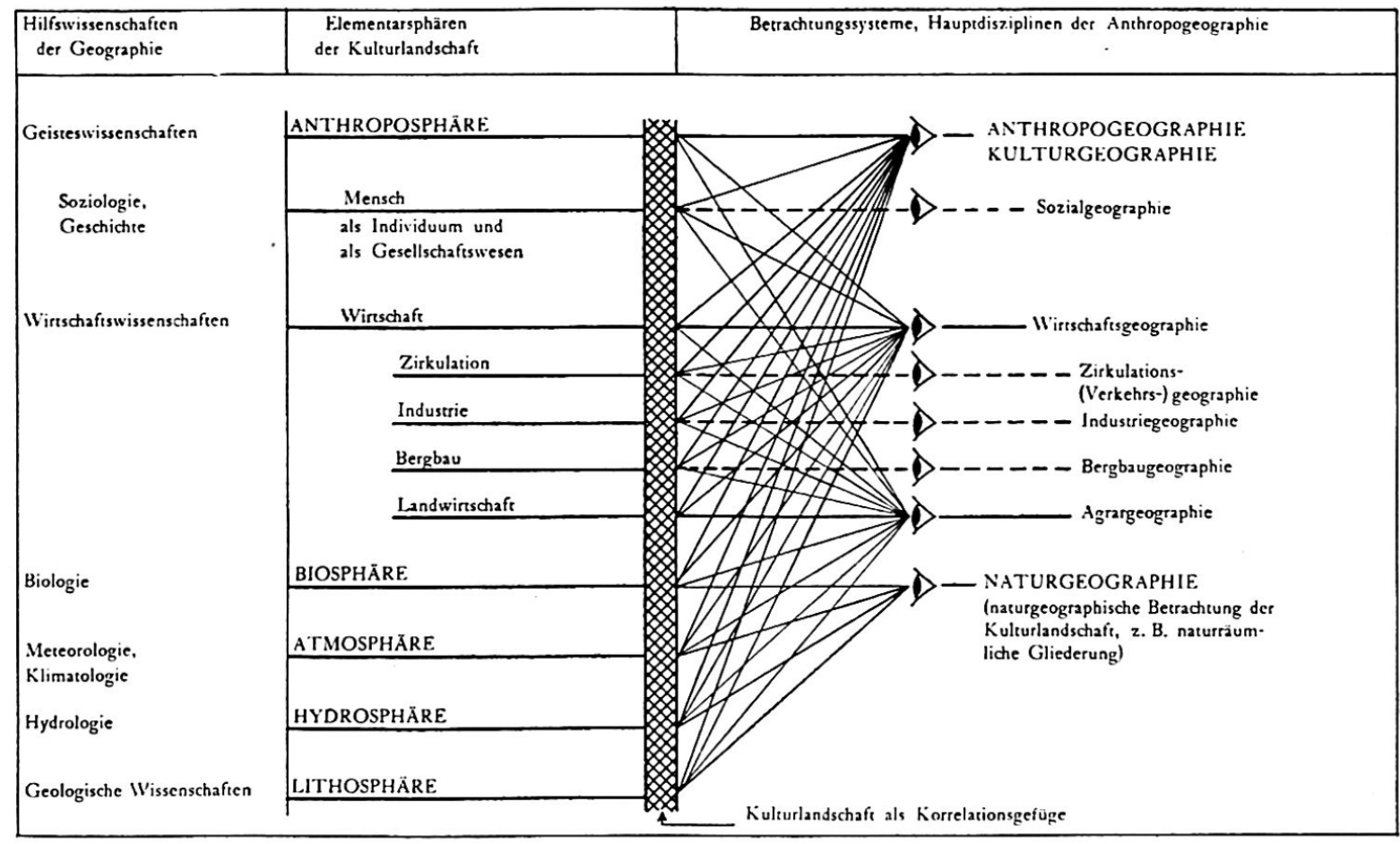

Abb. 2 Betrachtungssysteme zur Untersuchung der Kulturlandschaft. (Aus : Carol, Zur Diskussion um Landschaft und Geographie, Tabelle 2, S. 121.)

der Erdhülle, ist in Form des senkrecht stehenden Balkens dargestellt. Darauf ist das «Auge» des wissenschaftlichen Betrachters gerichtet. Jedes System, wie ersichtlich ist, macht die gesamte Landschaft zum Gegenstand; Unterschiede von System zu System liegen also nicht primär in der Auswahl, sondern in der verschiedenartigen, durch den Standpunkt bedingten Wertung der einzelnen Gegebenheiten begründet. So ist etwa die Agrargeographie «nicht bloß räumliche Untersuchung der Landwirtschaft als solcher (dies ist eine elementare Voraussetzung), sondern Betrachtung der ganzen Kulturlandschaft unter dem Gesichtspunkt ihrer landwirtschaftlichen Nutzung. Unter diesem spezifischen Blickwinkel werden alle relevanten Landschaftselemente vom Gestein bis zum Menschen gewertet...» ${ }^{56}$.

Die Systeme entsprechen, wie leicht einzusehen ist, den Disziplinen der Geographie. Überblickt man die Reihe der in Vorschlag gebrachten Disziplinen, so gewinnt man zunächst den Eindruck, die alte und übliche Aufgliederung der geographischen Wissenschaft vor sich zu haben. Entscheidend bleibt aber, daß mit der Gliederung im alten Sinne eine sachliche Unterteilung der Landschaft vorgenommen wurde, also jeweils bestimmte Landschaftserscheinungen zur Auswahl kamen. Die neuen Disziplinen hingegen befassen sich mit je einem Aspekt des umfassenden geomerischen (landschaftlichen) Seins ohne vorherige sachliche Einschränkung. Wenn nach der bisherigen Terminologie etwa von Wirtschaftsgeographie die Rede war, so dachte man sich dabei ein Arbeitsfeld, das durch und für die wirtschaftliche Tätigkeit des Menschen geschaffene Erscheinungen in der Landschaft zum Gegenstand hat. Die Wirtschaftsgeographie als Betrachtungssystem jedoch befaßt sich mit dem gesamten landschaftlichen Sein von der Welt des wirtschaftlich denkenden Menschen her. Siedlungsgeographie beispielsweise, wie sie bis anhin bestanden hat, gibt es bei der eben dargestellten Landschaftsauffassung deshalb nicht mehr, weil ihr keine auf die volle Landschaft gerichtete Betrachtungsweise entspricht.

${ }^{56}$ Carol, Zur Diskussion um Landschaft und Geographie, S. 121. 
Von allen aufgeführten Betrachtungssystemen ist vorerst das agrargeographische im einzelnen ausgebaut worden ${ }^{57}$. Aber auch die übrigen Systeme erfordern diesen Ausbau, wenn jeder Aspekt der Kulturlandschaft erfaßt werden soll. In analoger Art sind schließlich Systeme für die zwei unteren Integrationsstufen der Landschaft, die anorganische und die organische, zu entwerfen. Jedes Betrachtungssystem läßt sich dann allerdings auf jede Integrationsstufe anwenden. So kann beispielsweise eine Kulturlandschaft in ihrem naturgeographischen Aspekt, eine organische Landschaft aber auch kulturgeographisch untersucht werden, etwa mit agrargeographisch oder industriegeographisch eingestelltem Blickpunkt (Interesse). Das Betrachtungssystem verschafft in allen Fällen den Maßstab, und dieser wird an die jeweilige Landschaft angelegt. Daß innerhalb der Betrachtungssysteme auch vergangene Zustände der Landschaft und die gesamte Landschaftsentwicklung erkannt werden können, ist verständlich.

Unerläßlich ist nun noch die Einführung von Begriffen für das ausgelegte und damit wissenschaftlich zugänglich gemachte Geomer sowie für die ausgelegte geomerische Substanz. Als Parallelbegriff für «Geomer» wird in der vorliegenden Untersuchung der Begriff «Geoptom» ${ }^{8}$ verwendet, wobei die Parallelität so zu verstehen ist, daß Geomer und Geoptom dasselbe Sein meinen, das Geomer in umfassender Art, das Geoptom hingegen aspektweise. Es braucht mehrere Geoptoma, um dem Geomer näher zu kommen, und unendlich viele, wenn vollständige Deckung erreicht werden sollte. Ein Agrargeoptom beispielsweise ist nur der aus der «Welt des Bauern» erfaßte Aspekt des Geomers (der Landschaft). Dieser Aspekt ist nie gleichbedeutend mit der Landschaft selbst, weshalb es nicht angeht, den Begriff «Agrarlandschaft»zu verwenden. So gibt es richtigerweise auch keine Industrielandschaft und keine Wirtschaftslandschaft, sondern nur Industrie- und Wirtschaftsgeoptoma.

Die «Substanz « läßt sich auf der Seite des Ausgelegtseins übersetzen durch «Elemente». Als solche gelten, um zu verdeutlichen, gerade im Bereich des Agrargeoptoms: Untergrund, Relief, Klima, Wasser, Boden, Naturvegetation, Kulturvegetation, Kulturbauten, landwirtschaftliche Bevölkerung, Stand von Kultur und Technik, Betrieb, Markt, Organisation zur Versorgung der bäuerlichen Bevölkerung mit wirtschaftlichen und kulturellen Gütern, Verkehr. Untersuchungen über Elemente an sich gehören nur propädeutisch in die Landschaftskunde, weil gerade das typisch Landschaftliche, das Gestaltmäßige, außer acht gelassen wird. Die Bindungen zwischen verschiedenartigen Elementen bleiben dabei unberücksichtigt.

\section{Die sekundäre Auslegung: Betrachtungsrichtungen}

Ein Geoptom ist zu komplex, als daß es mit wissenschaftlichen Untersuchungsund Darstellungsmethoden in einem Zuge erfaßt werden könnte. Die Praxis erfordert eine Unterteilung. Auch diese hat selbstverständlich systematisch zu erfolgen und bestimmten Betrachtungsrichtungen ${ }^{59} \mathrm{zu}$ entsprechen. CAROL vergleicht den Prozeß mit der Darstellung eines Hauses etwa durch Grundriß und Aufriß und sagt, daß auch wir Geographen imstande sein müssen, aus wenigen aber bestimmten Teilaspekten ein Gesamtbild unseres Objektes zu schaffen. Für alle derart nach praktischen Bedürfnissen gebildeten Einheiten sei hier die Bezeichnung «Ptomatrop»60 eingeführt. Bei mehrmaliger Gliederung entstehen Ptomatropen niederer Ordnung.

${ }_{58}^{57}$ Vgl. Carol, Das agrargeographische Betrachtungssystem.

58 ptoma (griech.) = Fall.

59 Die Bezeichnung * Betrachtungsrichtung» ist von CAROL eingeführt worden und soll innerhalb des Betrachtungssystems für die sekundäre Auslegung allein Verwendung finden. Vgl. CARoL, Das agrargeographische Betrachtungssystem, S. 22-31.

${ }^{60}$ tropos (griech.) = Art und Weise. Ein Ptomatrop ist ein Teil der Landschaft, abgegrenzt auf Grund einer Betrachtungsrichtung und untersucht von diesem Gesichtspunkt aus. 
Zur Verdeutlichung der beiden Begriffe «Ptomatrop» und «Betrachtungsrichtung» dienen praktisch durchgearbeitete Beispiele. Besonders gut geeignet ist die «naturräumliche Gliederung Deutschlands», eine wertvolle Gemeinschaftsarbeit deutscher Geographen ${ }^{61}$. Gegenstand dieser Gliederung ist die gesamte Landschaft Deutschlands, gesehen durch das naturräumliche Betrachtungssystem, oder, anders ausgedrückt: die naturräumliche Auslegung der Landschaft, das naturräumliche Geoptom wird zum Objekt gemacht. (Auf die Definition der naturräumlichen Blickrichtung wird hier nicht eingegangen; wir verweisen für den vorliegenden Fall auf das Handbuch der naturräumlichen Gliederung Deutschlands, vorab auf die einführenden siebzehn Seiten.) Vom Geoptom werden, zweckgerichtet, jene Eigenschaften ausgelesen, die eine Gliederung ermöglichen, und das bedeutet, da $\beta$ das Geoptom nach einer bestimmten Betrachtungsrichtung eine Aufteilung in Ptomatropen erfährt. Die Betrachtungsrichtung entscheidet darüber, was in die Gliederung einbezogen werden soll. Die Ptomatropen sind also Gebilde, welche genau umschriebenen wissenschaftlichen Anforderungen zu entsprechen haben.

Bei der naturräumlichen Gliederung Deutschlands werden zunächst einmal die sogenannten Haupteinheiten ausgeschieden. Solche Haupteinheiten sind beispielsweise der Hintere Bregenzer Wald, das Bodenseebecken, die Allgäuer Hochalpen, das Karwendelgebirge, die Münchener Ebene, das untere Inntal usw. Offensichtlich ist das Relief maßgebend für ihre Abgrenzung. Was weiter berücksichtigt wird, zeigt etwa die hier auszugsweise wiedergegebene Charakterisierung des Hinteren Bregenzerwaldes: "Der Hintere Bregenzer Wald, der sich vom Tal des Alpenrheins zur Iller hinüberzieht, ist in seinem mittleren Teil aus Gesteinen der helvetischen Kreide aufgebaut, die im Norden und Süden von je einem Streifen von Flyschgesteinen begleitet werden. Im Süden wird der Hintere Bregenzer Wald von den massigen Triaskalken der westlichen Lechtaler Alpen beträchtlich überragt. Im Norden ist er durch den Südrand der Molasse begrenzt. Die Grenze Bayerns gegen Vorarlberg trennt von ihm einen östlichen Abschnitt ab, den man zu den Allgäuer Alpen rechnet. Nur dieser wird hier näher behandelt.» - a Die nördliche Flyschzone kulminiert im Riedberghorn $(1786 \mathrm{~m})$, die südliche im Fellhorn $(2037 \mathrm{~m})$. Das Kreidegebiet dazwischen ist in eine Reihe von parallelen Kämmen zerlegt und hat seinen höchsten Gipfel im Hohen Ifen $(2230 \mathrm{~m})$. Die drei Zonen sinken nach Nordosten gegen das Becken von Oberstdorf ab. Alle Gesteinsschichten sind stark gefaltet, aufgeschuppt, in Teildecken aufgegliedert und nach Norden überschoben.» «Der Flysch besteht aus Sandsteinen, Kalken und Mergeln, vereinzelt mit konglomeratischen Einlagerungen. Er verwittert leicht und bildet tiefgründige, lehmige Böden. Seine Oberflächenformen sind weich, gerundet, mit geraden Kämmen und gleichmäßigen Böschungen, die allerdings im Süden am Fellhornzuge auch außerordentlich steil sein können. Felswände und schroffe Gipfelformen sind jedoch dem Flyschgebiet fremd.» — - Die Zone der Kreidegesteine steht dazu in einem starken Gegensatz. Hier wechseln harte reine Kalke und Kieselkalke mit weichen mergeligen Kalken und mit glaukonitischen Sandsteinen und Mergeln, sodaß nackte Felsen und Wandstufen, flache Hänge und mit lehmigen Verwitterungsböden erfüllte Mulden in stetem Wechsel miteinander vorkommen. Vor allem der Schrattenkalk baut scharfe Grate und lange Wandfluchten auf und neigt sehr stark zur Verkarstung. Er bildet auch den Gipfel des Hohen Ifen und den nach Norden anschließenden Gottesacker, der mit seinen Dolinentrichtern und Karrenfeldern als das Musterbeispiel einer Hochgebirgskarstlandschaft gilt.» - «Das Streichen der Schichten zeichnet die Richtung der Täler vor. Die Entwässerung geht nach Westen zur Bregenzer Ache, nach Osten und Nordosten zur Iller. Beide Talsysteme stehen über einige flache Sättel und Talwasserscheiden in Verbindung. Im undurchlässigen Flysch liegen die Wasseradern sehr dicht nebeneinander, im löslichen Kalk dagegen gibt es Trockentäler, Gerinne mit nur gelegentlicher Wasserführung, sowie Karstquellen und Höhlenbildungen.» - "Die Berge des westlichen Allgäus haben während der Eiszeit ihre eigene Vergletscherung besessen, welche das ganze Gebirge überzogen hat. Die Täler sind daher hoch hinauf mit Moränenmaterial aus in der Umgebung anstehenden Gesteinen erfüllt, und die Vielfalt der Schuttböden wird um die undurchlässigen Böden des Geschiebelehms bereichert.» — " Der Winter bringt eine hohe Schneedecke, die auf der Nordseite bis in den Mai hinein liegenbleibt. Das feuchtkalte Klima mit Jahresniederschlägen von über $2000 \mathrm{~mm}$ auch in den Tälern, die Höhenlage und die kurze Vegetationsperiode bestimmen das Pflanzenkleid. Die Täler und Bergflanken gehören ursprünglich dem Bergwalde aus Buchen, Fichten und Tannen. In den tieferen Regionen herrscht die Buche, in den höheren die Fichte vor, an besonders feuchten und schattigen Orten die Tanne. Die obere Waldgrenze steigt von Norden nach Süden von etwa $1700 \mathrm{~m}$ auf $1800 \mathrm{~m}$ an. Ein Krummholzgürtel ist nur unvollkommen ausgebildet. Über der Baumgrenze tragen die lehmigen, undurchlässigen Böden des Flysches und der Kreidemergel eine dichte, von Bergblumen durch-

${ }^{61}$ Siehe: E. Meynen und J. Schmithüsen, Handbuch der naturräumlichen Gliederung Deutschlands (1953) und J. SchmithüsEN, Die naturräumlichen Einheiten auf Blatt 161 Karlsruhe (1952). 


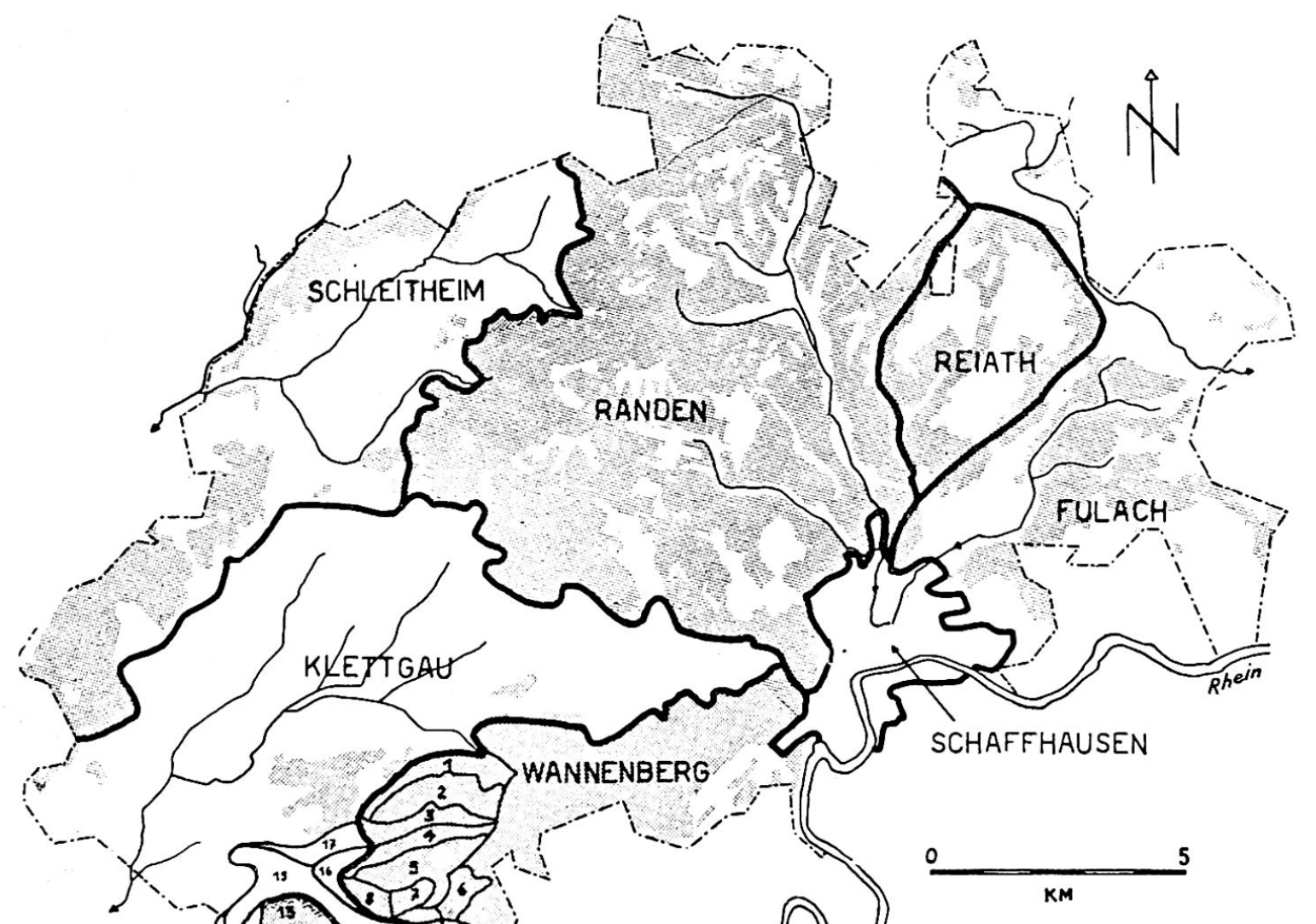

Abb. 3. Gross- und Mittelformale

Abbildung 3 Agraiformale 4 . Ordnung (Grọformale):

Wannenberg: Hochfläche, 600-700 m. ü. M. von Malmkalken, die stellenweise zu Bohnerzbildungen verwittert sind, gebildet. Keine Dauerquellen, daher unbesiedelt. Nur wo sandig-mergelige Sedimente überlagern, treten Quellen auf, die dauernde Besiedlung ermöglichten (z. B. Roßberghof). Nutzung: natürliche Buchenwälder mit Fichtenforsten.

Klettgau: Weite, fruchtbare Talung mit intensivem Ackerbau und ausgedehntem Rebbau an günstig exponierten Hängen.

Randen: Hochfläche (stark bewaldet oder Magerwiesen) aus durchlässigen Kalken und undurchlässigen Mergeln. Hauptsiedlungs- und Wirtschaftsraum in den geräumigen Talgründen.

Reiath: Hauptsiedlungs- und Wirtschaftsraum auf Hochflächen möglich, da die Kalktafel von sandig-tonigen Sedimenten überlagert ist. (Wasser! Boden!) Enge Tälchen, bewaldete Hänge, schmaler Siedlungsraum.

Agrarformale 3. Ordnung (Mittelformale): (Arabische Zahlen in Abbildung 3)

Beispiel I5 $_{5}$ : Sohle des Wangentales aus 10 Kleinformalen bestehend, die sich durch Relief, Untergrund, Boden und Nutzung unterscheiden. Als Ganzes: flaches Hauptackerbau-Areal von Osterfingen.

Beispiel r6: Reb-, Wies- und Obstbau an SW-bis NW-exponierten Hängen.

Beispiel 8: Steiler, bewaldeter SW-Hang.

Beispiel 5 : Bewaldete Hochfläche auf Malmkalken.

setzte Grasdecke, welche eine saftige Almweide darstellt. Auf hartem, durchlässigem Kalk findet sich hingegen nur eine lockere Vegetation von Polsterpflanzen. Hier haben nur die in Felsspalten und Dolinen zusammengeschwemmten Verwitterungsböden eine etwas dichtere und üppigere Pflanzendecke. ${ }^{62}$

Die "Haupteinheiten» erfahren eine Unterteilung in die "naturräumlichen Einheiten». Das von J. SснмітнüsEN ausgearbeitete Blatt Karlsruhe zeigt, daß auch bei den naturräumlichen Einheiten das Relief wesentlich mitbestimmend ist. Es gibt den Neckarschwemmkegel, den Gaisbergfuß, den Heidelberger Trichter, die Weinheimer Bergstraße, die St. Ilgener Niederung, die Mannheim-Oppenheimer Rheinniederung und andere Einheiten mehr. Zur eingehenden Charakterisierung dienen Nuancen in der Bodenbeschaffenheit, Details der Wasserverhältnisse, die noch vorhandene natürliche Vegetation und ferner auch durch den Menschen bestimmte Gegebenheiten. Der Neckarschwemmkegel zum Beispiel wird in folgender Ausstattung als Einheit gesehen: « Von Heidelberg

62 MeYnen und SchmithüsEn, Handbuch der naturräumlichen Gliederung Deutschlands, S. 49-50. 
Agrarformale 2. Ordnung:

Beispiel P: Sohle des mittleren Wangentales. Flacher, $0-3^{\circ}$ geneigter Talboden. Mächtige, mit Feinmateriel vermischte Schotter. In $12-20 \mathrm{~m}$ Tiefe Grundwasser. Durchlässigkeit und gute Oberflächendrainage verhindern schädigende Überschwemmungen. Mittelgründige, lehmige Braunerde, ergibt guten Ackerboden. Gelegentlich schädliche Kaltluftseen. Fast ausschließlich Ackerbau im ortsüblichen Fruchtwechsel.

Beispiel H: Geneigter Wiesenhang.

Beispiel L: Steiler SW-exponierter Rebberg.

Beispiel $K$ : Geneigte Wiesenmulde (Frostgefahr!).

Beispiel I: Steiler WSW-exponierter Rebberg.

Beispiel $N$ : Steiler Hang mit Magerwiesen und Kiesgruben (mergeliger Kalksteinschutt).

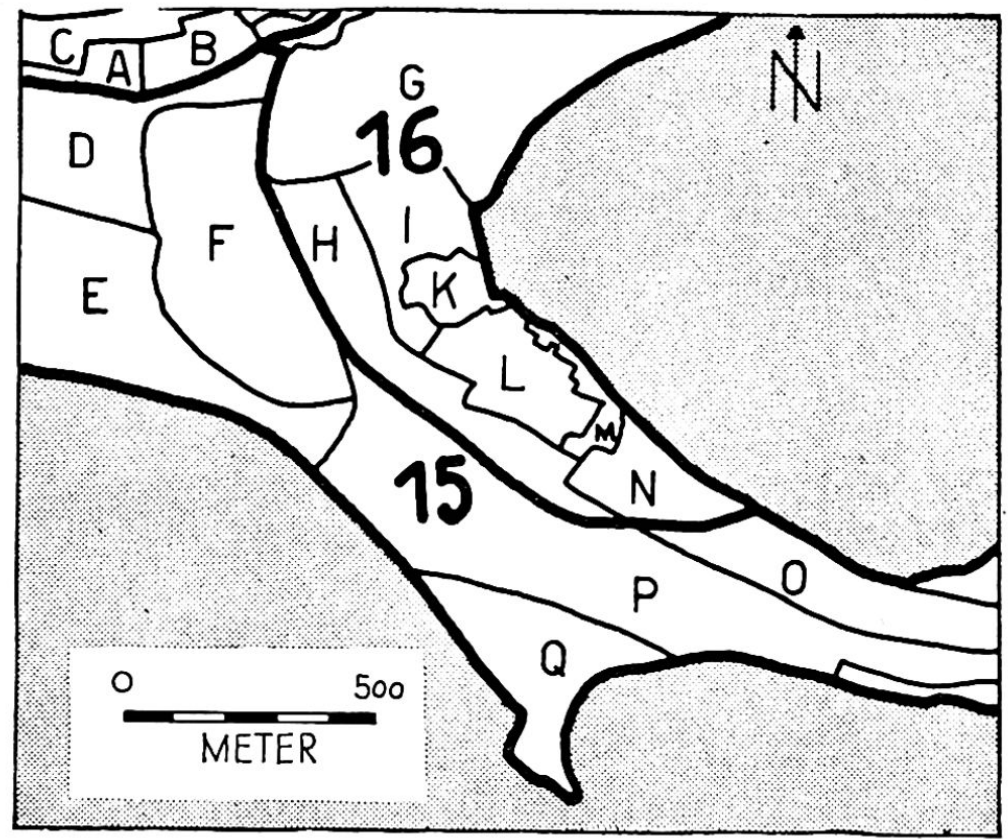

Abbildung 4 Agrarformale 2. Ordnung (Kleinformale):

(Nur das offene Kulturland ist in die Gliederung einbezogen worden).

nach $N, W$ und $S$ mit kaum merklichem Gefälle, insgesamt aber bis zu den Außenrändern um etwa $10 \mathrm{~m}$ abfallende waldfreie Ackerebene mit wechselnden Böden. Zumeist tiefgründiger Flußlehm oder Schwemmlöß über kalkhaltigem Untergrund, daneben sandige, stellenweise auch kiesige und in den Rinnen ehemaliger Neckarläufe humose bis anmoorige Böden. Das Grundwasser fließt im östl. Teil in 7 bis 11 , im W in 4 bis $8 \mathrm{~m}$ Tiefe unter der Oberfläche. Der Neckarschwemmkegel hat vielseitigen Acker-, Feldgemüse- und Gartenbau sowie um Ladenburg bedeutende Baumschulen. ${ }^{63}$

Zur Illustration der beiden Begriffe «Betrachtungsrichtung》 und «Ptomatrop》 eignen sich auch die Arbeiten CARols sehr gut. Carol hat vorläufig zwei Betrachtungsrichtungen innerhalb des agrargeographischen Betrachtungssystems ausgearbeitet und diese an verschiedenartigen Beispielen erprobt. Es sind dies die formale und die funktionale Betrachtungsrichtung. Damit übereinstimmend ergeben sich zwei Arten von Ptomatropen, nämlich die formalen und funktionalen Einheiten des agrargeographischen Geoptoms oder, kurz ausgedrückt: «Agrarformale» und «Agrarfunktionale $\gg 64$.

Was zunächst die Agrarformale betrifft, so kann in ihr Wesen Einblick genommen werden durch bisher unveröffentlichtes Material aus landschaftskundlichen Übungen, welche unter Leitung von P.-D. Dr. CAROL am Geographischen Institut der Universität Zürich durchgeführt worden sind. (Siehe Abbildungen 3, 4 und 5.) Wie zu erkennen ist, wurde eine Landschaft in den Grenzen des Kantons Schaffhausen bearbeitet. Zunächst stellt Abbildung 3 neben der Lage der behandelten Landschaft ihre Agrarformale vierter und dritter Ordnung (die Groß- und Mittelformale) dar; Abbildung 4 enthält Formale zweiter Ordnung (Kleinformale) und Abbildung 5 schließlich solche erster Ordnung ( $Z$ wergformale). Bei diesen kleinsten Einheiten handelt es sich um eine Detailgliederung, welche bis zu den einzelnen Ackerparzellen hinunterreicht und selbst so kleine Objekte wie Fahrwege und Bäche ausscheidet. (Die in Grau gehaltenen Waldfächen ermöglichen den richtigen Vergleich aller Abbildungen ${ }^{65}$.)

${ }^{63}$ Schмiтнüsen, Die naturräumlichen Einheiten auf Blatt 161 Karlsruhe, S. 23.

${ }^{64}$ Siehe: Carol, Das agrargeographische Betrachtungssystem.

${ }^{60}$ Bearbeiter des vorliegenden Materials ist Herr A. BEHRENs. 


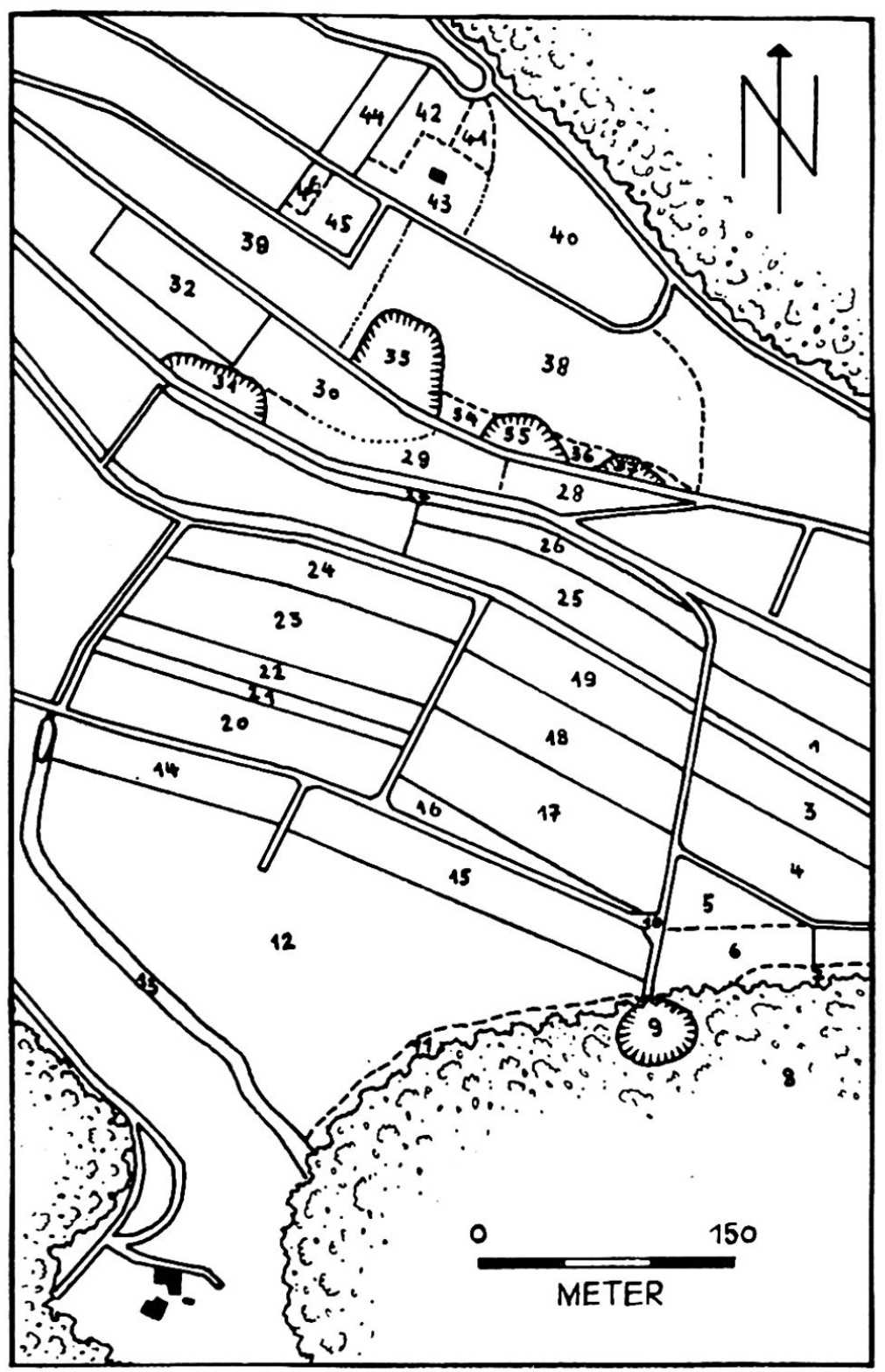

Abbildung 5 Agrarformale I. Ordnung (Zwergformale):

(Ausgezogene Linien: scharfe Begrenzung; gestrichelte Linien: deutliche Begrenzung; punktierte Linien: undeutliche Begrenzung.)

Agrarformale I. Ordnung:

(Zur Erleichterung der Orientierung: Die Häusergruppe am Südrand des Kartenausschnittes liegt im Kleinformal Q, Abb. 4.)

Beispiel I 2 : Schuttkegel * Steigwiesen " von $3-5^{\circ}$ Neigung, nordexponiert. Grober bis feiner Bachschutt; tiefgründige, lehmigtonige Braunerde. Keine Gefährdung durch Bach (13). Nutzung: Intensiv bewirtschaftete Naturwiese.

Beispiel 15: Winterweizen.

Beispiel I 8: Kunstwiese mit mehrjähriger Raygras- und Luzernemischung.

Beispiel I9: Kartoffelacker.

Untergrund, Boden, Wasserverhältnisse, Lokalklima können hier der Kürze halber nicht beschrieben werden; (siehe generelle Beschreibung unter Kleinformal P).

Die eben dargelegten formalen Einheiten sind durch die agrargeographische Betrachtungsweise der Landschaft gewonnen worden. Würde statt des agrargeographischen Maßstabes beispielsweise der naturräumliche (entsprechend der naturräumlichen Gliederung Deutschlands) gewählt und würden auf der so gewonnenen geoptomischen Ebene formale Einheiten abgeleitet, müßten diese ein wesentlich anderes Aussehen bekommen. Ein Versuch ist ebenfalls an der schon besprochenen Schaffhauser Landschaft unternommen worden, und das aufschlußreiche Resultat ist in Abbildung 6 dargestellt worden ${ }^{66}$. (Der auch hier grau eingetragene Wald ermöglicht den Lagevergleich der naturräumlichen Einheiten mit den Agrarformalen in den vorangehenden Abbildungen.)

Soweit das charakteristische Mosaik von Einheiten 3. Ordnung reicht (fette Zahlen), soweit erstreckt sich die nächst höhere Einheit. Sie deckt sich in diesem Falle ungefähr mit der agrarformalen Einheit 4. Ordnung, dem Wannenberg. Randen und Reiath müssen dagegen zusammen als eine einzige, naturräumliche Einheit 4. Ordnung aufgefaßt werden.

${ }^{66}$ Bearbeiter dieses Materials ist Herr H. Kaufman. 
Abb. 6 Naturräumliche Gliederung der Landschaft von Osterfingen, Schaffhausen.

Naturräumliche Einheiten 3. Ordnung (fette Zahlen):

Beispiel 2 : Steile Hänge, von der Hochfläche bis zur Talsohle reichend, potentiell und teils real von verschiedenen Waldgesellschaften eingenommen.

Beispiel $I$ : Flache, trockene Talsohle.

Beispiel 3 : Verschiedenartig ausgebildete Hochflächen.

Naturräumliche Einheiten 2. Ordnung (große Buchstaben):

Beispiel $C$ : Steiler Südwesthang von der Malmhochfläche $(645 \mathrm{~m})$ bis zur Talsohle $(409 \mathrm{~m})$ reichend. Im obersten Teile verschieden ausgebildeter Kalkschutt. Entsprechend den anorganischen Unterschieden (Untergrund, Neigung, Exposition) ist diese Einheit 2. Ordnung in 11 Einheiten 1. Ordnung differenziert.

Ferner in Kürze :

Beispiel $A$ : Steiler Südwesthang.

Beispiel E: Flacher, schottergefüllter Talgrund.

Beispiel D: Hochfläche (Malmkalk) mit Bohnerzbildung.

Beispiel F: Schuttkegel.

Man beachte die Unterschiede in der Gliederung der Landschaft, wenn sie statt unter dem naturräumlichen durch den agrarformalen Gesichtspunkt erfolgt.

Naturräumliche Einheiten I. Ordnung (kleine Zahlen):

Beispiel 6: Sehr steiler Südwesthang, durch * wohlgeschichtete Kalke» bedingt. Flachgründiger Humuskarbonatboden. Bei der relativen klimatischen Trockenheit, verstärkt durch extreme Durchlässigkeit des Bodens und durch starke Einstrahlung, entwickelte sich eine durch Kulturmaßnahmen wenig veränderte Flaumeichengesellschaft.

Beispiel 3: Steiler, SW-exponierter Hang mit mergeligem Kalksteinschutt. Tiefgründige Braunerde. Heutige Nutzung: Reben, Wiesen. Natürliche Waldgesellschaft wäre wahrscheinlich ein QuercetoCarpinetum (Eiche-Hagenbuchenwaldgesellschaft).

Zur Erläuterung des Agrarfunktionals diene eine Bearbeitung der großen Karru Südafrikas (Abbildung 7) ${ }^{67}$. Durch die hier angewendete funktionale Betrachtungsrichtung wird ein anderer Inhaltsbereich untersucht als durch die formale: «Während bei der formalen Betrachtung jene Gebiete zu Einheiten zusammengefaßt werden, die sich durch gleichartige Ausbildung der formalen Elemente auszeichnen, werden bei der funktionalen Betrachtung jene Gebiete zu Einheiten zusammengefaßt, die von der gleichen Organisation erfaßt werden, im gleichen organisatorischen Zusammenhang stehen und dadurch in wirtschaftliche Beziehung zueinander gesetzt sind»68. Dabei kann zum vorneherein an verschiedene, wissenschaftlich gleichwertige Kategorien von funktionalen Einheiten gedacht werden. CAROL führt einige wichtige Arten auf 69 :

Landwirtschaftliche Betriebe als relativ starke, selbständige Einheiten in vielseitiger Ausbildung vom Typus des kleinen Selbstversorgers bis zum weltmarkt-orientierten Großbetrieb einer Plantage oder zur zentral dirigierten Kolchose.

67 Siehe Carol, Das agrargeographische Betrachtungssystem.

${ }^{68}$ Carol, S. 25.

69 Carol, Zur Diskussion um Landschaft und Geographie, S. 125. 


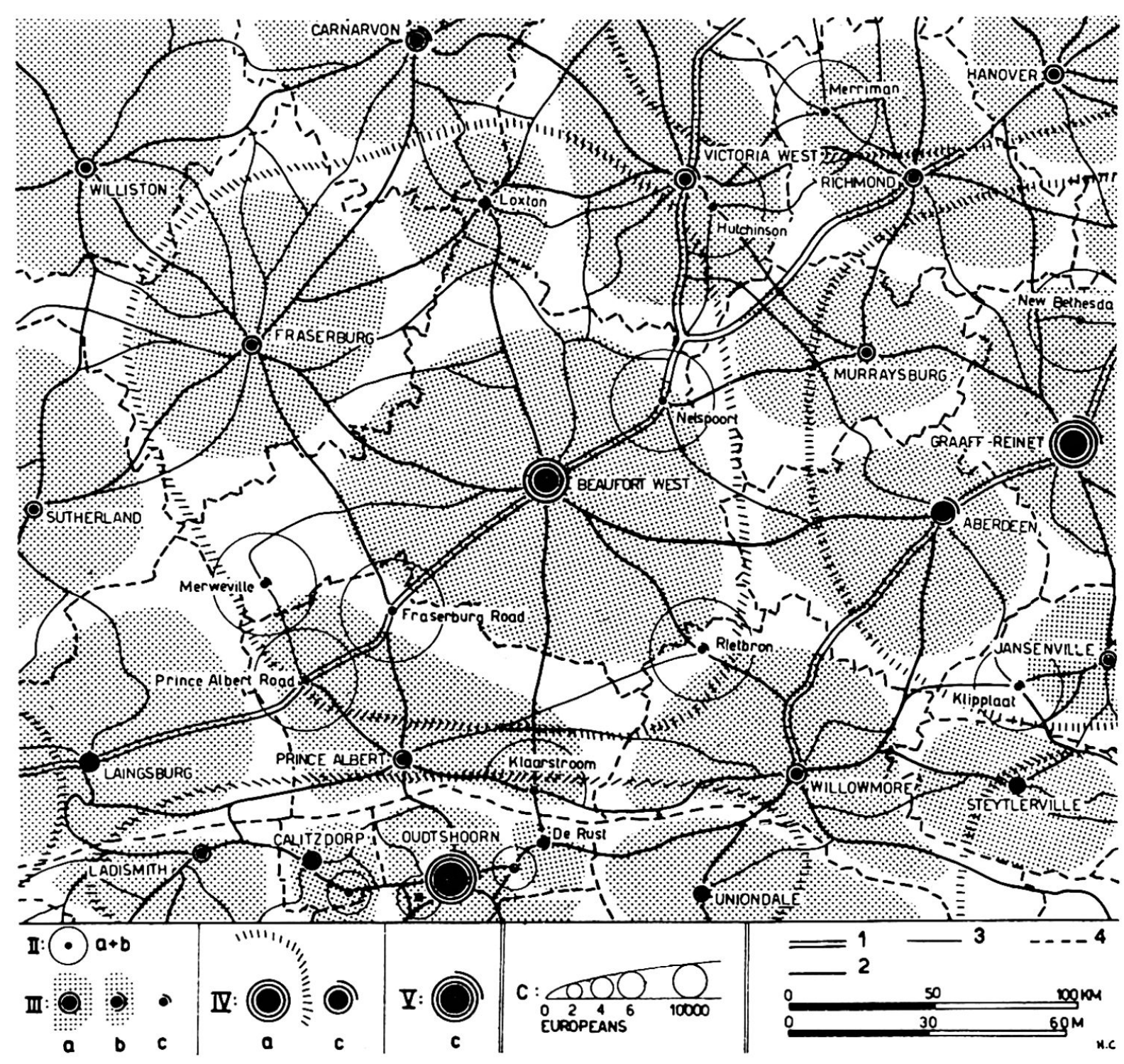

Abb. 7 Zentralörtliche Funktionale der Karru Süd-Afrikas. (Aus: CARoL, Das agrargeographische Betrachtungssystem, Fig 16, S. 60.)

$\mathrm{II}=$ Orte mit zentralen Diensten 2. Ordnung (Ergänzungsgebiet schematisch dargestellt)

III $=$ Orte mit zentralen Diensten 3. Ordnung (Kernzonen dargestellt)

IV $=$ Orte mit zentralen Diensten 4. Ordnung (Grenzen der Kernzonen dargestellt

$\mathrm{V}=$ Orte mit zentralen Diensten 5. Ordnung (Ergänzungsgebiete nicht dargestellt)

$\mathrm{a}=$ Typus vollzentraler Ort, $\mathrm{b}=$ Typus semizentraler Ort, $\mathrm{c}=$ Typus subzentraler Ort $\mathrm{C}=$ Zentralkreis, proportional zur Zahl der Europäer-Einwohner

$1=$ Nationale Straßen, $2=$ Hauptstraßen, $3=$ Verbindungsstraßen, $4=$ Distriktsgrenzen

\section{Zentralörtliche Funktionale}

a) spezielle (landwirtschaftliche) wie Molkereien, Mühlen, Trotten, landwirtschaftliche Märkte mit ihren Einzugsgebieten; Gemüse-, Milchgürtel um Konsumzentren.

b) allgemeine zentralörtliche Einheiten als Versorgungsbereiche der ganzen Bevölkerung von den untersten bis zu den höchsten Ordnungen: Gemeindezentrum, Marktort, Stadt, Großstadt, Metropole.

Staatliche Einheiten, die - je nach dem Wirtschaftssystem - die Landschaft in sehr starkem Maße bestimmen: z. B. staatlich dirigierte Betriebsformen im Gegensatz zum freien Bauerntum.

Agrarische Austauschgebiete, z. B. Aufzucht im Weidegebiet - Mast im Ackerbaugebiet. 
Im Beispiel der südafrikanischen Karru sind, wie Abbildung 7 zeigt, zentralörtliche Funktionale dargestellt. Sie setzen sich aus zentralem Ort und Ergänzungsgebiet zusammen. Jeder zentrale Ort ist der Standort von zentralen Diensten, und darunter werden wirtschaftliche und kulturelle Einrichtungen verstanden, die vorwiegend einem geschlossenen, räumlich begrenzten Bereich von Benützern dienen. Dieser Bereich wird als Ergänzungsgebiet bezeichnet. (Eine genaue Definition aller verwendeten Begriffe gibt CAROL auf den Seiten 27 und 28 seiner Arbeit über das agrargeographische Betrachtungssystem.)

\section{Das Begriffssystem}

Im System der eben verwendeten Begriffe erscheinen mit Absicht unverbrauchte Bezeichnungen, denn sie sollen Vorurteile und störende Gedankenassoziationen verhindern. (Es kann E. FELS an dieser Stelle nicht beigepflichtet werden, wenn er die Notwendigkeit bestreitet, «immer wieder neue Begriffe zu prägen» ${ }^{\mathbf{0}}$, verlangt doch eine differenzierte Betrachtungsweise auch eine entsprechende und vor allem eindeutige begriffliche Fixierung.) Die nachfolgende Übersicht soll nun zeigen, wie sich, den bisherigen Ausführungen entsprechend, unsere Begriffe $\mathrm{zu}$ einem einheitlichen Gebäude zusammenschließen.

Methoden :

Landschaftskunde

(Geographie)

Betrachtungssysteme (z. B. agrargeogr. Betrachtungssystem)

Betrachtungsrichtungen (z. B. formale Betrachtungsrichtung innerhalb des agrargeogr. Betrachtungssystems)

Elementare Betrachtung
Untersuchunsbereiche:

Geosphäre (Erdhülle)

Geomer (z. B. Landschaft der Schweiz)

Geoptom (z. B. Agrargeoptom; in der Literatur häufig als Agrarlandschaft bezeichnet)

Ptomatrop (Struktureinheit innerhalb eines Geoptoms) Ptomatropenkategorie

Ptomatropenordnung

Element (z. B. Relief)

\section{Erläuterungen :}

Absolutes Sein der Erdhülle in vollem Umfang

Absolutes Sein innerhalb eines beliebigen räumlichen Ausschnittes der Geosphäre

Wissenschaftliche Betrachtung des absoluten landschaftlichen Seins, notwendigerweise (ob zugegeben oder nicht) von bestimmten Standpunkten ("Welten") her

Sachliche Unterteilung der Geoptoma aus praktischen Gründen

Gruppe gleichwertiger Ptomatropen innerhalb eines Geoptoms

Kennzeichnung ungleichwertiger Ptomatropen

Grundbaustein, an sich ohne landschaftliche Qualitäten

Mit diesem System ist die Möglichkeit geschaffen, die neueren Landschaftsauffassungen gegeneinander abzuheben, auch dann, wenn sie nur subtile Unterschiede aufweisen sollten. Im Prinzip bestehen jetzt zwei Wege für das weitere Vorgehen: Jede Landschaftsauffassung läßt sich einzeln charakteriseren und nach den gewonnenen Kriterien beurteilen, oder man kann der Betrachtung das Bezugssystem selbst zugrundelegen und feststellen, welche Bedeutung allen seinen Stufen innerhalb der neueren Landschaftsauffassungen zukommt. Bei der Wahl des ersten Weges resultieren getrennte Schlußfolgerungen für jeden Landschaftsbegriff; der zweite Weg hingegen führt eher zu einem Gesamturteil. Für die Fortsetzung unserer Untersuchung sei der zweite Weg gewählt, denn er entspricht, wie gleich gezeigt werden soll, der gestellten Aufgabe besser als der erste.

${ }^{70}$ Fels, Der wirtschaftende Mensch als Gestalter der Erde. In: SiEBert, Wort, Begriff und Wesen der Landschaft, S. 79. 


\section{Die Vorstellung vom Landschaftsinhalt}

\section{Die ptomatropische Landschaftsauffassung}

a) Einführung - b) Einordnung des Landschaftsbegriffes aus der Zeit Bürgers -

c) Die gegenwärtige Bedeutung der Bürgerschen Auffassung

a) Anneliese Siebert schließt ihre im Jahre 1955 veröffentlichte Arbeit über «Wort, Begriff und Wesen der Landschaft» mit der Darstellung der Bürgerschen Auffassung, und sie ist - wie es scheint - der Meinung, damit die heutige Landschaftsauffassung charakterisiert zu haben. Wohl zählt die Autorin noch verschiedenste Landschaftsdefinitionen neuesten Datums auf, doch diese müssen als Belege zum ersten Teil der Schrift betrachtet werden. Das mag ein deutlicher Beweis dafür sein, daß es nur dann möglich ist, die jüngere Entwicklung der Landschaftsvorstellung zu sehen, wenn mit einem den Verhältnissen angepaßten Maßstab gemessen werden kann.

Am Schluß des vorigen Kapitels ist der Weg angedeutet worden, welcher für die Fortführung der Untersuchung eingeschlagen werden soll. Er entspricht tatsächlich der Themenstellung, geht es doch um die Aufgabe, ausfindig zu machen, ob und in welchem Sinn sich die Grundzüge des Landschaftsbegriffes in der letzten Zeit entwickelt haben. Die gesuchte Lösung ist dadurch noch nicht gegeben, daß einfach das bestehende Mosaik verschiedener Landschaftsauffassungen zur Darstellung kommt. Anstatt der Vielheit gerecht zu werden, ist aus dieser Vielheit das jeweils Neue und Wesentliche herauszulesen. Das Mosaik hat im Hintergrund zu stehen; seine Bausteine sollen in geeigneter Weise geordnet und an den Maßstab (an das nun abgeleitete, allgemeine Bezugssystem also) herangebracht werden. - Daß mit der Darstellung der ptomatropischen Stufe begonnen und das System in rückläufiger Reihenfolge verwendet wird, hängt mit der im gleichen Sinne laufenden geographischen Entwicklung der letzten Jahre zusammen.

b) Der ausgeprägteste ptomatropische Landschaftsbegriff ist der BürgERSCHE. Dieser findet sich somit nicht nur zeitlich am Beginn der zur Diskussion stehenden Periode, sondern er gehört auch inhaltlich auf die erste und einfachste Stufe. «Ptomatropisch» hat die Bedeutung von «wissenschaftlich direkt zugänglich», und in diesem Sinne ist der Landschaftsbegriff vor einem Vierteljahrhundert auch geschaffen worden. Man erstrebte damals offenbar keine Landschaftsauffassung, welche der gegebenen und spezifisch geographischen Wirklichkeit möglichst nahe kam, sondern man ließ sich vielmehr von Vorbildern aus einfacher strukturierten Wissenschaften leiten und schnitt die geographische Wirklichkeit auf diese Vorbilder hin zu. Die Feststellung, daß die Landschaft eine Gestalt sei, hätte zwar das Aufsuchen eines selbständigen Weges begünstigen können; die erste Reaktion auf die Entdeckung des Gestaltcharakters führte aber eher zu einer noch deutlicheren Anlehnung an andere Wissenschaftszweige, und dies deshalb, weil die Gestalt durchwegs im Sinne einer starren und geschlossenen Einheit gesehen wurde. - Schon zu Buergers Zeit gingen Landschaftsauffassungen über den üblichen Rahmen hinaus, aber es sollte offenbar nicht gelingen, Gesamtkonzeptionen auf höherer als der ptomatropischen Stufe zu verwirklichen. Auch war der Einfluß der einzelnen über ihre Zeit hinausreichenden Landschaftsbegriffe zu klein, als daß etwa dadurch die Weiterentwicklung maßgebend hätte beeinflußt werden können; es gibt sogar bis in die Gegenwart hinein ptomatropische Landschaftsbegriffe.

c) Noch für das Jahr 1955 läßt sich bei Anneliese Siebert lesen: «In dem gesamten Gewirr der unterschiedlichen geographischen Definitionen scheint mir die kritische Darlegung von K. BüRGER, die er vor 20 Jahren gegeben hat, bis heute noch gültig zu sein. Aus diesem Grunde wird sie in einem ausführlichen Auszug wiedergegeben, da sie m. E. in der Unsicherheit der unterschiedlichen Definitionen ein gewisses stabiles Gerüst darstellt». «Wenn auch mit jener Schrift die gesamte Problema- 
tik des Landschaftsbegriffes nicht gelöst werden konnte, weil alle Strömungen noch hin- und herwogen und noch alles im Fluß ist, so konnten doch von Bürger gültige Leitlinien herausgearbeitet und die Begriffe schärfer gefaßt werden. So möchte ich sie gleichsam als Leitprogramm in dem Gewirr der zahllosen Definitionen und Auffassungen für diejenigen voranstellen, welche die Landschaft schützen, pflegen und gestalten wollen ${ }^{71}$.

$\mathrm{Da}$ die Darlegungen Bürgers bis heute lebendig geblieben sind, beweisen Landschaftsdefinitionen wie diejenige von TROLL, welche sogar im Wortlaut mit der Bürgerschen Fassung übereinstimmt: «Unter einer geographischen Landschaft (Landschaftsindividuum, natürliche Landschaft) verstehen wir einen Teil der Erdoberfläche, der nach seinem äußeren Bild und dem Zusammenwirken der Erscheinungen sowie den inneren und äußeren Lagebezeichnungen eine Raumeinheit von bestimmtem Charakter bildet und der an geographischen, natürlichen Grenzen in Landschaften von anderem Charakter übergeht. Länder dagegen sind politisch oder verwaltungsmäßig umgrenzt, zum Teil historische Territorien oder von bestimmten Völkern bewohnte Gebiete »72. TROLL zählt zu den bekanntesten gegenwärtigen deutschen Geographen; somit ist belegt, welches Gewicht der ptomatropischen Landschaftsauffassung auch in der neuesten Zeit noch zukommt. Tatsächlich bedeutet die oben angebrachte Bemerkung «bis heute lebendig geblieben» nicht einfach: noch existierend, noch nicht untergegangen; vielmehr soll dieser Hinweis nach seinem vollen Gehalt, also in keiner Weise abgeschwächt, verstanden werden. TROLL sorgt selbst dafür, daß der ptomatropische Landschaftsbegriff weiterhin in uneingeschränktem Ansehen wirksam ist, indem er gerade jene zwei Stellen in Bürgers Formulierung intensiviert, welche heute am ehesten einer Neuorientierung unterzogen werden müßten. Er spricht im Zusammenhang mit der geographischen Landschaft von einem Landschaftsindividuum, und er betont, daß die Landschaften durch natürliche und nicht, wie die Länder, durch politische oder verwaltungsmäßig bedingte Grenzen voneinander geschieden werden. Just der Zweifel an der Existenz von natürlich geformten landschaftlichen Einzelindividualitäten war es, welcher in den letzten Jahren vereinzelt neues Leben in die Landschaftsdiskussion hineingebracht hat. Wenn eine Definition nun derart verfaßt ist, daß mit Absicht die verwundbaren Punkte gegen eine eventuelle freiere Interpretation geschützt werden, so kann das eben nur heissen, daß man die frühere Form der einfachen und praktischen ptomatropischen Landschaftsauffassung auch heute noch beibehalten möchte.

Es drängt sich die Frage auf, warum am ptomatropischen Landschaftsbegriff festgehalten werde. Zwei Antworten sind möglich. Entweder kennt man die voll umfängliche landschaftliche Wirklichkeit zu wenig genau und ist der Überzeugung, die ptomatropische Auffassung sei dieser Wirklichkeit angepaßt. Oder aber man hat den Eindruck, ohne einen Landschaftsbegriff im ptomatropischen Sinne, das heißt ohne die Vorstellung von einem fest umrissenen und inhaltlich genau bestimmten und überblickbaren Raumobjekt nicht wissenschaftlich arbeiten zu können. Es ist schwer zu sagen, welche Meinung beim einzelnen Geographen jeweilen vorherrscht; allgemein läßt sich aber feststellen, daß der Glaube an die Notwendigkeit, Ptomatropen besitzen zu müssen, überwiegt.

\section{Die geoptomische und die geomerische Landschaftsauffassung}

Sicher gibt es heute noch zu wenig Arbeiten, in welchen das Wesen des Landschaftsinhaltes systematisch erforscht worden wäre. Man weiß zwar mehr darüber als noch zur Zeit Bürgers, aber es fehlen auch jetzt die richtig überzeugenden Re-

${ }^{71}$ Siebert, Wort, Begriff und Wesen der Landschaft, S. 2-3.

72 TRoll, Die geographische Landschaft und ihre Erforschung, S. 165. 
sultate. BüRGER (wie schon vorne ausführlich festgestellt) und mit ihm nun auch TroLl, denken sich «ihre»Landschaften aufgebaut aus:

1. visuell in Erscheinung tretenden Komponenten,

2. den Bindungen zwischen diesen Komponenten,

3. den inneren und

4. den äußeren Lagebeziehungen,

aber aus allen diesen Gegebenheiten nur insofern aufgebaut, als sie mithelfen, abgerundete Raumganzheiten zu formen. Darüber hinaus bestehen nun aber neuere Auffassungen, die den Landschaftsinhalt entscheidend erweitern:

Vorweg sind es alle jene Vorstellungen, welche in der Landschaft nicht eine Ganzheit oder ein Individuum sehen und darum gelten lassen, daß auch erdumspannende und den Individualcharakter störende Erscheinungen mitgezählt werden. Die oben erwähnten Inhaltsgruppen sind bei solchen Vorstellungen gehaltreicher.

Und weiter: Mit den unter Punkt 2 genannten Bindungen zwischen den Komponenten sind ausschließlich kausale Wechselwirkungen gemeint (siehe auch Kapitel D II). A. Siebert belegt diese Feststellung, wenn sie sagt: ... « und zuletzt (wurde) eine Gesamterfassung angestrebt, welche Bild, kausale Verknüpfung und Seeleneindruck umschließt» ${ }^{73}$. Eine anders geartete Verknüpfung als die kausale wird nicht genannt, und doch bestehen daneben die verwandtschaftlichen oder «tektonisch-normativen $\gg 74$ Bindungen, womit einmal mehr der Landschaftsinhalt erweitert ist ${ }^{75}$.

Dann: Die Kausalität, von der wir sprachen, umfaßt nicht unbedingt auch die Bindungen in der organischen Welt und am wenigsten jene zwischen geistig bestimmten Wesen. Bовек und Sснмiтhüsen unterscheiden darum

«1. die' physikalische Kausalität,

2. die ,vitale Gesetzlichkeit', von der bisher nicht feststeht, ob sie letzten Endes auch in der physikalischen Kausalität auflösbar ist,

3. die Eigengesetzlichkeit geistig bestimmter Wesen, vorzüglich in ihrer Vergesellschaftung ${ }^{76}$.

Und ferner: «Die Kulturlandschaft ist sinngeladen, ist Werk des Menschen im Rahmen dessen, was die Natur erlaubt. Sie ist die gewaltige Objektivation des Geistes und offenbart deshalb auch die geistige Form ihrer Schöpfer ${ }^{77}$. Eine Landschaft erklären (sofern sie nicht bloß Naturlandschaft ist), heißt also, auch den menschlichen Geist, der dahinter steht, verstehen lernen, oder anders: die menschlichen Ideen aufdecken. Auch die menschlichen Ideen sind Bestandteile des Landschaftsinhaltes. Schмiтнüsen formuliert diesen Sachverhalt wie folgt:

«Kulturlandschaft ist ein ,überkausaler Wirklichkeitsbereich', in welchem sich aus schöpferischem Willen geschaffene Werte mit kausalem Getriebe und mit vitaler Entwicklung vereinen. Wir können nicht an diesem Geistigen vorbeigehen, das in der Kulturlandschaft von Stoff und Lebewelt Besitz ergriffen hat. Wir erfassen es aber nicht, wenn wir immer nur nach dem Warum fragen. Die Frage nach der Kausalität zielt in eine Dimension, die nicht die des Geistes ist. Wir müssen vielmehr auch fragen, welche geistigen Gehalte in der Kulturlandschaft erkennbar sind, wie sie im

${ }^{73}$ Siebert, Wort, Begriff und Wesen der Landschaft, S. 38.

${ }^{74}$ Wir übertragen diese treffende Bezeichnuug aus dem Werke Paul Nigglis über "Probleme der Naturwissenschaften" (S. 20) in die geographische Landschaftsanalyse. Im Abschnitt DII wird dann zu zeigen versucht, welche zentrale Bedeutung gerade diesen tektonisch-normativen Bindungen zukommt.

${ }^{75}$ BoвeK und Schmithüsen sagen, daß zum Wesen eines Teilraumes der Erdhülle u. a. auch gehören: ... seine «innere Gliederung oder Struktur». (Die Landschaft im logischen System der Geographie, S. 112.) Vielleicht sind mit der inneren Gliederung die tektonisch-normativen Beziehungen gemeint?

${ }^{76}$ BoBek und Schmithǘsen, Die Landschaft im logischen System der Geographie, S. 112-113.

77 Schwind, Sinn und Ausdruck der Landschaft, S. 196. 
einzelnen zum Ausdruck kommen, und wer die Träger dieser geistigen Prägung sind $\gg 78$.

Endlich finden sich heute mehrere Landschaftsdefinitionen, welche den materiellen Inhalt nicht mehr von der Bedingung abhängig machen, daß er visuell in $\mathrm{Er}$ scheinung treten müsse. Sie zählen die gesamte «organische Welt», die «vitale (nicht geistbestimmte organische) Welt» und die «geistbestimmte Welt, d. h. die Menschheit und ihre Werke» ${ }^{79}$ zum Untersuchungsobjekt unserer Wissenschaft.

Somit ergibt sich nun als Zusammenfassung aller bekannten neuesten Vorstellungen über den Landschaftsinhalt folgendes Resultat:

I. Stoffliche Komponenten

(alle in der Geosphäre vorhandenen materiellen Erscheinungen)

1. anorganische Welt

2. vitale Welt

3. Mensch und menschliche Werke

II. Geistige Komponenten (alle landschaftsbestimmenden menschlichen Ideen)

III. Komponenten-Bindungen 80

1. physikalische Kausalität

2. vitale Gesetzlichkeit

3. Eigengestzlichkeit geistig bestimmter Wesen

4. Lagebeziehungen 81

5. tektonisch-normative (verwandtschaftliche) Beziehungen.

Wie schon erwähnt, war die ptomatropische Auffassung nicht nur zu Beginn der hier untersuchten Epoche auffindbar, sondern sie ist von führenden Fachleuten bis in die Gegenwart hinein beibehalten worden. Und doch ist nun festgestellt worden, daß eine deutliche Entwicklungstendenz dahin geht, die Landschaft umfassender zu verwerten. Methodologen wie Bobek, Carol, Lautensach, Schmitthenner, SchmithüSEN und WINKLER stehen eindeutig über der ptomatropischen Stufe; sie sind entweder geoptomisch oder geomerisch eingestellt. Keine ihrer Landschaftsdefinitionen engt den Inhalt irgendwie ein; was die Erdhülle aufweist, kann nach ihrer Meinung auch landschaftlich relevant sein und in eine geographische Untersuchung miteinbezogen werden.

Nun bedeutet allerdings auch die geoptomische Auffassung gegenüber dem absoluten Gehalt in der Erdhülle eine Einengung. Auf Seite 22 ist gesagt worden, daß jedes Geoptom nur einen Aspekt der umfassenden Wirklichkeit darstelle; die eigentliche Wirklichkeit selbst wurde mit dem Ausdruck «Geomer» bezeichnet. Es mag Geographen geben, welche diese Gegensätzlichkeit als außerhalb der Wissenschaft liegend ansehen und einen Verwertungsversuch vielleicht als Spielerei beurteilen. Die Entwicklung der Landschaftsauffassung geht aber tatsächlich dahin, auf den erwähnten Sachverhalt Rücksicht zu nehmen. Vorläufig enthält die geographische Methodologie zum mindesten Andeutungen.

\footnotetext{
${ }^{78}$ Schmithüsen, Der geistige Gehalt in der Kulturlandschaft. In : SIEBERT, Wort, Begriff und Wesen der Landschaft, S. 77.

79 Bobek und Schmithüsen, Die Landschaft im logischen System der Geographie, S.112-113.

${ }^{80}$ Der von Bовек und SchmiтhüSEN verwendete Ausdruck "Wirkungsgefüge" scheint mir nicht günstig gewählt zu sein, denn er gemahnt zu sehr an eine aktive, gegenseitige Beeinflussung und verunmöglicht es beispielsweise, auch die tektonisch-normativen Beziehungen darunter aufzuführen.

${ }^{81}$ Der Ausdruck "Lagebeziehungen» wird übernommen, obwohl seine Bedeutung nicht vollständig geklärt ist. (Siehe unsere Auseinandersetzung mit der Landschaftsdefinition von BürGER.) BÜRGER versteht darunter vermutlich kausale Wirkungen, welche in auffälliger Art an eine bestimmte Lage gebunden sind. Darüber hinaus ist es aber m. E. auch möglich, die Lagebeziehungen als solche als individuelle Landschaftseigenschaften zu berücksichtigen.
} 
Schmitthenner äußert sich so: «Das, was der Geograph unter Ländern und Landschaften versteht, ist die Zusammenfassung alles dessen, was er auf induktivem Wege über Ähnlichkeit und Verschiedenheit und über die Lagebeziehungen erkannt hat, und zwar von seinem Standpunkt her erkannt hat. Es ist eine Nachbildung des als gegeben Erschauten 》 82. Einen Schritt weiter geht K. H. PAFFEN, insofern nämlich, als er auf verschiedene Auslegungsarten hinweist. Allerdings zieht auch PAFFEN für das praktische Arbeiten keine Konsequenzen; man bekommt eher den Eindruck, er empfinde das Nebeneinander mehrerer Landschaftsinterpretationen als störend, und er rechne damit, daß zu gegebener Zeit eine Vereinfachung und Vereinheitlichung der Verhältnisse möglich werde: «So einig man sich in Geographenkreisen aber auch über die Bedeutung der Landschaftsforschung im Rahmen der modernen Geographie ist, so verschiedenartig sind die Auffassungen über Wesen, Inhalt, Vorstellung und Abgrenzung von Landschaften. Mag man hierin zum Teil den Ausfluß einer voneinander abweichend disponierten Denkweise und des persönlichen Blickwinkels zum Gegenstand der Landschaft sehen, so liegt der Hauptgrund hierfür doch wohl im Objekt selbst, indem so komplexen, schwer faßbaren, selten scharf umrissenen und für unsere menschlichen Proportionen kaum mit einem Blick zu überschauenden Wesen der Landschaft»83. - BRüNGer ahnt offensichtlich die Möglichkeit, daß der «persönliche Blickwinkel» zu einer geduldeten Freiheit in der Landschaftsbetrachtung werden könnte; er glaubt aber nicht daran, daß dadurch ein Fortschritt erzielt würde, und er versucht darum, der Entwicklung Einhalt zu gebieten. Er spricht von der Landschaft als von einer Einheit in naturwissenschaftlichem Sinne und sagt dann: «Bedeutsam ist nun, daß diese Einheit der Landschaft mit ihrer auch nur als Einheit $\mathrm{zu}$ verstehenden erdräumlichen Ordnung und Gliederung nicht durch wechselnden Standpunkt in der Analyse genetischer Betrachtung verloren geht, wozu die heterogene Ursächlichkeit verschiedener Einzelfaktoren so außerordentlich leicht verleitet» ${ }^{\mathbf{4 4}}$.

Der obersten Stufe, der Stufe des Geomers, auf welcher die verschiedenartigen Auslegungsmethoden des absoluten Seins voll anerkannt werden, kommt Erich SANDER mit einer neuesten Arbeit über «Landschaft und Mensch» (Januar 1957) am nächsten. Er schreibt darin: ... «was wir Landschaft nennen, ist jedesmal eine anschauliche Abstraktion.» Dabei spielt beim Abstrahieren «unsere Ansicht» eine Rolle, und damit meint er «unsere jeweilige Einstellung zu den Dingen dieser Welt. Unsere Einstellung aber besteht in bestimmten, traditionell übernommenen oder mutativ neuwüchsigen Denkgewohnheiten, Sehweisen, Gefühlsrichtungen, Geschmacksformen u. a. Und sie gründet zu unterst und immer, zu allen Zeiten und in allen Räumen, auf Absichten und Planungen, die wir im dumpfen Drange nach Selbsterhaltung unseres Daseins verfolgen und zu realisieren streben.» «Insgesamt haben wir es hier mit jenen ,selbstverständlichen' Voraussetzungen unseres Wahrnehmens, Denkens und Handelns zu tun, die zumeist übersehen werden, weil sie unbewußt wirken. Aber gerade sie bedingen nun einmal zu tiefst die sprudelnde Fülle unserer menschlichen, nach Raum und Zeit so unterschiedlichen, oft sogar gegensätzlichen ,Ansichten' von den Dingen dieser Welt $\gg \mathbf{8 5}$.

Eindeutiger Vertreter der geomerischen Landschaftsauffassung ist Carol. Nicht nur seine theoretischen Äußerungen, sondern auch die praktisch durchgeführten Landschaftsuntersuchungen zeugen dafür. Auf die geomerische Auffassung an dieser Stelle näher einzutreten, erübrigt sich nun aber, da sie bereits auf den Seiten 17 bis 29 der vorliegenden Arbeit zur Darstellung kam. In der Tat entstammt das dort abgeleitete Begriffssystem als Ganzes, wie leicht einzusehen ist, der geomerischen Auffassung,

82 Schmitthenner, Zum Problem der Allgemeinen Geographie und der Länderkunde, S. 20.

${ }^{83}$ PAFFEN, Oekologische Landschaftsgliederung, S. 167.

84 BrÜnger, Gedanken über das Wesen ... der Siedlungsgeographie, S. 126-127.

85 SANDER, Landschaft und Mensch, S. 298. 
und die einzelnen Stufen, aus denen es sich aufbaut, weisen den Weg für die wissenschaftlich-geomerische Durchdringung unseres Objektes. Wir haben die verschiedenartigen Landschaftsvorstellungen nun effektiv im Lichte der geomerischen Auffassung betrachtet, und als Ergebnis zeigte sich, daß jede Vorstellung je einer Stufe des geomerischen Systems entspricht.

Abschließend sei festgehalten, daß es jeweilen leicht ist, eine ptomatropische Landschaftsauffassung als solche zu erkennen, in der Regel hingegen schwer, die geomerische von der geoptomischen zu unterscheiden. Doch kann nun als Hilfe die zusammenfassende Tatsache dienen, daß mit der Anerkennung des geomerischen Landschaftsbegriffes mehrere Betrachtungssysteme, welche ihrerseits eine gleiche Zahl Maß-Systeme bedingen, in die Landschaftskunde Eingang finden; der geoptomischen Auffassung jedoch entspricht nur ein Betrachtungssystem und damit auch nur ein Maßstab.

\section{Die Vorstellung von der Landschaftsstruktur}

a) Der Rahmen zu allen individuellen Vorstellungen - b) Die Variationen der Ganzheitshypothese - c) Das Raumkontinuum - d) Lockere Elementenbindungen und bindungsloses Nebeneinander - e) Praktische Beispiele zur Ganzheitsauffassung - f) Auffassungen aus verschiedenen Kulturkreisen.

a) Die heutige Situation inbezug auf die Vorstellung von der Landschaftsstruktur läßt sich in Kürze durch zwei Aussagen charakterisieren:

1. «Die einzelnen Bestandteile (der Landschaft) stehen unter inniger gegenseitiger Beeinflussung und sind gegenseitigen Wechselwirkungen unterworfen ${ }^{86}$. Die Landschaft ist «ein Funktionsgefüge vieler physischer sowie kultureller Kräfte». «Bei analytischer Betrachtung der Landschaft fällt uns eine große Summe von landschaftlichen Einzelinhalten auf, die aber nie isoliert sind, sondern eine Einheit, eine Ganzheit, eine Gestalt repräsentieren 》 87 .

2. Es «läßt sich sagen, daß abiotische und biotische Ganzheiten durch besondere Kräfte, Hüllen, Gefüge, Organisationen zusammengehalten werden, während Landschaften... solche nicht aufweisen und ihnen ganzheitlich machende Bindungen fehlen. Wir haben es zu tun mit Zusammenstellungen summativen Charakters und infolgedessen kann bei ihnen nicht von Individuen gesprochen werden $\gg 88$.

Damit ist auch die uns interessierende Entwicklung seit Bürger aufgezeigt: Sie ist über zwei diametral voneinander wegführende Geleise verlaufen, und ein Resultat steht darum im krassen Gegensatz zum anderen. Einerseits ist die Bürgersche Auffassung selbst durch alle Jahre hindurch weitergetragen und dabei, wie es scheint, noch ausgebaut worden; andererseits hat sich der Geobotaniker ScHMID ganz davon abgewendet und ist zu einer gegenteiligen Auffassung gelangt. Ebenso ist dokumentiert, wie klein auch heute noch das sichere Wissen über die Landschaftsstruktur bleibt. Offensichtlich ist vieles nicht mehr als bloße Behauptung, und zukünftige Untersuchungen müssen über die haltbaren Auffassungen entscheiden.

b) Die obige Darlegung ist insofern unvollständig, als nur zwei extreme Äußerungen erwähnt sind, nicht aber auf das große, dazwischen liegende Feld mit den verschieden nuancierten vermittelnden Ansichten hingewiesen wird. Auf diese meines Erachtens wirklichkeitsnäheren Auffassungen muß auch noch eingegangen werden. Dabei stellt sich gerade vorweg die Frage nach einer sinnvollen Anordnung. Wünschenswert wäre es, den Grad der Übereinstimmung mit der Wirklichkeit berück-

${ }^{86}$ Windler, Zur Methodik der geogr. Grenzziehung, S. 130.

87 W AGNER, Der erdkundliche Unterricht, S. 16 und S. 43.

88 SснміD, Der Ganzheitsbegriff in der Biocoenologie und in der Landschaftskunde, S. 156. 
sichtigen zu können. Ein derartiger Plan läßt sich aber eben nicht durchführen, und deshalb wird als Weg der Darstellung der Übergang von einer extremen Auffassung zur anderen gewählt. Wir beginnen bei der Ganzheitsauffassung.

Wie schon erwähnt, verwertet auch noch die gegenwärtige Landschaftskunde zu einem großen Teil unüberprüfte Annahmen. Einzelne davon sind bestimmt verzeihlich, denn unsere Wissenschaft ist jung und das Untersuchungsobjekt überaus komplex: «Die Fehlerquellen bei der Apperzeption der... landschaftskundlichen Erscheinungen sind zahlreich. Je komplizierter (und mit wissenschaftlichen Mitteln unzugänglicher) ein Objekt wird, desto mehr beteiligt sich dabei eine gewisse Voreingenommenheit. Nur zu oft ist bei der Aufnahme durch die Sinnesorgane das Bedürfnis vorhanden, zu komplettieren, ähnlich wie eine zur Hälfte zerstörte Netzhaut das Objekt nicht halbiert, sondern ganz, wenn auch kleiner, sieht. Vermöge seiner Begabung, seiner Kenntnisse, seiner Erfahrung apperzipiert jeder anders. Dazu kommt noch, daß wir viel zu sehr geneigt sind, mit einer überkommenen Begriffswelt zu arbeiten, mit Kategorien, welche dem Phänomen nicht adäquat sind»89. Für nicht entschuldbar halte ich es aber, wenn gerade die entscheidenden Grundlagen, auf die sich alles Arbeiten stützen muß, bloße Behauptungen statt bewiesene Tatsachen sind, und zu diesen unbewiesenen Grundlagen zählt die Ganzheitsauffassung von der Landschaft. Seltsamerweise ist die Ganzheitsauffassung auch in unserer wissenschaftlichen Zeit stark - wenn nicht von allen Landschaftsvorstellungen überhaupt am stärksten - verbreitet. Nach v. Regel und WinkLer zu schließen, sind führende Sowjetgeographen eindeutig Anhänger davon. «So ergab die Diskussion so gut wie einhellig, daß die Sowjetgeographen an der Landschaft als einer grundlegenden Kategorie und einem realen Objekt ihrer Wissenschaft festhalten wollen und dies auch in einem gewissen Sinne in überzeugender Weise zu begründen verstehen. Hierbei ist Landschaft immer als ein ,charakteristisches Teilstück der Erdoberfläche' verstanden, das sich qualitativ von andern 'Teilstücken unterscheidet, natürliche Grenzen besitzt und eine ganzheitliche, wechselseitig bedingte, d. h. gesetzmäßige Anhäufung (Kombination) von Gegenständen und Erscheinungen darstellt »90. Aber auch im deutschsprachigen Kulturbereich scheint man vielerorts die Ganzheitsauffassung als gesichertes Fundament zu betrachten ${ }^{91}$.

Solange man sich bewußt ist, daß Ganzheiten nur behelfsmäßige Wunschgebilde sind und erst noch mit sachlichen Erkenntnissen belegt werden müßten, ist für eine nicht behinderte Weiterentwicklung Gewähr geboten. Die Entwicklung wird aber gehemmt oder sogar unmöglich gemacht, wenn die Landschaftsganzheit als Voraussetzung jeder wissenschaftlichen Betätigung angesehen wird. Interessanterweise können Vertreter unseres Faches die Ganzheiten zum vornherein bejahen und gleichzeitig zu einem objektiven und sachlichen Arbeiten mahnen. So sagt etwa W. BRünger: «Derjenige kommt der wesenhaften Schaı und Durchschau einer Landschaft am nächsten, der sich ihr als Einheit gegenüber zunächst rein beobachtend und gewissenhaft beschreibend verhält, unter dem ständigen $Z_{\text {wang }}$ unmittelbarer Beobachtungen und kritischer Sachkorrektur einfache Zusammenhänge erschaut, nicht erdenkt und allmählich zur Überzeugung größerer Zusammenhänge bis zur wirklichkeitsgetreuen Verzahnung aller Faktoren im spezifischen Landschaftsbild aufsteigt. Dabei kann von übereilter Betonung konstruktiver Gedanken, einseitiger Teilwahrheiten oder Lieblingsideen auf Grund einseitiger Schulung, Forschung oder Neigung nie genug gewarnt werden $\gg \mathbf{9 2}$.

${ }^{89}$ Schmid, Der Ganzheitsbegriff in der Biocoenologie und in der Landschaftskunde, S. 156.

90 von REgeL und WinkLER, Zur Landschafts-Diskussion in der Sowjetgeographie, S. 246.

${ }^{91}$ In der Dissertation WindLers (Zur Methodik der geogr. Grenzziehung) findet sich auf S. 130 der Satz: "Die ganzheitliche Auffassung der Landschaft darf heute als gesichert gelten.»

92 BRÜNGER, Gedanken über das Wesen ... der Siedlungsgeographie, S. 127. 
Der Ganzheitscharakter der Landschaft steht im Zusammenhang mit der ptomatropischen Auffassung. Jener wie diese hat den gleichen Hintergrund: das Bedürfnis nach einem einfachen, überblickbaren, abgerundeten und begrenzten Untersuchungsgegenstand. Etwas anderes als eine reale Ganzheit ist nun aber die im Geist vollzogene Einheit, und es muß darum zwischen beiden deutlich unterschieden werden. Die geistige landschaftliche Einheit ist die Synthese der aus der Landschaftsbetrachtung gewonnenen Einzelerkenntnisse - also das erstrebte Ziel geographischen Forschens. (Siehe dazu auch Abschnitt D III der vorliegenden Arbeit.) «Für die Darstellung ist daher nun auch der Charakter der geographischen Gebiete eine Einheit, die nicht mehr sekundär ist, - sagt SchmitrthenNeR - «sondern das aus der Forschung für sie Herausgeholte, Gewollte und den Zweck erhaltende Primäre, menschgewollt, nicht mehr wie bei Ritter gottgewollt»93. Es ist oft schwer feststellbar, ob der geographische Ganzheits- oder Einheitsbegriff auf die realen Tatsachen oder auf die wissenschaftliche Synthese angewendet wird. Nur im ersten Fall muß von einer Ganzheitsauffassung der Landschaft gesprochen werden; die synthetische Ganzheit der Resultate wird bei jeder sinnvollen geistigen Betätigung gesucht. Ich glaube, daß es ein zuverlässiges Kriterium für die Unterscheidung gibt, nämlich die jeweilige Einstellung des betreffenden Wissenschafters $\mathrm{zu}$ den Landschaftsgrenzen. Nur eine reale Ganzheit besitzt auch reale Grenzen oder, anders ausgedrückt: nur wer reale Grenzen zu sehen geneigt ist, denkt an wirkliche Landschaftsganzheiten. Dabei ist die genannte Abhängigkeit so eng, daß linienartige Grenzen mit einer bestimmteren Einheitsauffassung verbunden sind als bänderartige.

Die Arbeit Windlers ${ }^{94}$ zeigt sehr übersichtlich verschiedene schon unternommene Grenzziehungsversuche, und sie spiegelt darum die bestehenden und sich zum Teil nur leicht voneinander abhebenden landschaftlichen Ganzheitsauffassungen wider. Im allgemeinen läßt sie erkennen, daß eine Entwicklung im Sinne einer Auflockerung stattgefunden hat. Die eindrückliche Reihe folgender Grenzen-Bezeichnungen diene als Beleg: Grenzlinie, Grenzstreifen, Grenzsaum oder -gürtel, Grenzraum, generelle und relative Grenze.

c) Wir haben bis anhin stillschweigend mit der Richtigkeit der Hypothese gerechnet, daß innige Elementen-Bindungen und landschaftliche Ganzheitsauffassung untrennbar zusammen gehören. $\mathrm{Zu}$ dieser Annahme verleitete die unter a) genannte erste Aussage über die Landschaftsstruktur. Dort wurde als selbstverständlich hingestellt, daß die gegenseitige Beeinflussung der einzelnen Landschaftsbestandteile landschaftliche Ganzheiten hervorrufe. An dieser Voraussetzung läßt sich nun aber mit Recht zweifeln, und einen neuen Gesichtspunkt ergibt der Hinweis auf die Existenz eines geographischen Raumkontinuums.

Bовек schreibt den Satz: «Die zweite Grundvoraussetzung ist die ebenfalls schon mehrfach gemachte Feststellung, daß die geographische Substanz der gesamten Erdoberfläche ein Kontinuum bildet, dessen Struktur aber von Ort zu Ort durch Teilveränderungen einem Wandel unterliegt» ${ }^{95}$. Und Lautensach übernimmt Ausführungen Kants über den Raum des Philosophen: «Die Eigenschaft der Größen, nach welcher an ihnen kein Teil der kleinstmögliche (kein Teil einfach) ist, heißt die Kontinuität derselben. Raum und Zeit sind quanta continua, weil kein Teil derselben gegeben werden kann, ohne ihn zwischen Grenzen (Punkten und Augenblicken) einzuschließen, mithin nur so, daß dieser Teil selbst wiederum ein Raum oder eine Zeit ist. Der Raum besteht also nur aus Räumen, die Zeit aus Zeiten. Punkte und Augenblicke sind nur Grenzen, d. i. bloße Stellen ihrer Einschränkung; Stellen aber setzen

${ }^{93}$ Schmitrthenner, Zum Problem der Allgemeinen Geographie und der Länderkunde, S. 29.

04 Windler, Zur Methodik der geogr. Grenzziehung.

95 Bobek, Lautensachs "Geographischer Formenwandel », S. 289. 
jederzeit jene Anschauungen, die sie beschränken oder bestimmen sollen, voraus, und aus bloßen Stellen, also aus Bestandteilen, die noch vor dem Raum oder der Zeit gegeben werden könnten, kann weder Raum noch Zeit zusammengesetzt werden»96. (Vgl. die im Abschnitt C I geäußerten Ansichten über das Geomer.)

Wohl ist es richtig, daß einzelne Sphären der Erdhülle Unterbrüche aufweisen (so beispielsweise die Anthroposphäre), jedoch werden derartige Unstetigkeiten durch andere Sphären überbrückt, und der Erdhülle als Ganzem kommt die Eigenschaft der Kontinuität zu. Damit ist aber, wie mir scheint, gleichzeitig gesagt, daß in der Erdhülle nicht auch Raumganzheiten bestehen können, denn diese und das Raumkontinuum schließen sich gegenseitig aus.

Nun liest man zwar die Ansicht, daß Gegenstände anderer Fachgebiete ähnlich kontinuierlich ineinander übergehen würden wie die geosphärische Substanz und man sich trotzdem veranlaßt sehe, sie als begrenzte Ganzheiten anzusprechen. WinkLER und WindLer geben diese Feststellung zu bedenken. Winkler zitiert Ostwald: «Der Mangel ganz vollständiger und eindeutiger Grenzen (ist) eine ganz allgemeine Erscheinung bei allen natürlichen Erscheinungen... ${ }^{97}$. Und WINDLER beruft sich auf BERTALANFFY, welcher zeige, "wie unklar die Umrisse biologischer, als auch anderer Objekte bei eingehender Betrachtung $\gg 98$ seien. Für uns ist aber Tatsache, daß das Nebeneinander biologischer Objekte nicht als Kontinuum gelten kann, und wenn eine andere Erscheinung sich kontinuierlich wandelt (etwa die Lithosphäre, der Untersuchungsgegenstand des Geologen), dann setzt sie sich nicht gleichzeitig auch aus fest umrissenen Einheiten zusammen. Der Geologe begrenzt sein Objekt ganz willkürlich; er gliedert es nach von ihm aufgestellten Gesichtspunkten.

LAUTENSACH berücksichtigt die Eigenart des Erdhüllenkontinuums, wenn er in seinem Werk über den geographischen Formenwandel die vier auf die «fließenden Übergänge» Bezug nehmenden «Lagekategorien》 einführt. Selber sagt er dazu: «Die Kontinuität der Erscheinungen der empirischen Wirklichkeit bildet ... den Ausgangspunkt eines Buches von Hempel und Oppenherm ,Der Typusbegriff im Lichte der neuen Logik', dessen erster Satz lautet: ,Nach einer verbreiteten Anschauung ist alle wissenschaftliche Begriffsbildung mit einer unvermeidlichen Unvollkommenheit behaftet, die sich etwa folgendermaßen kennzeichnen läßt: Während die Eigenschaften der Objekte, die die Erfahrung uns darbietet, durch stetige Reihen möglicher Zwischenformen kontinuierlich, ohne scharfe Grenzen, miteinander verbunden sind, stellen die wissenschaftlichen Begriffe ihrer Funktion nach starre Formen dar, die scharfe Grenzen ziehen, wo fließende Übergänge bestehen, und die daher niemals zu einer angemessenen Darstellung unserer Erfahrungsbefunde mit ihrer mannigfaltigen Kontinuität zu führen vermögen.' Von dieser Schwäche der bisherigen wissenschaftlichen Begriffsbildung ausgehend, entwickeln die Verfasser die Umrisse einer neuen Logik, in der dem ,klassifikatorischen Typenbegriff' (Klassenbegriff) der ,abstufbare 'Typenbegriff' (Ordnungsbegriff) gegenübergestellt, und neben dem ,klassifizierenden Gesetz' das ,topologisch ordnende Gesetz' eingeführt wird. Die Verfasser betonen am Ende ihres Buches, daß diese Aufstellung abstufbarer Typenbegriffe und topologisch ordnender Gesetze nicht auf die Wissenschaften beschränkt ist, denen sie ihre Beispiele vorzugsweise entnehmen. Die Ergebnisse von Hempel und Oppenheim können gerade für die Geographie von weittragender Bedeutung werden, da die geographische Substanz der gesamten festen Erdoberfläche die Eigenschaft der Kontinuität in vollem Umfang besitzt. Es wird daher im folgenden bis zu der Entwicklung abgestufter geographischer Typenbegriffe vorgeschritten, wie ich sie, noch ohne Kenntnis des Buches von Hempel und Oppenheim,... im System des ,geographischen Formenwan-

${ }^{96}$ Lautensach, Über die Begriffe Typus und Individuum, S. 10.

97 von Regel und WinkLer, Zur Landschafts-Diskussion in der Sowjetgeographie. S. 244 (Fußnote).

98 WindLer, Zur_-Methodik der geogr. Grenzziehung, S. 130. 
dels' entwickelt habe «99. Die Auffassung, welche Lautensach über das Raumkontinuum besitzt und auch zu verwerten geneigt ist, wirkt überzeugend. Schade ist jedoch, daß die für das Neue aufgekommene Begeisterung gedämpft wird, denn er benützt seine für die landschaftliche Kontinuität eingeführten Begriffe, um hinterher künstlich die Diskontinuität wieder zu schaffen ${ }^{100}$. In der Tat besteht das Ergebnis seiner Formenwandellehre in den von ihm selbst überwundenen Landschaftsganzheiten.

d) Wie wir bis jetzt festgestellt haben, werden landschaftliche Raumganzheiten entweder als real angenommen oder künstlich aus einer verwoben gedachten Erdhülle herausgelöst. Eine vollständige Distanzierung von der Ganzheitsauffassung läßt sich dann erreichen, wenn die. Erkenntnis durchgedrungen ist, daß Elementenbindungen mit der immer wieder angenommenen Straffheit gar nicht bestehen. Denken wir so, dann gelangen wir in die Nähe der eingangs zum vorliegenden Kapitel erwähnten zweiten Aussage, in welcher von Landschaften als von "Zusammenstellungen summativen Charakters» gesprochen wurde. Persönlich bin ich nun der Meinung, daß wir gerade auf dem Übergang der Wirklichkeit am nächsten stehen. Es gibt heute einige Geographen, welche ein nicht durchwegs starres Beziehungsgefüge zwischen den Elementen für richtig halten, und man trifft für ihre Auffassungen etwa folgende Formulierungen an:

Boвeк und Schmithüsen: «Die Landschaft wird so zu einer Integration höchsten Ranges, im ganzen aber nur schwacher Intensität. Bei den einzelnen räumlichen Bestandteilen kann der Grad der Integration sehr unterschiedlich sein. Die Raumeinheiten, aus denen sich die Landschaft stufenförmig so aufbaut, daß jeweils niedere Einheiten in den höheren eingeschlossen sind, sind teilweise geschlossene dynamische Systeme von großer ökologischer Einheitlichkeit und einer gewissen Stabilität (Oekotope), teilweise aber nur sich ständig wandelnde offene Systeme, bei denen es schwierig ist, in dem Wandel das Bleibende zu erkennen ${ }^{101}$.

Carol: Die «Seinsbereiche überlagern, durchdringen sich und sind in verschiedenster Art und Weise stärker oder schwächer miteinander verknüpft, wobei sich insbesondere der Mensch zwar nie völlig, aber doch weitgehend von einer zwingenden Bindung lösen kann» ${ }^{102}$. «Wären die Elementarsphären unverbunden überschichtet, so würde die elementarwissenschaftliche Forschung zur Erklärung der Geosphäre genügen, eine Geographie wäre überflüssig. Tatsächlich kommen aber alle Grade von Verbindungen zwischen den Sphären, extensive bis sehr intensive, vor ${ }^{103}$.

Detaillierte Aussagen über die Art des Beisammenseins der Landschaftselemente lassen sich bis zur Gegenwart nicht finden. Durch die genannten Zitate ist immerhin mit einiger Bestimmtheit eine neue Auffassung abgegrenzt, und es wird in Zukunft darum gehen müssen, sie zu vertiefen. Die extreme Vorstellung ScHMIDs vom summativen Charakter des Landschaftlichen kehrt bei anderen Autoren nicht wieder, und es darf aus dieser Tatsache der Schluß gezogen werden, daß sie einseitig ist und am Rande steht. Die Landschaft hat also auch in den Augen der heutigen Geographen Gestaltcharakter; die Frage ist jedoch immer noch nicht endgültig entschieden, welches die spezifischen Eigenschaften dieser Gestalt seien.

e) $\mathrm{Da}$ die methodologische Literatur ihre Postulate und Auffassungen nicht oder doch allzu spärlich mit praktischen Beispielen belegt, ist es unmöglich, jede theoretische

${ }^{99}$ Lautensach, Über die Begriffe Typus und Individuum, S. 10-11.

100 Vgl. auch Schmitrhenner, Zum Problem der Allgemeinen Geographie und der Länderkunde, S. 20 .

101 Bовек und Schmiтhüsen, Die Landschaft im logischen System der Geographie, S. 119.

102 Carol, Das agrargeographische Betrachtungssystem, S. 19.

103 Carol, Zur Diskussion um Landschaft und Geographie, S. 115. 
Äußerung anschaulich zu machen und zu begründen. Einige Beispiele können immerhin die Ganzheitsauffassung der Landschaft illustrieren. - Ein extremer Anhänger davon ist J. H. Schultze. Für ihn sind Landschaftsganzheiten gegebene Realitäten. «Wenn zwei Wissenschaftler - sagt er - ein und dieselbe Landschaft verschieden abgrenzen, so liegt das nicht an der Landschaft, sondern an Irrtümern, die bei ihrer Erfassung unterlaufen können» ${ }^{104}$. Er veröffentlicht selbst die hier wiedergegebenen Gliederungen Ostafrikas (Abbildung 8) und erklärt den unterschiedlichen Grenzverlauf wie folgt: «Man sieht aus der Abbildung sehr deutlich, daß gewisse Grundtatsachen der landschaftlichen Realität sowohl von KLUTE wie von mir in der gleichen Weise erfaßt sind. Denn die Landschaften ordnen sich in vier meridionale Streifen an, die von Mittelafrika zum Indischen Ozean hin aufeinanderfolgen: die zentralafrikanische Schwelle, das Unjamwesi-Uganda-Becken, die ostafrikanische Hochlandschwelle und die Küstenabdachung. Im einzelnen jedoch weichen die Abgrenzungen sehr voneinander ab. Beispielsweise ist auf Grund meines Materials die Herausschälung einer besonderen Landschaft um den Victoria-See notwendig, ja sogar noch ihre Unterteilung in einen nördlichen und einen südlichen Abschnitt; auch wandeln sich die Geofaktoren in kurzem Abstand von der Küste des Indik so schnell, daß der Kü-

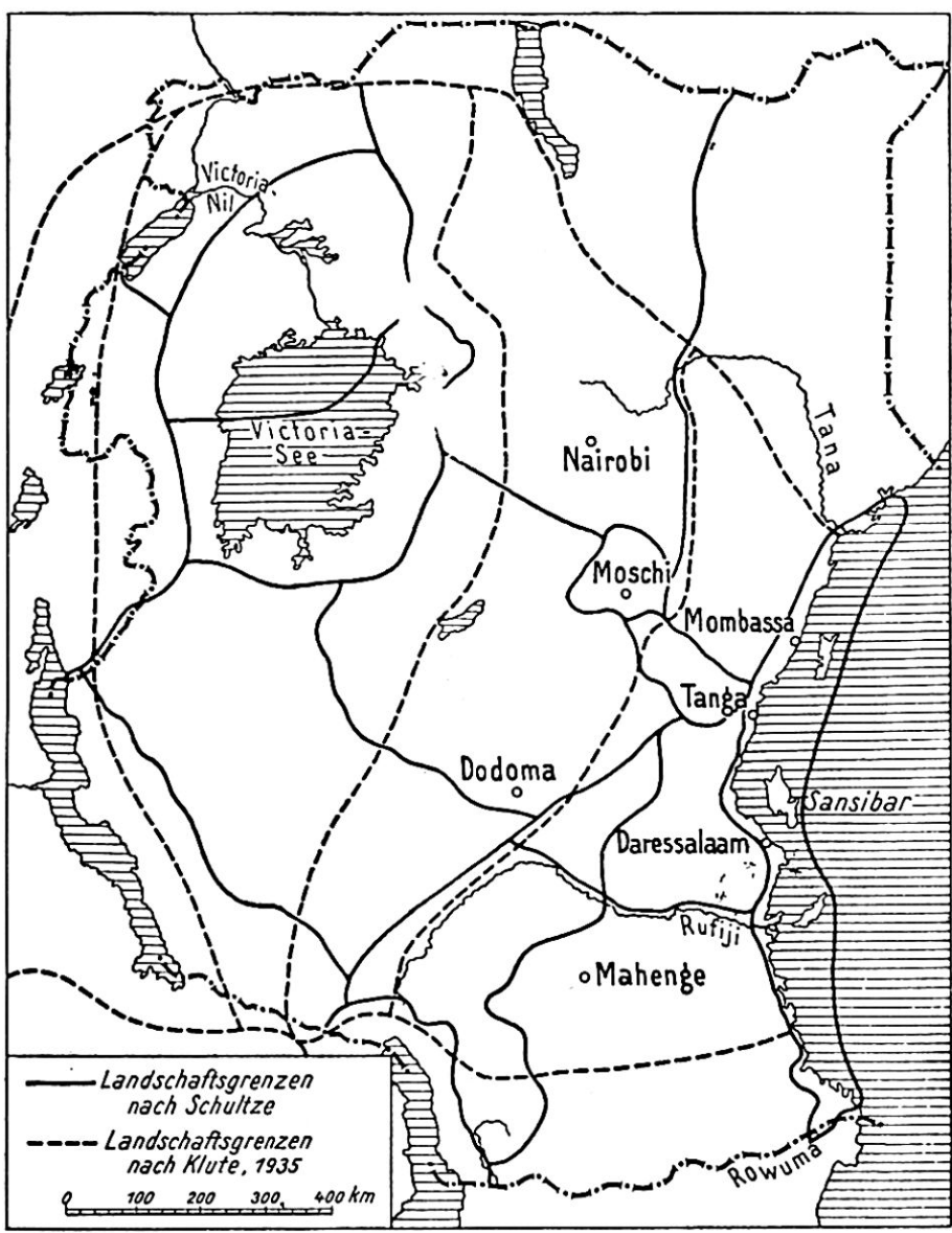

Abb. 8 Ostafrika in der (kultur-) landschaftlichen Gliederung von F. Klute (1935) und J. H. Schultze (1955).

(Aus: Schultze, Begriff und Gliederung geogr. Landschaften, S. 295.) stenstrich, die sogenannte Mrima, besonders abgegliedert werden sollte usw. usw. Dies also sind Divergenzen auf Grund des Standes der Kenntnisse bzw. der Auffassungen von dem Wirkungsgefüge der Landschaft. Die beiden Gliederungen Ostafrikas entstanden intuitiv. Solche Divergenzen lassen sich weitgehend beheben, wenn eine genaue $\mathrm{Er}$ mittlung der einzelnen Geofaktoren eingeschaltet wird $\gg 105$.

In der Arbeit über «Die Naturbedingten Landschaften der Deutschen Demokratischen Republik» stellt Schultze zwei weitere Beispiele einander gegenüber. (Abbild. 9.) Die theoretischen Voraussetzungen für die beiden Darstellungen unterscheiden sich zwar voneinander. Im einen Fall (Meynen und SchmithüSEN) ist bewußt nur eine «naturräumliche» (also nicht gesamtlandschaftliche) Gliederung vorgenommen worden; die andere Karte hin-

$10 \pm$ Schultze, Begriff und Gliederung der geogr. Landschaft, S. 294-295.

105 Schultze, Begriff und Gliederung der geogr. Landschaft, S. 295. Bei der Abbildung beachte man besonders den willkürlichen Grenzverlauf im Indik und im Victoria-See. 

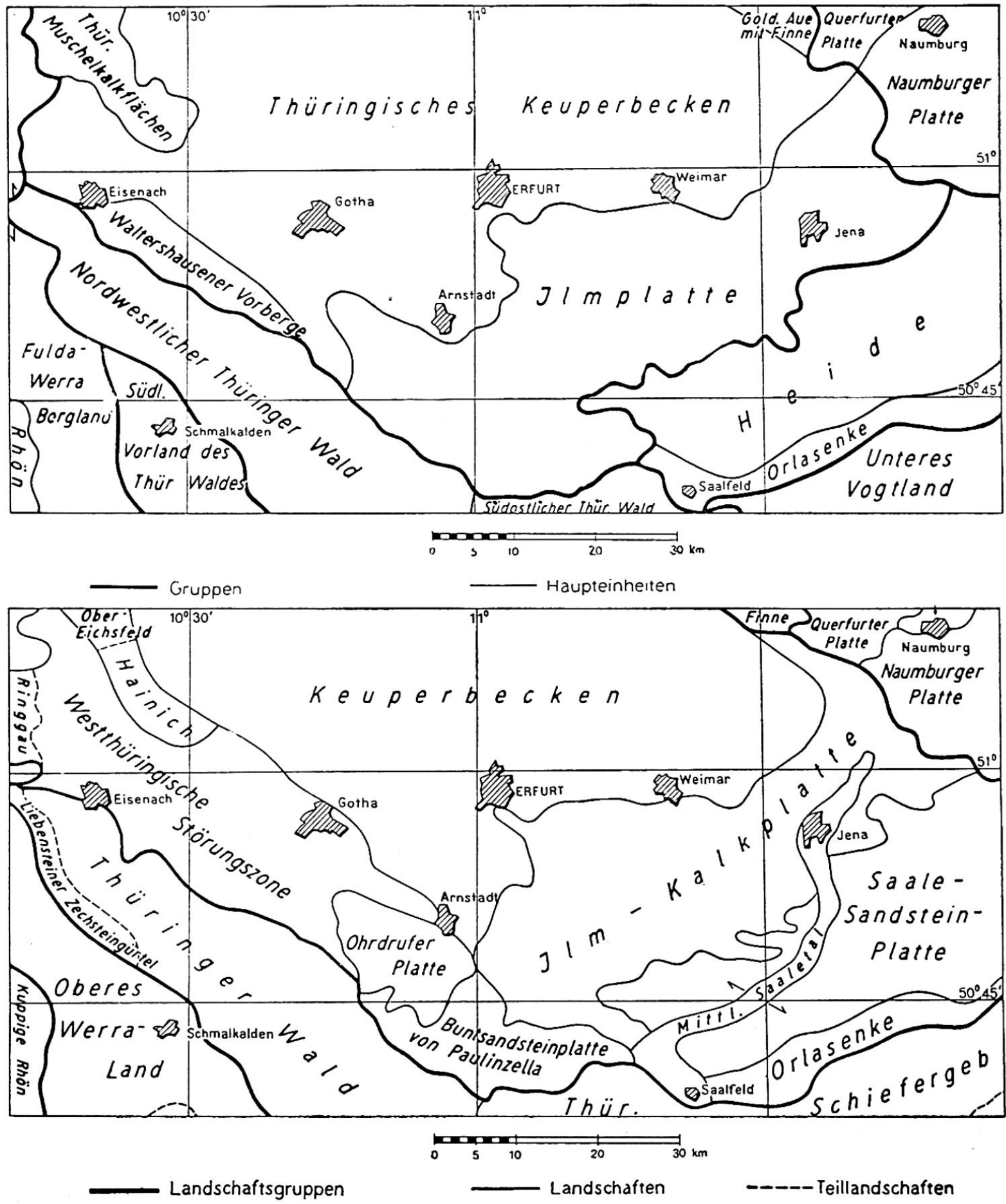

Abb. 9 Das südliche Innerthüringen. Oben in der naturräumlichen Gliederung von MeYNen und SCHMithüses 1951. Unten in der physisch-geographischen Gliederung von SCHULTZE 1948-1952. (Aus: Schultze, Die Naturbedingten Landschaften der Deutschen Demokratischen Republik.)

gegen zeigt Landschaften. (Genau: «naturbedingte Landschaften», und dazu zählen «diejenigen geographischen Landschaften, die sich unter den heutigen ökologischen Verhältnissen bei Aufhören jeglicher menschlicher Einflußnahme entwickeln würden» 106.) Schultze findet jedoch, daß die zwei Ergebnisse miteinander verglichen werden dürfen, denn für beide, sagt er, seien die gleichen Faktoren zu berücksichtigen gewesen. «J. SснмiтнüsEN und ich sind uns darüber klar geworden, daß die Unterschiede in der Konzeption so geringfügig sind, daß sie an sich zu den gleichen

${ }^{106}$ Schultze, Die Naturbedingten Landschaften, S. 3. 


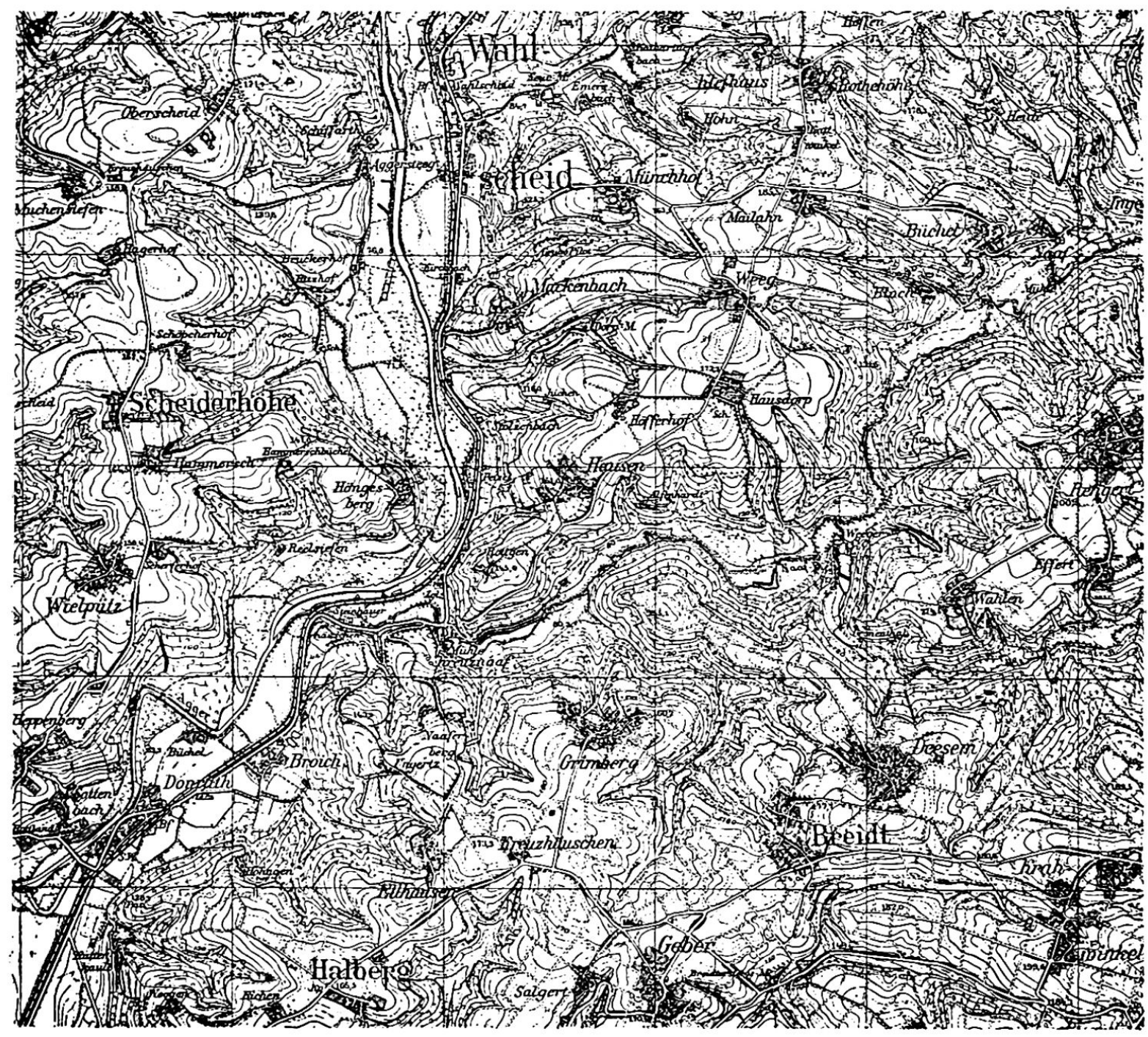

Abb. 10 Landschaftsausschnitt aus dem Bergischen Land beiderseits des unteren Aggertales (nach Meßtischblatt Wahlscheid 5109). (Aus: Troll, Die geogr. Landschaft und ihre Erforschung.)

Ergebnissen führen müßten» ${ }^{107}$. - Wie zu sehen ist, weichen aber auch diese beiden Beispiele auffällig voneinander ab. Schultze behilft sich mit einer entsprechenden Erklärung, wie sie schon zur Darstellung Ostafrikas gegeben worden ist: «Wenn die naturbedingten Landschaften andere Begrenzungen erfahren als die naturräumlichen Einheiten, so begründet sich dies vor allem durch die intensivere Durcharbeitung der genannten Landschaften seitens eines Stabes von Gebietskennern»108. An anderer Stelle von Schultze aufgeführte Flächenzahlen sollen die Gleichheit der Resultate beider Gliederungen belegen. «Die Größe der Landschaft bestimmt nicht der Autor, sondern die Natur mit ihren anorganischen und biotischen Geofaktoren sowie die Kultur mit ihren Geofaktoren der geistbestimmten Welt. Es ist daher kein Zufall, daß diese naturbedingten Landschaften eine durchschnittliche Größe von $614 \mathrm{~km}^{2}$ haben, die naturräumlichen Regionen Deutschlands eine solche von $825 \mathrm{~km}^{2}$. Dazu paßt recht gut das Durchschnittsmaß der Kulturlandschaften in Neugriechenland mit $550 \mathrm{~km}^{2} \gg 109$.

Unsere Erkenntnisse über die vermeintlichen Landschaftsganzheiten sind dargelegt worden. Auch die Belege von Schultze ändern an den früheren Feststellungen

107 Schultze, Die Naturbedingten Landschaften, S. 25.

108 SChultze, S. 25.

109 Schultze, Begriff und Gliederung der geogr. Landschaft, S. 295. 




Abb. 11 Die Gliederung des Landschaftsausschnittes von Abb. 10 in Oekotope oder Landschaftszellen. 1. Lößlehmbedeckte Hochflächenreste, 2. Steinige oder felsige Talhänge, 3. Von Lößlehm überkleidete, weniger steile Talhänge, 4. Bachbettlose Quellmulden der Hochfläche oder Dellen, 5. Schwemmkegel der Seitenbäche, 6. Schotterterrassen des Aggertales, 7. Feuchte Sohlen der Bachtäler und des Aggertales. (Aus: Troll, Die geogr. Landschaft und ihre Erforschung.)

nichts. Der in Zahlen ausgedrückte Flächenvergleich vermag zwar den Eindruck zu erwecken, als wären «Landschaften» tatsächlich reale Gegebenheiten. Es muß uns aber nochmals klar werden, daß in die Landschaft gezogene Grenzlinien immer standpunktbedingt sind und daß gleiche Einheiten nur resultieren, wenn für ihre Begrenzung auch gleiche Standpunkte eingenommen wurden. Da zudem jeder Standpunkt nur einen Aspekt der Landschaft vermittelt, ist es auch nicht möglich, eine der umfassenden Gesamtlandschaft zugeordnete Grenze zu finden. Im übrigen weist ja gerade Schultze selbst auf die Schwierigkeiten seiner Landschaftsbegrenzung hin.

Die landschaftliche Ganzheitsauffassung kann auch indirekt durch das von Troll in Abbildung 11 dargestellte Zellenmuster illustriert werden. (Abbildung 10 zeigt im gleichen Maßstab den entsprechenden Kartenausschnitt.) Unter Landschaftszellen werden «ökologisch homogene, aber in Mehrzahl vorhandene Standortsein- 
heiten» verstanden 110. Dazu zählen beispielsweise Talwiesensohlen, Ackerbauhochflächen, steile Talhänge, Siedlungsblöcke an einem Stadtrand. Derartige Einheiten kommen nach der Meinung Trolls «in jeweils charakteristischer Vergesellschaftung» vor und setzen «in einem bestimmten Raumgefüge die kleinsten Landschaftsindividuen zusammen»111. - $\mathrm{Zu}$ dieser Art der Herleitung von Landschaftsganzheiten seien hier zwei Fragen aufgeworfen: Ist es tatsächlich möglich, aus dem Mosaik der Landschaftszellen einheitliche Gruppierungen, klar begrenzte Ornamente, herauszulesen? Das Beispiel weicht dieser Frage aus, indem es statt der ganzen «Landschaftseinheit» bloß einen Ausschnitt darstellt. Und zweitens: In welcher Weise wird der für die Zellenbildung nicht maßgebende Landschaftsinhalt verwertet? Selbstverständlich schätzen wir die wissenschaftliche Bedeutung der Zellengliederung wie jede andere strukturelle Gliederung der Landschaft hoch ein. Die Zellen (Oekotope, Naturkomplexe ${ }^{112}$ ) sind aber bloß ptomatropische Einheiten im Bereich der anorganischen Landschaft, und sie allein konstituieren die Gesamtlandschaft nicht. Sie sind durchzogen und überlagert von andern Strukturen (z. B. dem ganzen organischen Gefüge der Landschaft), die andern Blickpunkten entsprechen.

$\mathrm{Da}$ viele Geographen bis in die jüngste Gegenwart hinein Vertreter der Ganzheitsauffassung sind, bestätigt eine eben veröffentlichte Arbeit von Walter JAHN (Juni 1957): «Es würde zweifellos zu weit führen, sollten alle Deutungen genannt werden, die das Wesen einer geographischen Landschaft erfahren hat. So uneinheitlich sie bei flüchtigem Hinsehen auch wirken mögen, so herrscht doch mehr Übereinstimmung, als es bisweilen den Anschein hat (Schmithüsen) ... Die Mehrheit (der Fachvertreter) steht auf dem Standpunkt, Landschaften seien ganzheitliche Räume, also Gebiete mit weitgehend gleichartiger Beschaffenheit und Ausprägung sowie dem Charakteristikum der Begrenzbarkeit» ${ }^{113}$.

f) Anneliese Siebert charakterisiert die Entwicklung der Landschaftsvorstellung folgendermaßen: «Am Anfang der Entwicklung des Landschaftsbegriffes standen unvollständige, zusammenhanglose Kompilationen. Dann wurde der Kausalzusammenhang entdeckt und dargestellt, das Wesentliche vom Unwesentlichen geschieden, das Schwergewicht vom Genetischen auf das Dynamische verlegt und zuletzt eine Gesamterfassung angestrebt, welche Bild, kausale Verknüpfung und Seeleneindruck umschließt. Mit dieser Vervollständigung und Vertiefung der geographischen Landschaftsauffassung erkennt man allmählich auch immer deutlicher, daß nicht die allgemein geographische Betrachtung der Gesetzmäßigkeiten der landschaftlichen Einzelerscheinungen, sondern die Erfassung der Landschaft als ,Ganzes', als ,Individuum' der eigentliche Gegenstand der geographischen Wissenschaft ist ${ }^{114}$. - Nach meiner eigenen Untersuchung glaube ich nun aber sagen zu müssen, daß A. SiEBERT falsch beraten ist und den Entwicklungsgang eher in der verkehrten als in der effektiv abgelaufenen Richtung beschreibt. Tatsache ist doch, daß die Ganzheitshypothese am Anfang und nicht am heutigen Ende steht; von der Ganzheitsauffassung ist die Landschaftskunde ausgegangen, und ohne Ganzheitsauffassung hätte die Landschaftskunde vermutlich gar nie entstehen können. Die Idee von der Ganzheit war der zündende Funke zur Begründung der Landschaftskunde. In den letzten Jahren wurde jedoch die Ganzheitshypothese von einzelnen Forschern genauer durchleuchtet, und die Resultate ihrer Arbeit weisen einigermaßen deutlich auf eine Befreiung von dieser Hypothese hin.

${ }^{110}$ TroLl, Die geographische Landschaft und ihre Erforschung, S. 169.

111 TroLl, ebd.

${ }^{112}$ Siehe Zusammenstellungen von Troll und Carol: TROLL, Die geogr. Landschaft und ihre Erforschung, S. 169-173. CAROL, Das agrargeogr. Betrachtungssystem, S. 22-24.

${ }^{118}$ JahN, Die Diskussion über den Begriff “ Landschaft» und ihre Bedeutung für die Schulgeographie, S. 213.

${ }^{114}$ SIEBERT, Wort, Begriff und Wesen der Landschaft, S. 37-38. 
Damit müssen wir auch Landschaftsvorstellungen aus andern Kulturbereichen anders beurteilen. Bis dahin war es nämlich üblich, alle nicht ganzheitlichen Vorstellungen als unentwickelt zu taxieren. Mit den neu gewonnenen Erkenntnissen werden wir aber bestimmt vorsichtiger und glauben darum beispielsweise nicht mehr, daß britische Geographen nur wegen unscharfen Formulierungen in unserer Literatur und wegen Übersetzungsschwierigkeiten die von uns immer wieder proklamierten landschaftlichen Ganzheiten nicht anerkennen können. Walther MANSHARD sagt nämlich: "Interessant sind in diesem Zusammenhang die Reaktionen britischer Geographen auf Gedankengänge von Vertretern der neueren deutschen Landschaftskunde. Bis zu einem gewissen Punkt... wird ohne weiteres gefolgt. Sowie aber Vokabeln wie ,ganzheitlich', ,harmonisch', ,disharmonisch' u. a. auftreten, setzt auffallend ein Bruch ein. Gerade bei diesen Begriffen sollten wir uns darüber klar sein, daß sie, zumal nach Übersetzung in eine andere Sprache, immer wieder Anlaß zu Mißverständnissen und schiefen Interpretationen geben $\gg \mathbf{1 1 5}$. Und ebenso glauben wir nicht, daß etwa die Landschaftsvorstellung in China deshalb weniger weit entwickelt wäre als die unsere, weil der Landschaftsbegriff noch nicht derart gefaßt ist, "wie wir ihn in der westlichen geographischen Wissenschaft anzuwenden gewohnt sind», d. h. weil die «Ganzheit Landschaft eine untergeordnete Rolle» spiele. Vielmehr ist richtig, was der Autor dieses Satzes weiter sagt: «Dennoch dürfen wir doch nicht über die chinesische Einstellung zur Landschaft hinwegsehen, die, obwohl aus eigener, uns gänzlich fremden Sphäre beleuchtet, doch eine große Bedeutung hat. Aus seiner engen Naturverbundenheit heraus besitzt der Chinese ein tiefes Landschaftsempfinden, dessen sichtbarer Ausdruck in zahlreichen Landschaftsbeschreibungen zutage tritt ${ }^{116}$.

\section{DIE VERWENDBARKEIT DES LANDSCHAFTSBEGRIFFES}

\section{Das Wort \& Landschaft .}

a) «Landschaft» ist verbraucht - b) "Landschaft" bezeichnet nicht die geographische «Landschaft» - c) Auch innerhalb der Geographie bedeutete bis anhin «Landschaft" nichts Verbindliches - d) Eine vorläufige Regelung.

a) Der Landschaftskunde ging in früheren Jahrzehnten und Jahrhunderten das Erforschen der Erde und besonders der Erdoberfläche im Sinne der heutigen Spezialwissenschaften voraus. Einzelne Arbeitszweige verselbständigten sich, nachdem ihre Stoffmenge im umfassenderen Rahmen nicht mehr zu bewältigen war. Die Landschaftskunde kann als Reaktion auf diese Verfächerung betrachtet werden. Man erkannte immer deutlicher, daß durch das spezialwissenschaftliche Vorgehen entscheidende Werte, die nur im Zusammensein der Einzelerscheinungen begründet liegen, zu wenig oder überhaupt nicht berücksichtigt wurden. Die Wahl des Namens «Landschaft » für das Zusammenspiel der Einzelerscheinungen war gegeben, denn vermeintlich bezeichnete dieses Wort schon von jeher dasselbe in außerwissenschaftlichen Bereichen, was man nun in die Geographie aufzunehmen gedachte. Und doch war das Vorgehen nicht glücklich: es verhinderte einen klaren Aufbau des neuen $Z_{\text {weiges der }}$ geographischen Wissenschaft mehr als daß es ihm dienlich gewesen wäre.

Schuld daran ist die Tatsache, daß die Bezeichnung «Landschaft» offensichtlich untrennbar mit der populären Landschaftsvorstellung verbunden ist. Man konnte nicht einfach nur eine sinnvolle Etikette übernehmen, sondern man trug mit der Etikette auch den populären Landschaftsinhalt in die Geographie hinein. Und dieser Inhalt entspricht (nach heutiger Erkenntnis) nun doch nicht der «landschaftlichen» Wirklichkeit, wie ursprünglich geglaubt wurde. Der Geograph ließ sich jedoch gerne $\mathrm{zu}$ einer Vermengung beider Gegebenheiten verleiten. Durch ein geschichtlich belaste-

115 Manshard, Der «Site"-Begriff in der britischen Geographie, S. 285.

116 Scholz, Die geographische Wissenschaft in China, S. 44. 
tes Wort wurde er also in seiner Objektivität und Unvoreingenommenheit beeinflußt, und dies ist für mich ein erster Grund zu behaupten, daß es für die geographische Wissenschaft von Nutzen gewesen wäre, wenn sie die Landschaftsbezeichung nie gebraucht hätte, und von Nutzen wäre, wenn sie auch in der Zukunft auf eine weitere Verwendung verzichten könnte.

b) Das Wort «Landschaft» besitzt aber nicht nur die eben erwähnte Suggestivwirkung, durch die ein einwandfreies wissenschaftliches Arbeiten gestört wird; das Objekt, wofür der Name einmal geprägt wurde, stellt auch dem Wesen nach etwas anderes dar als der Gegenstand der Geographie.

Ein Resultat der vorliegenden Untersuchung ist die Feststellung, daß der wissenschaftlich verstandene Landschaftsbegriff nur für das absolute und umfassende Sein eines Erdhüllenausschnittes - also nur für ein Geomer - stehen sollte. Deutlich ist hervorgehoben worden, daß Landschaft im Sinne einer menschlichen, wenn auch objektiv-wissenschaftlichen Interpretation des Absoluten immer eine Einengung der Wirklichkeit und somit auch eine unzulässige Verfälschung des geographischen Gegenstandes bedeuten müßte. Nun ist aber gerade der geschichtlich gewachsene, populäre Landschaftsbegriff nur Interpretation, und es geht keineswegs an, die gleiche Bezeichnung für zwei grundverschiedene Gebilde zu gebrauchen.

Das Wort «Landschaft» sei der Volkssprache entnommen, sagt Bürger. «In ihr hatte es bestimmte Bedeutungen, war es mit bestimmten Vorstellungen verbunden, längst, bevor es die geographische Wissenschaft übernahm» ${ }^{117}$. Er führt sieben volkstümliche Verwendungsarten auf, und es ist keine darunter, die nicht eindeutig auf den Menschen bezogen wäre. Besonders häufig finde man den Ausdruck «Landschaft», wenn man eine Gegend nach dem Eindruck, den deren (leblose) Natur auf den Beschauer mache, charakterisieren wolle, stellt er fest, und er erinnert in diesem $\mathrm{Zu}$ sammenhang an Redewendungen wie, «öde», «düstere» oder 《malerische» Land-

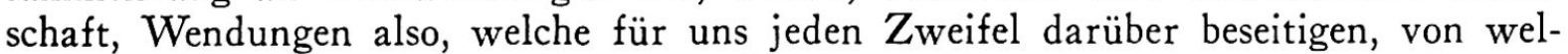
cher Art der populäre Landschaftsbegriff ist.

c) Und eine dritte Tatsache: Nachdem der Ausdruck «Landschaft» einmal in die Geographie übernommen war, mußte er als Bezeichnung jeder Art von Objektsvorstellung dienen. Es gelang den Wissenschaftern bis anhin nicht, sich zu einigen und die Landschaftsbezeichnung in nur einer Bedeutung zu gebrauchen. Das hatte wiederum eine Verwirrung zur Folge. Der Landschaftsname wurde nicht allein für die Gegenstandsbenennug auf den verschiedenen Stufen vom einfachsten Ptomatropen bis hinauf zum Geomer verwendet, sondern er diente sogar innerhalb der einzelnen Stufe zur Kennzeichnung methodischer Differenzierungen. Bei BoвEK, SchmiтнüSEN und LAUTENSACH beispielsweise ist die Rede von Land und Landschaft, wobei unter «Land» ein Raum-Individuum (Geomer) unter «Landschaft» aber ein RaumTypus verstanden wird. Darüber hinaus ist sogar die Möglichkeit erfaßt worden, nur den Typus als solchen mit «Landschaft»zu benennen und ihn seiner räumlichen Realisierung gegenüber $\mathrm{zu}$ stellen, welche bei weiteren Wissenschaftern ebenso kurz einfach «Landschaft» heißt. - Irgend eine andere Bezeichnung hätte wohl diese vielfältigen Dienste nicht erwiesen, da sie kaum in gleichem Maße schillernd gewesen wäre wie der Name «Landschaft».

Natürlich liegt die hier aufgeworfene Problematik nur zum Teil in der Namengebung begründet. Es ist uns bewußt, daß das Objekt selbst - eben die sogenannte Landschaft - die hauptsächlichsten Schwierigkeiten verursacht. Mit einer klareren Vorstellung vom Gegenstand vereinfacht sich auch die Frage der Benennung.

d) Konsequenterweise sollte in der Geographie nun aber doch auf eine weitere Verwendung des Landschaftsnamens verzichtet werden. Dieser hat sich bis heute je-

117 BÜrger, Der Landschaftsbegriff, S. 6. 
doch derart in die Wissenschaft eingebürgert, daß er kaum mehr ganz zu verdrängen sein wird, und es sei darum eine Kompromißlösung in Vorschlag gebracht. Sie bestehe darin, den Ausdruck «Landschaft» (wenigstens vorläufig) beizubehalten, ihn aber bloß noch auf die folgenden beiden Arten zu gebrauchen:

1. zusammen mit einem der drei Zusätze: in geomerischem, in geoptomischem oder in ptomatropischem Sinne oder

2. ohne einschränkende Bezeichnung für das umfassende Sein, also für das Geomer.

Im Schlußteil der vorliegenden Arbeit wird der Landschaftsname in der zweiten Art verwendet.

\section{Die landschaftliche Analyse}

a) Eine kritisierbare Kritik - b) Scientologische Erkenntnisse - c) Zugeständnisse von Geographen - d) Die analytischen Bereiche des Landschaftlichen - e) Die tektonisch-normativen Korrelationen.

a) «Das ungeheure Anwachsen der Spezialwissenschaften bereitet heute dem Geographie Studierenden nicht unerhebliche Schwierigkeiten, und auch in der Schulstube kann man oft feststellen, daß der einseitig in nur einer Hilfsdisziplin Bewanderte den richtigen Weg zur Länderkunde schwer findet oder - was noch bedauerlicher ist - nicht zum Kern der länderkundlichen Einheit und Ganzheit vordringt »118. Dieser Satz von Julius WAGNer weist ohne $Z$ weifel auf eine wunde Stelle der Geographie hin, aber leider lassen sich die notwendigen Konsequenzen nicht ohne weiteres ziehen, da der Weg, der zum Ziele führt, nirgends aufgezeigt ist. Auch mit bester Kenntnis des Geforderten ist noch wenig erreicht, weshalb auch eine positive Aussage wie die folgende ohne große praktische Wirkung bleiben muß: Man erkennt «allmählich auch immer deutlicher, daß nicht die allgemein geographische Betrachtung der Gesetzmäßigkeiten der landschaftlichen Einzelerscheinungen, sondern die Erfassung der Landschaft als Ganzes, als ,Individuum', der eigentliche Gegenstand der geographischen Wissenschaft ist ${ }^{119}$.

Das aufgeworfene Problem ist erst in zweiter Linie von der Art der Ausbildung und vom guten Willen des einzelnen Geographen abhängig; vorab bleibt es ein Problem prinzipieller Natur. Der Landschaftsbegriff könnte sogar durch und durch geklärt und sein tieferes Wesen jedem Geographen geläufig sein, es stellte sich auch dann noch die nicht unwesentliche Frage, wie weit sich die konkrete Landschaft mit wissenschaftlichen Mitteln wiedergeben ließe. Offensichtlich gibt es Dinge, welche der Wissenschaft nicht oder doch nur zum Teil zugänglich sind, und es ist zu untersuchen, ob nicht auch die Landschaft dazu zählt. Darauf kann jedoch nur mehr die Scientologie antworten.

b) Bei der Beschäftigung mit dem allgemeinen Wesen des Wissenschaftlichen läßt sich zunächst einmal eine immer wiederkehrende, charakteristische Eigenschaft feststellen, welche im Hinblick auf die Beurteilung des Landschaftsbegriffes von Interesse ist. Sie sei im folgenden in fünf prägnanten Formulierungen aufgeführt, um anschließend verwertet $\mathrm{zu}$ werden.

1. Das Gemeinsame aller Wissenschafts-Definitionen ist das ehrliche Bemühen um Wahrheit, wobei dieses Bemühen einen methodisch begründeten und systematischen Charakter tragen muß. «In jedem Falle zeigt sich, daß Wissenschaft zunächst grundsätzlich als methodische Wahrheitsforschung im weitesten Sinne

118 W AGNER, Der erdkundliche Unterricht, S. 16.

119 Siebert, Wort, Begriff und Wesen der Landschaft, S. 38. 
unter Beachtung eines Systematisierungsstrebens ihrer Erkenntnisse verstanden wird $\gg 120$.

2. «Das Erkennen mit wissenschaftlichen Methoden ist unter den allgemeinen Satz zu bringen: Alles Erkennen ist Auslegung $\gg 121$.

3. Zur Anwendung gelangen zwei sich immer wieder ergänzende Methoden, die erklärende und die beschreibende (Abschnitt B II, Seite 10).

4. «Die Klarheit wissenschaftlichen Denkens scheidet Universalwissenschaft aus, um als Wissenschaft sich stets im Besonderen zu verwirklichen. Es gibt nur Einzelwissenschaften.» «Echtes Wissen tritt immer als Einzelwissen auf ${ }^{122}$.

5. Durch die reine, wissenschaftliche Weltorientierung löst sich die Totalität eines Weltbildes auf, und «statt eines Systems des Ganzen gibt es als wahr nur noch Systematik, kategoriale und methodologische relative Ordnung» ${ }^{123}$.

Was kann den fünf Aussagen entnommen werden? - Der Schluß liegt nahe, daß echte Wissenschaftlichkeit im analysierenden Arbeiten gesucht werden mu $\beta$, und daß die Ergebnisse umso reiner in Erscheinung treten, je weiter die Analyse fortgeschritten ist. Hieß es doch, daß das Erkennen Auslegung (also nicht Gesamtschau) sei, daß es durch bestimmte zergliedernde und vergleichende Methoden (nicht aber durch irgend welche Integration) vollzogen werde, und daß schließlich Klarheit nur im Einzelwissen (nicht bei der Totalität aller Kenntnis) realisierbar bleibe.

c) Tatsache ist, daß der Landschaftskunde immer wieder und selbst von Geographen ein Mangel an Wissenschaftlichkeit vorgeworfen wird. Am eindrücklichsten ist das Zeugnis Passarges, des Schöpfers der Landschaftskunde, welcher dem «neuen Zweig»der Geographie noch im Jahre 1949 Problemlosigkeit nachsagt und feststellt, daß es sich bei allen Lösungen lediglich um eine Angelegenheit der Darstellung handle 124. Die übrigen Urteile gleichen dem Passargeschen. Erich OBst schreibt an einer Stelle: «Mit dem Gegensatz Ptolemäus-Strabo beginnt in der Antike jener unglückselige Dualismus, an dem die Geographie bis heute krankt. Er zieht sich durch die Jahrhunderte hin mit der Maßgabe, daß die Lehre von der Größe, Gestalt und physischen Beschaffenheit des Erdkörpers und seiner Sphären in steigendem Maße exakte wissenschaftliche Methoden entwickelt, während die Landschafts- und Länderkunde wesentlich dahinter zurückbleibt.» «Es soll bestimmt nicht übersehen werden, daß dank Karl Ritter, Alfred Hettner und vor allem Joseph Partsch die Landschafts- und Länderkunde endlich ein wissenschaftliches Fundament erhielt und derartig zum Lichte drängte, daß führende Vertreter der Allgemeinen Erdkunde (Richthofen, Penck, Passarge, Supan u. a. m.) unsere Wissenschaft auch durch hervorragende Werke länderkundlicher Art befruchteten. Aber dessen ungeachtet blieb nicht nur der Dualismus Allgemeine Erdkunde - Länderkunde bestehen, sondern es galt auch weiterhin als ungeschriebenes Gesetz, daß wirklich wissenschaftliche Arbeit eigentlich nur im Bereich der Allgemeinen Erdkunde Frucht tragen könne, daß nur hier wissenschaftlich einwandfreie Methoden zur Anwendung gelangen und nur hier allgemeingültige ,Gesetze' erkannt werden könnten. Die Landschafts- und Länderkunde, seien wir ganz ehrlich, wurde und wird mehr als eine Nebenfrucht geographischer Arbeit gewertet; sie galt und gilt, wenn wir das in absichtlich leichter Übertreibung so formulieren dürfen, in weiten Kreisen der Fachgenossen als populärwissenschaftliches Gegenstück zu der exaktwissenschaftlichen Forschung im Bereich der Allgemeinen Erdkunde»125.

120 Siehe "Universitas Litterarum ", S. 393-423.

121 JaSPERS, Einführung in die Philosophie, S. 76.

122 Jaspers, Philosophie, S. 136 und 138.

123 JASPERS, S. 114.

124 Schmitthenner, Zum Problem der Allgemeinen Geographie und der Länderkunde, S. 15.

${ }^{125}$ OBst, Das Problem der Allgemeinen Geographie, S. 2 ff. 
Hinter den Vorwürfen bleibt nun aber die Frage offen, ob sich die beanstandeten Verhältnisse je ändern lassen. Es ist jedenfalls auffällig, daß die Landschaftskunde als «synthetisierende»Wissenschaft, so, wie man sie sich wohl immer wieder vorstellte, im Gegensatz zu den vorne hergeleiteten Wissenschaftskriterien steht. SchмITTHENNER zieht aus der bestehenden Situation bereits folgenden Schluß: «Der Geograph muß sich dessen bewußt sein, daß die einzelnen Faktoren ebenso wie die Länder auch die Eigenart der ganzen Oberfläche der Erde zusammensetzen und daß großartige Zusammenhänge nicht mehr generell, sondern individuell erfaßt werden können»126. Und an anderer Stelle betont er schließlich, was effektiv und ohne Voreingenommenheit erforscht werden müsse, nämlich der Zusammenhang der Erscheinungen, also nicht das Komplexe des Landschaftlichen, sondern das Lineare. Erst in einem nachfolgenden Denkprozeß, sagt er, werde dann das Land erfahren. Dabei setze aber die «schaffende Gestaltung ein, eine Synthese, die künstlerische Kraft, das kombinatorische Denkvermögen, die Fähigkeit der Entwirrung und zugleich der funktionellen Verbindung der einzelnen Fäden in zutreffend abwägendem Denken zu einer geistigen Einheit»127. (Vgl. das ausführliche Zitat auf Seite 54 der vorliegenden Arbeit.)

d) Wenn die bisherigen Äußerungen auch bekräftigen, daß die Landschaftskunde als solche nicht den Charakter einer Wisssenschaft nach üblicher Auffassung besitzt, so zeigen sie doch, für welche Teilbereiche der Anspruch auf Wissenschaftlichkeit im genannten Sinne erhoben werden kann: für die «Allgemeine Erdkunde» einerseits und für die Klärung des «Zusammenhangs der Erscheinungen» (der Wechselwirkungen, der Funktionen) andererseits. Es gibt also auch Geographen, welche mehr oder weniger deutlich durchblicken lassen, daß «echte Wissenschaft» im analysierenden Arbeiten gesucht werden muß, denn sowohl die Resultate der allgemeinen Geographie wie auch der «Zusammenhang der Erscheinungen» sind nur durch strenge Analyse zu finden. Nun vertreten wir allerdings mit E. Oвsт die Meinung, «daß eine allgemeine Geographie im Sinne der Geographia generalis ... des Varenius heute nicht mehr möglich sei, sondern der Inhalt als Wissenschaft nur innerhalb der verschiedenen Fachwissenschaften mit deren Methoden bearbeitet werden könne»128. Der «Zusammenhang der Erscheinungen» hingegen ist in der letzten Zeit vom Geographen immer deutlicher in sein Blickfeld gerückt worden, und es stellt sich jetzt die Frage: Wollen und können wir auf diesen analysierbaren Teilbereich der Landschaft eine wissenschaftliche Geographie aufbauen? Zunächst ist jedoch zu prüfen, ob nicht noch andere landschaftliche Gegebenheiten durch die Analyse allein zu klären sind; die bisherige Auswahl hat sich ja bloß aus unsystematisch zusammengetragenen Zitaten ergeben.

Bei der Darstellung der ptomatropischen Landschaftsauffassung ist auf den heute anerkannten Landschaftsinhalt verwiesen worden. Nach der auf Seite 33 abgedruckten Zusammenfassung zählen dazu:

I. Stoffliche Komponenten,

II. Geistige Komponenten und

III. Komponenten-Bindungen.

Unter den Komponenten-Bindungen ist der schon erwähnte «Zusammenhang der Erscheinungen 》 zu verstehen. Die stofflichen Komponenten als solche gehören in den Untersuchungsbereich der alten allgemeinen Geographie und sind nun zu Objekten der Spezialwissenschaften geworden. Auch die geistigen Komponenten schließlich (sofern nicht schon ihre Auswirkungen auf die Landschaft gemeint werden) sind Gegen-

${ }^{126}$ Schmitthenner, Zum Problem der Allgemeinen Geographie und der Länderkunde, S. 12. 127 SCHMITTHENNER, S. 28-29.

${ }^{128}$ Vgl. Schmitthenner, Zum Problem der allgemeinen Geographie, S. 124. 
stand der Spezialwissenschaften. Also bleibt doch bloß der «Zusammenhang der Er. scheinungen» einer geographischen Analyse vorbehalten. Der «Zusammenhang der Erscheinungen» wäre nach allen bisherigen Erwägungen das einzige landschaftliche Teilgebiet, welches von der Geographie als analysierende Wissenschaft untersucht werden müßte!

Auch wenn wir die eben erwähnte Feststellung hinnehmen, so bedeutet das keineswegs eine besondere Entwertung unseres Faches. Die gegenseitigen Bindungen zwischen den Landschaftserscheinungen - die Korrelationen in anderer Terminologie scheinen das Wesentliche an unserem Untersuchungsgegenstand $\mathrm{zu}$ sein. Der Gestaltcharakter der Landschaft ist betont worden, und alle besonderen Kennzeichen einer Gestalt liegen in der Korrelation begründet. Folglich bleibt die Geographie wenigstens so weit Wissenschaft, als sie den Kernteil ihres Objektes zu ergründen sucht.

Ist es aber nicht auch üblich, daß sich die Spezialwissenschaften um Korrelationen bemühen, um Korrelationen, welche die Abhängigkeit ihrer Untersuchungsobjekte von der Umwelt bedingen? Und sind die spezialwissenschaftlich relevanten Korrelationen nicht zugleich auch die geographischen? Stellen doch die Untersuchungsgegenstände der Spezialwissenschaften die Elemente der Landschaft dar. - Der angedeutete Kompetenzkonflikt ist bald gelöst, und zwar zugunsten der Spezialwissenschaften. Diese kennen ihre Objekte im Detail, für sie sind es nicht nur Bestandteile eines größeren Ganzen, und darum können sie auch die Wirkungen aus der Umwelt besser begreifen und ihre Folgen zuverlässiger beurteilen. Es ist keine prinzipielle Frage, ob der Geograph oder der Spezialwissenschafter die Korrelationen untersuchen soll; es ist höchstens eine Frage der Zeit, wann die Spezialwissenschaften soweit fortgeschritten sind, um dem Geographen diese Arbeit in vollem Umfang abnehmen zu können. SchmitthenNer ist demnach, wie mir scheint, nicht im Recht, wenn er schreibt: «Das, was wir in der Länderkunde ohne Voreingenommenheit erforschen können und müssen, ist der Zusammenhang der Erscheinungen ${ }^{129}$.

Diese Tatsache bedeutet zwar noch kein endgültiges Urteil. Ist es nicht so, daß die Spezialwissenschaften nur die Abhängigkeit ihres Objektes von der Umwelt betrachten, nicht aber die Wirkungen, die vom Objekt selbst ausgehen? - Die gestellte Frage wird beispielsweise von P. Fickeler bejaht, wenn er in «Grundfragen der Religionsgeographie» sagt: «Die Beziehungen von Religion und Umwelt sind wechselwirkender Art, so daß man ihre Untersuchung in die beiden Hauptfragen kleiden kann: Wie wirkt die Umwelt, hier also das Volk, Landschaft und Land, auf eine religiöse Form, und wie wirkt umgekehrt eine religiöse Form wieder auf das Volk, Landschaft und Land zurück? Die Erfolg versprechende Untersuchung der ersten Fragestellung bildet mehr eine Aufgabe der Religionswissenschaft, der die Geographie die hierzu nötigen landschafts- und landeskundlichen Unterlagen liefert; die Untersuchung der zweiten Fragestellung dagegen ist mehr die Aufgabe der Religionsgeographie, der die Religionswissenschaft und andere Kulturwissenschaften die hierfür benötigten Unterlagen zur Verfügung stellen » ${ }^{130}$. Ich selbst bin anderer Meinung als Fickeler: Dadurch, daß die Abhängigkeit jedes Objektes von seiner Umwelt durch Spezialwissenschaften untersucht wird, sind auch die Ausstrahlungen jedes einzelnen Objektes bekannt. Es fehlt dann allerdings noch die Zusammenfassung vom Standpunkte des Landschaftskundlers aus, aber diese vorzunehmen kann keine eigentlich

129 Schmitthenner, Zum Problem der Allgemeinen Geographie und der Länderkunde, S. 28. Auf unserer Seite steht E. NEEF, wenn er sagt: "Die Tochterwissenschaften aber können ihrer Aufgabe nur gerecht werden, wenn sie sich nicht isolieren. Alle ihre Gegenstände sind nur reell in der Verflochtenheit mit dem gesamten geographischen Komplex. Löst man sie aus diesem heraus, so verliert man den Anschluß an die Wirklichkeit...» (Die axiomatischen Grundlagen der Geographie, S. 86.)

${ }^{130}$ FiCKELER, Grundfragen der Religionsgeographie, S. 121. 
wissenschaftliche Aufgabe sein. (Vgl. dazu Kapitel D III über die landschaftliche Synthese.)

Aber immer noch bleibt eine Frage ungelöst: Untersuchen die Spezialwissenschaften auch die Beziehungen zwischen Objekts-Komplexen? - BoBEK äußert sich deutlich zum aufgeworfenen Problem in der Arbeit über «Stellung und Bedeutung der Sozialgeographie». Einer seiner Sätze lautet: «Neben der Würdigung der Gesellschaft als landschaftsgestaltender Faktor erscheint die Aufgabe, die Gesellschaft als regionale Erscheinung an sich in den Kreis der geographischen Betrachtung zu ziehen»131. Er befürwortet also in seiner Aussage eine geographische Betrachtung der Gesellschaft nicht nur im Hinblick auf ihre Bedeutung für die Landschaft, sondern er möchte sogar die Gesellschaft als regionale Erscheinung - also eigentlich die Ausstrahlungen der Landschaft (der Umwelt, um zu verdeutlichen) auf die Gesellschaft - in den Untersuchungsbereich der Geographie einbeziehen. Auch gegenüber BoвEK bin ich anderer Auffassung. Keinesfalls scheint es mir sinnvoll und aussichtsreich zu sein, wenn wir den Soziologen konkurrenzieren und die Auswirkungen der Umwelt (der Landschaft) auf die Gesellschaft studieren wollen. Der Soziologe ist bestimmt in günstigerer Position als der Geograph. Und ebensowenig steht es uns an, den Einfluß der Gesellschaft auf die Umwelt - das heißt im Grunde genommen doch: auf einzelne betroffene Komplexe - zu erforschen. Sowohl die Komplexe selbst wie auch ihre gegenseitigen Beziehungen kommen von einer immer größer werdenden $Z$ ahl spezieller Wissenschaften zur Darstellung. Ich denke neben der Soziologie etwa an Biologie, Medizin, Psychologie, Biocœnologie, Meteorologie. Der Geograph hat für die Spezialwissenschaften fruchtbare Vorarbeit geleistet, aber die fortschreitende Spezialisierung verringert laufend seine Zuständigkeit.

e) Wir könnten an dieser Stelle zur Resignation veranlaßt sein. Wir haben nun festgestellt, daß echte Wissenschaft Analyse ist, daß überdies wesentliche landschaftliche Teilerscheinungen zwar der Analyse zugänglich sind, diese Erscheinungen aber vorteilhafter von Spezialwissenschaften als von der Geographie bearbeitet werden. Und doch bleibt in unserer Untersuchung eine nicht unbedeutende Lücke offen! Die Untersuchung ist nämlich insofern unvollständig, als sie den «Zusammenhang der Erscheinungen» noch nicht so umfassend wie möglich berücksichtigt hat. Es gibt zwei im Grunde verschiedene Deutungen für diesen Zusammenhang, und bis anhin ist nur eine davon zur Diskussion gestanden. Unter dem «Zusammenhang der Erscheinungen» kann einerseits aktives, gegenseitiges Sich-Beeinflussen verstanden werden; es lassen sich andererseits aber auch passive, verwandtschaftliche Bindungen damit bezeichnen. Diese passiven Bindungen sind noch nicht berücksichtigt worden, sie sind für den Landschaftscharakter aber keinesfalls weniger bedeutsam als die aktiven. Bei der Kennzeichnung des Landschaftsinhalts im Kapitel C II wurden die verwandtschaftlichen (die tektonisch-normativen) Beziehungen in aller Kürze aufgeführt. Die tektonisch-normativen Korrelationen zwischen den einzelnen Landschaftselementen gehören eindeutig ins Arbeitsfeld des Geographen. Sie lassen sich nur erfassen, wenn die Gesamtlandschaft im Auge behalten wird. Sie überbrücken verschiedene Sphären der Erdhülle, bilden Struktureinheiten und verbinden dadurch die Interessenbereiche der Spezialwissenschaften. Was allgemein unter diesen Korrelationen zu verstehen ist, hält in prägnanter Weise Paul NiggLI fest. Seine eingehenden Darlegungen hier wiederzugeben ist unerläßlich, wenn volle Klarheit erreicht werden soll.

Er stellt, den beiden Korrelationsarten entsprechend, zwei wissenschaftliche Methoden einander gegenüber. "Wir wollen, bewußt der Schwierigkeiten und gefaßt auf Einwände, die eine Methode (X) die abstrakt-generalisierende oder atektonisch-imperative bzw. ursächlich-erklärende, die andere (Y) die vergleichend-systematische oder tektonisch-normative bzw. urbildlich-erläuternde nennen.»

${ }^{131}$ BoвEK, Stellung und Bedeutung der Sozialgeographie, S. 123. 
Die Methode $\mathrm{Y}$ ist die uns jetzt interessierende. «Die Methode $\mathrm{Y}$ geht ihrerseits vom Dasein und dem So-und-nicht-anders-sein aus. Sie ist also ursprünglich, im Gegensatz zur dynamischen Methode eine mehr statische und vergleichende. Als Vorbild für die Erklärung dient ihr die Aufdeckung der Ideen, nach denen die Welt geformt erscheint. Voraussetzung ist die Möglichkeit zur Systematisierung und Klassifizierung, zunächst aber weniger, wie bei $X$, der Ereignisse als des Seins. Es muß versucht werden, ob in die scheinbar unerschöpfliche Mannigfaltigkeit der Natur eine Ordnung gebracht werden kann, die gesetzmäßige Beziehungen als leitende Prinzipien aufleuchten läßt. Auch das ist eine Entdeckungsfahrt, obgleich das Gefühl der Erfindung oder der Bestätigung einer Idee nicht selten das Vorherrschende ist. Der Typus des Verständnisideals ist der des Einordnens in große Zusammenhänge, der Erkennung der wesentlichen Prinzipien, die einer Sache zugrunde liegen, anthropomorph gedacht der Zusammenhang zwischen Idee, Urbild und Verwirklichung. Besteht bei $X$ die Spannung zwischen Theoretisch und Praktisch, so liegt sie hier im Gegensatz Ideal und Real begründet. Auch diese Methode muß generalisieren bzw., wie sie sagt, idealisieren. Um die Grundprinzipien zu erkennen, muß sie von vielen zunächst unwesentlich erscheinenden Beobachtungen absehen, den ,Kern der Sache' erfassen, Sammelbegriffe bilden, die durch ihre Brauchbarkeit sich als ,natürliche' Zusammenfassungen erweisen. Aber ihr Ziel ist von vornherein nicht die Eliminierung der Tektonik (d.h. des Werteverhältnisses der Teile zueinander) und der Formen der Welt, sondern deren unmittelbare Begreifbarkeit gemäß unserer Fassungskraft. Sie ist vergleichend systematisch und morphologisch, sie sucht nach Homologien und Analogien, schafft Gruppenbeziehungen und Korrelationen. Sie benutzt Ähnlichkeitssätze und geometrisch-topologische Erkenntnisse. Der Raum ist für sie von vornherein ein Systemsraum. Sie geht von der vorwissenschaftlich erkennbaren Inhomogenität und Diskontinuität aus. Individuen und Systeme werden als wesentlich angesehen und nun typisiert. Sie beantwortet die Warumfrage durch die Aufdeckung des Verhältnisses zu einem Normativen oder durch Einordnung in allgemeinere Gestaltungsprinzipien und die Lehre von der Verwandtschaft. Das Allgemeine scheint sich nicht wie bei der Methode $X$ zwangsweise dem Spezialfall unterordnen zu wollen, sondern ein Zielpunkt zu sein, auf den der Einzelfall, als etwas Ausgewähltes, bezogen werden kann. Sagt der Kausalforscher, ohne weitere Präzisierung, A ist die Ursache von $B$, so findet man in der Morphologie häufig Redewendungen wie: $B$ hat die Tendenz, A zu bilden, oder: B erweist sich als die und die Abwandlung von A. Gerade das hat zu manchen Mißverständnissen geführt, indem man glaubte, es handle sich um eine finalkausale Erklärung oder gar um eine Forschung nach Zweckursachen. Aber damit hat die Methode Y nichts gemein; sie wird sich selbst untreu, wenn sie derartige Bahnen beschreitet. Determination bzw. Kausalität ist bei ihr ganz ersetzt durch die Bestimmung des rein wissenschaftlichen Rangverhältnisses von Normen zueinander und zu Hauptnormen. Die aufgestellten Normen und Urbilder oder Symbole sind bereits Gesetze (Friedmann). Es entsteht, wie Gegenbaur schreibt, durch die Vergleichung ein Bild des Zusammenhanges, welches die Verwandtschaft bezeugt. ,Der vergleichenden Arbeit liegt ein bestimmtes Erleben der Natur als gestaltender Macht zugrunde' (Medicus).»

«Ist die Methode $X$ als ursprünglich dynamische affektreich, dem Pathos verpflichtet, so ist die Methode Y affektfreier, eher mit dem Ethos vergleichbar. Das bedeutet jedoch nicht inaktives Verhalten, auch kaum ein Mehr an Intuition. Immerhin hat die eine Methode nähere Beziehungen zur Technik, die andere zur Kunst. Beide Methoden sind, wie die kurzgefaßten Bemerkungen zeigten, bei allen Unterschieden eng miteinander verwandt, da sie beide dem Hauptziele, ein naturwissenschaftliches Weltbild zu formen, entsprechen. Auch die Methode Y erweckt dann, wenn sie Makromorphologisches mit Mikro- oder Submikromorphologischem, Struktur und Bauplan, korreliert, den Eindruck, Gründe und Ursachen für eine Erscheinung anzugeben. 
Sie muß mittels statistischer Verfahren das Normale ableiten, um es mit einem Normativen zu vergleichen. Da nun aber auch die Großzahl der Gesetze X statistische Gesetze sind oder auf statistischer Grundlage gewonnene generalisierte Aussagen enthalten, verwischt sich der Unterschied. Auch das imperativ Scheinende von $X$ ist zu einem Normativen geworden, aus einem ,Müssen' ist ein ,Sollen' geworden. Die beim Vorgehen $\mathrm{X}$ gewonnenen Einsichten, daß nur eine große Zahl von gleichartig zu behandelnden und vorauszusetzenden Einzelakten und Einzelerscheinungen die ,kausale' Betrachtung ermöglichen, ist, wie bereits betont, eigentlich eine morphologische Feststellung, die eines der wichtigsten Prinzipien von $\mathrm{Y}$, das Symmetrieprinzip, enthält. Die Strukturgesetze sowie topochemische und topophysikalische Aussagen haben die Bedeutung der Gestalt und Tektonik der Welt offenbart ${ }^{132}$.

«Gestalt» ist offenbar ein Begriff, der im Zusammenhang mit den tektonischnormativen Korrelationen erwähnt werden muß. Der gleiche Begriff war es, welcher die Landschaft als eigenständiges Gebilde verstehen ließ, und somit ist die enge Verbindung zwischen der tektonisch-normativen Arbeitsmethode und einer eigentlichen Landschaftskunde aufgezeigt.

Es ist im übrigen wohl kaum Zufall, daß gerade das neuere geographische Schaffen das Auffinden tektonisch-normativer landschaftlicher Strukturen zum Ziele hat: die naturräumliche Gliederung Deutschlands, die Kartierung der naturbedingten Landschaften der Deutschen Demokratischen Republik, die Landschaftsgliederungen Trolls und Paffens, die Darstellung der agrarformalen und agrarfunktionalen Einheiten durch CAROL oder die Gliederung der Amerikanischen Landschaft durch Boesch. Es scheint in der heutigen Geographie zu einer Selbstverständlichkeit zu werden, daß die tektonisch-normativen Strukturen ins Zentrum des Arbeitsfeldes gerückt werden.

\section{Die landschaftliche Synthese}

a) Analyse und Synthese - b) Die Synthese ist eine geistige Leistung - c) Synthese als Darstellung

a) Wir haben die Geographie an einer allgemeinen Auffassung von Wissenschaftlichkeit gemessen, und es ist fraglich, ob nicht von allem Anfang an das dem Fache anhaftende Besondere hätte gesucht werden müssen, ist doch bekannt, daß die Landschaft einen außergewöhnlich komplexen Untersuchungsgegenstand in Form einer Gestalt darstellt. Einem Objekt mit Gestaltcharakter scheint man eher durch die der Analyse entgegengerichteten Synthese als durch die Analyse beizukommen.

Was ist eigentlich Synthese? - Der amerikanische Philosoph Dewey sagt darüber: "So wie Analyse als eine Art in Bestandteile Zerlegen betrachtet wird, faßt man Synthese als einen Prozeß auf, der einem stofflichen Zusammensetzen gleicht. In diesem Licht betrachtet, hat sie etwas Geheimnisvolles an sich. Es verhält sich aber so, daß Synthese überall dort stattfindet, wo die Zusammenhänge zwischen Tatsachen und Schlüssen oder zwischen allgemeinen Prinzipien und Tatsachen erfaßt werden. So wie Analyse betont, ist Synthese ein ,Auf den richtigen Platz'-Stellen. Das eine bewirkt, daß die betonten Tatsachen oder Eigenschaften sich als bedeutsam abheben, das andere stellt die Zusammenhänge zwischen den gewählten Daten her. Jedes Urteil ist insofern analytisch, als es unterscheidet, auseinanderhält, das nicht zur Sache Gehörige und das Wesentliche trennt; und es ist insofern Synthese, als es im Denken eine Gesamtsituation hinterläßt, in der die gewählten Tatsachen ihren Platz gefunden haben.»

«Geistiger Fortschritt wird analytisches Vorgehen erfordern, ein Betonen jener Merkmale, die wichtig sind, so daß sie sich deutlich abheben.» Andererseits können Merkmale nicht verständlich sein, ehe sie nicht in einen Zusammenhang eingeord-

132 Niggli, Probleme der Naturwissenschaften, S. $20-29$. 
net sind. «Analyse führt zu Synthese, und die Synthese vervollständigt die Analyse.» «Diese enge Wechselbeziehung zwischen selektivem Betonen und Erklären ... ist überall dort anzutreffen, wo die Reflexion normal abläuft. Daher ist es unsinnig, Analyse und Synthese gegeneinander auszuspielen $\gg 133$.

b) Synthese ist keine selbständige wissenschaftliche Tätigkeit, sondern setzt die konkreten Forschungsresultate der Analyse voraus. Sie können (und sollen bei sinnvoller Arbeit) synthetisch gewertet werden. Diese Wertung ist jedoch eine individuelle geistige Leistung und läßt sich nicht, wie die analytischen Erkenntnisse, durch Anwendung bestimmter und erlernbarer Methoden erreichen. Synthese besteht darin, wurde eben festgestellt, daß sie in unserem Denken eine Gesamtsituation hinterläßt, in der die gewählten Tatsachen ihren Platz gefunden haben. Sie gleicht der Vision. Mit den Ausführungen Deweys stimmen eindeutig Erfahrungen von Geographen überein. Bei SchmitthenNer beispielsweise liest man:

«Aus diesen Einsichten wird dann zur Bewältigung der unendlichen Mannigfaltigkeit des räumlichen Substrats und des Raumkontinuums der Erdoberfläche in einem anderen, zweiten Denkproze $\beta$ das Land erfahren und in der Beschreibung und kausalen Durchdringung erkannt. Der Weg der Länderkunde ist es, aus dieser Erforschung zu Erkenntnissen zu führen und Teilen des Kontinuierlichen geistige Gestalt zu geben. Hier setzt die schaffende Gestaltung ein, eine Synthese, die künstlerische Kraft, das kombinatorische Denkvermögen, die Fähigkeit der Entwirrung und zugleich der funktionellen Verbindung der einzelnen Fäden in zutreffend abwägendem Denken zu einer geistigen Einheit ${ }^{134}$.

Und SANDER formuliert den Sachverhalt mit den Worten: «Die Gesamtheit jeweils zusammenwirkender Landschaftsbildner können wir treffend als dreidimensionales Konditionalgitter bezeichnen. In dem Moment nun, da uns dieser ,Gesamt'-Blick aufgeht, dies ,Gitter'-Bild einleuchtet, haben wir bereits den entscheidenden Punkt im Akt unserer Landschafts-Erkenntnis erreicht. Denn jetzt und hier schlägt unsere bisherige induktive, sozusagen passiv-registrierende Erfassung der (landschaftsbildenden) Einzelerscheinungen, um in eine schöpferisch zusammenfassende Ballung ihrer Vielheit zur komplexen Einheit, zu einer Raum-Ganzheit, zur geographischen ,Gestalt' der Landschaft. Das ist ein ganz seltsamer Wrgang. Ganz plötzlich geschieht es, daß am sich erschließenden Gegenstand (= dinglich erfülltem Erdenraum) der ihm zugeordnete Begriff (= der Landschafts-,Gestalt') sich konstituiert. Ganz plötzlich findet diese schöpferische Begegnung statt, dies synoptisch identifizierende Erfassen von Verschiedenerlei. Es ist, als erhöbe sich in unserer Seele ein bereits schlummernd vorhandenes, ahnendes Vorwissen von synthetischer Raum-Einheit ganz plötzlich über die Schwelle unseres Bewußtseins und würde wach, so daß es nunmehr als helles, klares Begreifen geschieht $\gg{ }^{135}$.

c) Wenn sich auch die Synthese nur als persönliche Einzelleistung im Geiste vollzieht, so kann sie doch durch geschickte Darstellung der analytischen Ergebnisse gefördert werden. Gute landschaftskundliche Lehrbücher erfüllen diesen $Z$ weck. Es muß uns aber bewußt bleiben, daß derartige darstellerische Versuche außerhalb eines eigentlichen Wissenschaftssbetriebes liegen, der jedem intellektuell Begabten zugänglich ist und in jedem Fall reproduzierbare und verifizierbare Resultate hervorbringt.

Für LaUtensach ist auch die Darstellung Wissenschaft ${ }^{136}$; er unterscheidet allerdings zwischen «populären Büchern》 und eigentlichen «wissenschaftlichen Monographien». Populäre Bücher werden nach ihm häufig von Verfassern geschrieben werden müssen, die an erster Stelle geschickt darzustellen verstehen und in mühsamer

${ }^{133}$ Dewey, Wie wir denken, S. 116-121.

${ }^{134}$ Schmitthenner, Zum Problem der Allgemeinen Geographie und der Länderkunde, S. 28-29.

135 SANDER, Landschaft und Mensch, S. 297.

${ }^{196}$ Lautensach, Forschung und Kompilation in der Länderkunde. 
Kleinarbeit die geographischen Tatsachen des betreffenden Landes additiv, etwa nach dem länderkundlichen Schema, aneinanderreihen. Dieses Verfahren, die Kompilation, hat ebenfalls (wie er sagt) seine Berechtigung. Man darf es nur nicht mit dem wissenschaftlichen verwechseln und alle länderkundliche Arbeit von vornherein als kompilatorisch bewerten.»

Zwischen populären landschaftskundlichen Büchern und wissenschaftlichen Monographien besteht nun aber kein prinzipieller Unterschied. Einen wesentlichen qualitativen Unterschied mag es geben, und dieser liegt in den persönlichen Fähigkeiten der Autoren begründet. Jedenfalls sind sowohl die «kompilatorische» wie die «wissenschaftliche» Darstellung individuelle Leistungen Einzelner, und das typisch Wissenschaftliche, eine Methode und damit in gewissem Sinne doch ein unpersönlicher Forschungsbetrieb, tritt nicht in Erscheinung ${ }^{137}$.

137 Vgl. Jaspers, Philosophie, S. 53-292.

\section{ZUSAMMENFASSUNG}

Der Landschaftsbegriff ist zum zentralen Begriff der Geographie geworden. Es gilt nun noch, ihn nach Inhalt und Umfang besser zu erhellen, damit die geographische Wissenschaft ihm entsprechend in allen Einzelzügen konzipiert werden kann. Die vorliegende Arbeit will sowohl an die eingehende Klärung dieses Begriffes wie auch an den Aufbau einer Gesamtkonzeption der Geographie einen Beitrag leisten. Im wesentlichen enthält sie folgende acht Feststellungen:

1. Die neuere Entwicklung der geographischen Methodologie hat die Zahl der voneinander abweichenden Landschaftsauffassungen nicht vermindert, sondern vermehrt. Die verschiedenartigen Auffassungen brauchen sich jedoch gegenseitig nicht auszuschließen. Sie bleiben sinnvoll, wenn sie als Interpretationsversuche einer umfassenden, absoluten Landschaft gewertet werden.

2. Ungleiche Interpretationen gehen von unterschiedlichen Maß-Systemen aus. Wird eine Vielzahl von Interpretationen anerkannt, dann müssen auch mehrere Maß-Systeme in die Geographie Eingang finden. Dadurch ist eine einheitlich geographische Betrachtungsweise der Landschaft ausgeschlossen.

3. Unter „Landschaft“ kann konsequenterweise nur mehr das absolute landschaftliche Sein verstanden werden. Es ist darum unzweckmäßig, den Landschaftsnamen anch für jede einzelne Interpretation zu verwenden. Er sollte allein zur Bezeichnung des Absoluten dienen oder, um keine weitere Unklarheit entstehen zu lassen, aus der Wissenschaft ausgeschieden werden.

4. Die bisherigen Landschaftsinterpretationen kommen dem absoluten landschaftlichen Sein in verschiedenem Grade nahe. In der vorliegenden Arbeit werden sie in ein hierarchisches System eingegliedert und als notwendige Betrachtungsschritte zur Erhellung der Gesamtlandschaft erkannt.

5. Die verbreitete Auffassung, wonach Landschaften begrenzte Raumeinheiten darstellen würden, ist nicht haltbar. Es gibt nur standpunktbedingte, subjektive Landschaftsgrenzen und somit nur Einheiten im Bereich der Interpretation.

6. Am Erfassen der einzelnen Landschaftserscheinungen haben verschiedene Spezialwissenschaften Anteil. Sich in allen zu betätigen, ist für den Geographen je länger desto mehr unmöglich. Er $\mathrm{mu} ß$ jedoch ihre landschaftlich relevanen Ergebnisse kennen und verstehen, um sie seiner eigenen Aufgabe dienstbar zu machen.

7. Der Arbeitsbereich der wissenschaftlichen Geographie kann indessen nicht in einer Zusammenschau der Erkenntnisse anderer Wissenschaften bestehen. Synthese als Zusammenschau ist unseres Erachtens nur durch künstlerische Darstellung zu verwirklichen.

8. Echte Wissenschaft ist analysierend und synthetisierend zugleich. Die Analyse vollzieht jeweils den primären Schritt; die Synthese ordnet die gewonnenen Resultate in einen höheren $\mathrm{Zu}$ sammenhang ein. In diesem Sinne von der wissenschaftlichen Geographie zu untersuchen sind die tektonisch-normativen Korrelationen in der Landschaft. Diese Korrelationen stehen über den landschaftlichen Einzelerscheinungen, und ihre Durchdringung setzt die Kenntnis der wesentlichen Resultate der Spezialwissenschaften voraus. In den tektonisch-normativen Korrelationen offenbart sich die Gestalt und damit das eigentliche Wesen der Landschaft. 


\section{LITERATURVERZEICHNIS}

1 Apel, M.: Philosophisches Wörterbuch. Sammlung Göschen, Band 1031. Berlin 1953.

2 BECK, H.: Moritz Wagner als Geograph. Erdkunde, Archiv für wissenschaftliche Geographie, 7, 1953, S. $125-128$.

3 Behrendt, R. F.: Aktuelle Probleme der soziologischen Forschung. Schweizerische Hochschulzeitung, 3, 1955, S. 123-131.

4 Bовек, H.: Stellung und Bedeutung der Sozialgeographie. Erdkunde, Archiv für wissenschaftliche Geographie, 2, 1948, S. 118-125.

5 Вовек, H. und Schmithüsen, J.: Die Landschaft im logischen System der Geographie. Erdkunde, Archiv für wissenschaftliche Geographie, 3, 1949, S. 112-120.

6 Вовек, H.: H. Lautensachs "Geographischer Formenwandel» - ein Weg zur Landschaftssystematik. Erdkunde, Archiv für wissenschaftliche Geographie, 7, 1953, S. 288-293.

7 Bochenski, J. M.: Die zeitgenössischen Denkmethoden. Dalp-Taschenbücher, Bern 1954.

8 Boesch, H.: Die Wirtschaftslandschaften der Erde. Zürich 1947.

9 BoEsch, H.: Spanische Geographie. Geographica Helvetica, 4, 1949, S. 93-97.

$10 \mathrm{BoEsch,} \mathrm{H.:} \mathrm{Amerikanische} \mathrm{Landschaft.} \mathrm{Neujahrsblatt,} \mathrm{herausgegeben} \mathrm{von} \mathrm{der} \mathrm{Naturforschenden}$ Gesellschaft in Zürich für das Jahr 1955.

11 BoEsch, H.: Beiträge zur Frage der geographischen Raumgliederung in der amerikanischen Literatur. Vierteljahrsschrift der Naturforschenden Gesellschaft Zürich, 1946, S. 37-50.

$12 \mathrm{Boesch}, \mathrm{H}$. und Carol, H.: Principles of the concept a Landscape ״. Manuskript 1956.

13 BRÜNger, H.: Gedanken über das Wesen, Methoden und die Begriffsbildung der Flur- und Siedlungsgeographie. Erdkunde, Archiv für wissenschaftliche Geographie, 2, 1948, S. 126-146.

14 BÜRgER, K.: Der Landschaftsbegriff. Ein Beitrag zur geographischen Erdraumauffassung. Dresdner Geogr. Studien, 7. Dresden 1935.

15 CAPr, Annette: Die Anwendung von Granoe's Methode zur Landschaftsgliederung am Beispiel des Kantons Zürich. Diss. Zürich 1947.

16 Carol, H.: Begleittext zur wirtschaftsgeographischen Karte der Schweiz. Geographica Helvetica, 1, 1946, S. $185-245$.

17 Carol, H.: Die Wirtschaftslandschaft und ihre kartographische Darstellung. Geographica Helvetica, 1, 1946, S. 246-279.

18 Carol, H.: Das agrargeographische Betrachtungssystem. Ein Beitrag zur landschaftskundlichen Methodik, dargelegt am Beispiel der Karru in Südafrika. Geographica Helvetica. 7, 1952, S. $17-67$.

19 Carol, H.: Zur Diskussion um Landschaft und Geographie. Geographica Helvetica, 11, 1956, S. $111-133$.

20 Carol, H.: Sozialräumliche Gliederung und planerische Gestaltung des Großstadtbereiches. Dargestellt am Beispiel Zürich. Raumforschung und Raumordnung, 14, 1956. Carl Heymanns Verlag KG Köln-Berlin.

21 Carol, H.: Grundsätzliches zum Landschaftsbegriff. Petermanns Geographische Mitteilungen, 101, 1957, S. 93-97.

22 Carol, H. und Neef, E.: Zehn Grundsätze über Geographie und Landschaft. Petermanns Geographische Mitteilungen, 101, 1957, S. 97-98.

23 Carol, H. und BoEsch, H. vide 12.

24 Cools, R. H. A.: Die Entwicklung und der heutige Stand der Sozialgeographie in den Niederlanden. Erdkunde, Archiv für wissenschaftliche Geographie, 4, 1950, S. 1-5.

25 Davis, D. G.: Zum Problem der Heckenlandschaft. Erdkunde, Archiv für wissenschaftliche Geographie, 7, 1953, S. 139-140.

26 Dewey, J.: Wie wir denken. Die Beziehung des reflektiven Denkens zum Prozeß der Erziehung. Zürich 1951.

27 ENEQUist, G.: Die jüngere Entwicklung der Geographie in Schweden. Erdkunde, Archiv für wissenschaftliche Geographie, 7, 1953, S. 111-123.

28 Fickeler, P.: Grundfragen der Religionsgeographie. Erdkunde, Archiv für wissenschaftliche Geographie, 1, 1947, S. 121-144.

29 Fochler-Hauke, G.: Geographische Forschung und Lehre in Argentinien. Erdkunde, Archiv für wissenschaftliche Geographie, 7, 1953, S. 40-48.

30 FREYER, H.: Theorie des gegenwärtigen Zeitalters. Stuttgart 1955.

31 von FreYtag-Löringhoff : Logik, ihr Sytem und ihr Verhältnis zur Logistik. Zürich-Wien 1955.

32 Fugmann, R.: Aufgabe und Zielsetzung der Wirtschaftsgeographie. Zeitschrift für Wirtschaftsgeographie, 1, S. 8-14. Hagen, Januar 1957.

33 GeIPEL, R.: Soziale Struktur und Einheitsbewußtsein als Grundlagen geographischer Gliederung. Rhein-Mainische Forschungen, Heft 38. Frankfurt am Main 1952.

34 Gex, M.: Einführung in die Philosophie. Bern 1946.

35 Grayö, J. G.: Reine Geographie. Acta Geographica, Helsinki 1929.

36 Grassi, E. und v. Uexküll, Th.: Von Ursprung und Grenzen der Geisteswissenschaften und Naturwissenschaften. Bern 1950. 
37 Grassi, E. und v. Uexküll, Th.: Die Einheit unseres Wirklichkeitsbildes und die Grenzen der Einzelwissenschaften. Bern 1951.

38 Gurlitt, D.: Grundbegriffe der Geographie. Universitas, Zeitschrift für Wissenschaft, Kunst und Literatur, 3, 1948, S. 427-436.

39 Gutersohn, H.: Geographie und Landesplanung. Kultur- und Staatswissenschaftliche Schriften der Eidg. Techn. Hochschule Zürich, Heft 31, 1942.

40 Gutersohn, H.: Harmonie in der Landschaft. Arbeiten aus dem Geogr. Institut der Eidg. Techn. Hochschule Zürich, 4, 1946.

41 Gutersohn, H.: Landschaften der Schweiz. Zürich 1950.

42 Häberlin, P.: Naturphilosophische Betrachtungen, I: Eine allgemeine Ontologie. Zürich 1939.

43 Hartke, W.: Gliederung und Grenzen im Kleinen. Erdkunde, Archiv für wissenschaftliche Geographie, 2, 1948, S. 174-179.

44 HartKe, W.: Die "Sozialbrache» als Phänomen der geographischen Differenzierung der Landschaft. Erdkunde, Archiv für wissenschaftliche Geographie, 10, 1956, S. 257-269.

45 Hartmann, M.: Die philosophischen Grundlagen der Naturwissenschaften. Jena 1948.

46 Hartshorne, R.: The Nature of Geography. A critical survey of current thought in the light of the past. Annals of the Association of American Geographers. Second printing. Lancaster, Pennsylvania 1946.

47 Heiss, R.: Der Gang des Geistes. Eine Geschichte des neuzeitlichen Denkens. Bern 1948.

48 Hettner, A.: Die Einheit der Geographie in Wissenschaft und Unterricht. Geographische Abende im Zentralinstitut für Erziehung und Unterricht, Heft 1. Berlin 1919.

49 Hetrner, A.: Die Geographie, ihre Geschichte, ihr Wesen und ihre Methoden. Breslau 1927.

50 Husserl, E.: Die Idee der Phänomenologie. Haag 1950.

51 James, E. und Jones, F.: American Geography, Inventory \& Prospect. Syracuse 1954.

52 JaHN, W.: Die Diskussion über den Begriff «Landschaft» und ihre Bedeutung für die Schulgeographie. Geographische Rundschau, 9, 1957, S. 213-216.

53 Jaspers, K.: Philosophie. Zweite unveränderte Auflage. Berlin/Göttingen/Heidelberg 1948.

54 Jaspers, K.: Philosophie und Wissenschaft. Antrittsvorlesung an der Universität Basel. Zürich 1949.

55 Jaspers, K.: Einführung in die Philosophie. Zürich 1953.

56 JASPERs, K.: Die geistige Situation der Zeit (1931). Sammlung Göschen, Band 1000, 3. Abdruck der 5. Auflage. Berlin 1953.

57 Kraus, Th.: Räumliche Ordnung als Ergebnis geistiger Kräfte. Erdkunde, Archiv für wissenschaftliche Geographie, 2, 1948, S. 151-155.

58 Kraus, Th.: Geographie als individuelle Länderkunde. Erdkunde, Archiv für wissenschaftliche Geographie, 5, 1951, S. 193-196.

59 KüchleR, A.W.: Die Entwicklung der Pflanzengeographie in den Vereinigten Staaten. Erdkunde, Archiv für wissenschaftliche Geographie, 6, 1952, S. 266-270.

60 Lautensach, H.: Forschung und Kompilation in der Länderkunde. Geographische Rundschau, 5, 1953, S. 4-6. Braunschweig 1953.

61 Lautensach, H.: Paul Choffat und die länderkundliche Forschung in Portugal. Geographica Helvetica, 4, 1949, S. 97-105.

62 Lautensach, H.: Der Geographische Formenwandel. Studien zur Landsschaftssystematik. Colloquium Geographicum, Band 3. Bonn 1952.

63 Lautensach, H.: Über die Begriffe Typus und Individuum in der geographischen Forschung. Münchner Geogr. Hefte, 3, 1953.

64 Lautensach, H.: Ist Länderkunde möglich? Geographische Rundschau, 5, 1953, S. $260-262$. Braunschweig 1953.

65 Lehmann, H.: Die Physiognomie der Landschaft. Studium Generale, 1950, S. 182-195. Berlin/Göttingen/Heidelberg 1950.

66 Lehovec, O.: Erdkunde als Geschehen. Landschaft als Ausdruck eines Kräftespiels. Erdkundliches Wissen, 2, 1953. Remagen 1953.

67 Lehovec, O.: Betrachtungen zur Landschaftskunde. Geogr. Rundschau, 6, 1954, S. $259-262$. Braunschweig 1950.

68 Lütgens, R.: Die geographischen Grundlagen und Probleme des Wirtschaftslebens. Erde und Weltwirtschaft, Band 1. Stuttgart 1950.

69 Manshard, W.: Der «Site»-Begriff in der britischen Geographie. Erdkunde, Archiv für wissenschaftliche Geographie, 6, 1952, S. 284-286.

70 Manshard, W.: Vom Geographiestudium an britischen Universitäten. Geographica Helvetica, 8, 1953, S. $8-10$.

71 Maull, O : Die Einheit der Landschaft und länderkundliche Einheiten. Comptes rendus du Congrès International de Géographie, Amsterdam 1938, Band 2, S. 150-157.

72 Medicus, F.: Vom Wahren, Guten und Schönen. Kulturphilosophische Abhandlungen. Erlenbach-Zürich 1943.

73 NeEF, E.: Das Kausalitätsproblem in der Entwicklung der Kulturlandschaft. Wissenschaftliche Zeitschrift der Universität Leipzig, Heft 2, 1, 1951/52. 
74 NeEF, E.: Einige Grundfragen der Landschaftforschung. Wissenschaftliche Zeitschrift der KarlMarx-Universität Leipzig, Mathematisch-Naturwissenschaftliche Reihe, Heft 5, 5, 1955/56.

75 NeEf, E.: Die axiomatischen Grundlagen der Geographie. Geographische Berichte. Mitteilungen der Geographischen Gesellschaft der Deutschen Demokratischen Republik, 2, 1956.

76 Neef, E. und Carol, H. vide 22.

77 NigGLl, P.: Schulung und Naturerkenntnis. Erlenbach-Zürich 1945.

78 Niggli, P.: Vom Nutzen der wissenschaftlichen Forschung. Kultur- und staatswissenschaftliche Schriften der Eidg. Techn. Hochschule, Nr. 58. Zürich 1947.

79 Niggl, P.: Probleme der Naturwissenschaften, erläutert am Begriff der Mineralart. Wissenschaft und Kultur, Band 5. Basel 1949.

80 Oвsт, E.: Das Problem der Allgemeinen Geographie. Deutscher Geographentag München, 1948. Landshut/Bay. 1950.

81 Ochsner, K.: Vom Sinn der Wissenschaft. Ein Beitrag zur Überwindung des Relativismus. Winterthur 1953.

82 Oppenheimer, R.: Wissenschaft und allgemeines Denken. Rowohlts Deutsche Enzyklopädie. Hamburg 1955.

83 Otremba, E.: Die Grundsätze der naturräumlichen Gliederung Deutschlands. Erdkunde, Archiv für wissenschaftliche Geographie, 2, 1948, S. 156-167.

84 Otremba, E.: Allgemeine Agrar- und Industriegeographie. Erde und Weltwirtschaft, Band 3. Stuttgart 1953.

85 Overbeck, H.: Die Entwicklung der Anthropogeographie (insbes. in Deutschland) seit der Jahrhundertwende und ihre Bedeutung für die geschichtliche Landesforschung. Koblenz a/Rh. 1954.

86 Paffen, K. H.: Oekologische Landschaftsgliederung. Erdkunde, Archiv für wissenschaftliche Geographie, 2, 1948, S. 167-173.

87 Passarge, S.: Vergleichende Landschaftskunde. Hefte 1-4. Berlin 1921 bis 1924.

88 Passarge, S.: Einführung in die Landschaftskunde. Leipzig und Berlin 1933.

89 Platt, R. S.: Die Entwicklung der Kulturgeographie in Amerika. Erdkunde, Archiv für wissenschaftliche Geographie, 6, 1952, S. 260-263.

90 Regel, C. voN, und WiNKLER, E.: Zur Landschafts-Diskussion in der Sowjet-Geographie. Geographica Helvetica, 8, 1953, S. 234-248.

91 SANDER, E.: Landschaft und Mensch. Über die Aufgabe der Erdkunde in unserer Zeit. Erdkunde in der Schule, 2, S. 295-300. Hagen, Jan. 1957.

92 Siebert, A. und Brüning, K.: Wort, Begriff und Wesen der Landschaft. Umschaudienst des Forschungsausschusses «Landschaftspflege und Landschaftsgestaltung der Akademie für Raumforschung und Landesplanung. 5. Jahrgang, Heft 2. Hannover 1955.

93 Sinnhuber, K. A.: Die Geographie auf der 115. Jahrestagung der British Association for the Advancement Science. Erdkunde, Archiv für wissenschaftliche Geographie, 8, 1954, S. 69-71.

94 SchaffNer, W.: Die geographische Grenze zwischen Jura und Mittelland. Ein Beitrag zur Landschaftskunde der Schweiz. Diss. Zürich 1946.

95 Schmid, E.: Der Ganzheitsbegriff in der Biocoenologie und in der Landschaftskunde. Geographica Helvetica, 10, 1955, S. 153-162.

96 Schmithüsen, J. und Meynen, E.: Handbuch der naturräumlichen Gliederung Deutschlands. Erste Lieferung, hgg. im Auftrage der Bundesanstalt für Landeskunde. Remagen 1953.

97 Schmithüsen, J.: Die naturräumlichen Einheiten auf Blatt 161 Karlsruhe. Stuttgart 1952.

98 Schmitthenner, H.: Zum Problem der allg. Geographie. Geographica Helv., 6, 1951, S. 123-137.

99 Schmitthenner, H.: Zum Problem der Allgemeinen Geographie und der Länderkunde. Münchner Geogr. Hefte, 4, 1954. Kallmünz/Regensburg 1954.

100 Schmitthenner, H.: Studien zur Lehre vom geographischen Formenwandel. Münchner Geogr. Hefte, 7, 1954. Kallmünz/Regensburg 1954.

101 Schmitthenner, H.: Die Entstehung der Geomorphologie als geographische Disziplin (18691905). Petermanns Geographische Mitteilungen, 100, 1956.

102 Schneider, F.: Philosophie der Gegenwart. Glauben und Wissen, Heft 12. Basel 1953.

103 Scholz, H.: Die Geographische Wissenschaft in China. Geographica Helvetica, 5, 1950, S. 40-46.

104 Sснотт, C.: Die Geographie in Kanada. Erdkunde, Archiv f. wissensch. Geogr., 7, 1953, S. 229-232.

105 Sсноеск, H.: Soziologie. Freiburg/München 1952.

106 SCHöLleR, P.: Wege und Irrwege der politischen Geographie und Geopolitik. Erdkunde, Archiv für wissenschaftliche Geographie, 11, 1957, S. 1-20.

107 Schöller, P.: Aufgaben und Probleme der Stadtgeographie. Erdkunde, Archiv für wissenschaftliche Geographie, 7, 1953, S. 161-184.

108 Schul.tZe, J. H.: Die Naturbedingten Landschaften der Deutschen Demokratischn Republik. Ergänzungsheft Nr. 257 zu «Petermanns Geogr. Mitteilungen». Gotha 1955.

109 Schultze, J. H.: Begriff und Gliederung geographischer Landschaft. Forschungen und Fortschritte, 29, 1955, S. 291-297.

110 Schwind, M.: Sinn und Ausdruck der Landschaft. Studium Generale, 1950, S. 196-201. Berlin/Göttingen/Heidelberg 1950.

111 Schwind, M.: Geographie in Japan. Erdkunde, Archiv für wissensch, Geographie, 5, 1951, S. 82. 
112 Staiger, E.: Versuch über den Begriff des Schönen. Trivium, Schweiz. Vierteljahresschrift für Literaturwissenschaft und Stilkritik, 3, 1945.

113 Troll, C.: Die geographische Wissenschaft in Deutschland in den Jahren 1933 bis 1945. Erdkunde, Archiv für wissenschaftliche Geographie, 1, 1947, S. 3-48.

114 Troll, C.: Die geographische Landschaft und ihre Erforschung. Studium Generale, 4, 1950. Berlin/Göttingen/Heidelberg 1950.

115 Troll, C.: Stand und Aufgabe der Geographie von heute. Geographische Rundschau, 5, 1953, S. 1-4. Braunschweig 1953.

116 Troll, C.: Ein Markstein in der Entwicklung der medizinischen Geographie. Erdkunde, Archiv für wissenschaftliche Geographie, 7, 1953, S. 60-64.

117 Universitas Litterarum, hgg. von SCHUDER, W.: Handbuch der Wissenschaftskunde. Berlin 1955.

118 Wagner, J.: Der erdkundliche Unterricht. Handbuch der Mittelschulpädagogik in Einzeldarstellungen, hgg. von Nikolaus Maassen. Hannover 1955.

119 Weigr, E.: Wirtschafts- und Sozialgeographie. Zeitschrift für Wirtschaftsgeographie, 1, S. 1-8. Hagen, Januar 1957.

120 Weigt, E.: Die Geographie. Eine Einführung in Wesen, Methoden, Hilfsmittel und Studium. Braunschweig 1957.

121 Windler, H.: Zur Methodik der geogr. Grenzziehung am Beispiel des Grenzbereiches der Kantone Schwyz, Zug und Zürich. Geographica Helvetica, 9, 1954, S. 129-185.

122 Winkler, E.: Das System der Geographie und die Dezimalklassifikation. Eidg. Techn. Hochschule, Arbeiten aus dem Geogr. Institut. Zürich 1946.

123 Winkler, E.: Landschaft als Inbegriff der Geographie. Zu einem Sonderheft des Studium Generale. Geographica Helvetica, 6, 1951, S. 137-140.

124 Winkler, E. und Regel, C., von vide 90.

125 Winkler, E.: Das Handbuch der naturräumlichen Gliederung Deutschlands. Erdkunde, Archiv für wissenschaftliche Geographie, 9, 1955, S. 320-322.

126 Winkler, E.: Landschaft. Gefährdung und Regeneration des menschlichen Lebensraums. Atlantis : Länder, Völker, Reisen, 28, 1956.

\section{THE DEVELOPMENT OF THE REGIONAL CONCEPT} IN RECENT YEARS

The regional concept and the regional method have become the central objectives in modern scientific geography. What the present study attempts to do is to examine and determine the scope and nature of this concept, so that geography as a science may be conceived in all its details according to a more comprehensive and, at the same time, more exact definition of what we understand by the term region, or landscape. We thus hope to contribute to a clearer notion of its structural elements and to a deeper foundation of the scientific character of geography. The following statements and conclusions of this investigation seem to us to be essential:

1. The recent changes in geographical methodology have not reduced, but rather increased the number of diverging conceptions of landscape. The various conceptions, however, need not exclude one another. They preserve their meaning if they are regarded as attempts to interpret the totality of region seen in its various aspects.

2. Diverging interpretations have their cause in different systems of values. If we accept a variety of interpretations, we must also allow several value systems to be introduced into geography. A uniform geographical approach to landscape is impossible.

3. The term landscape or region, as we must understand it, can only stand for an absolute entity. To avoid ambiguity it should denote the absolute only, or else be altogether excluded from scientific nomenclature. It is inexpedient to apply it to any concrete interpretation.

4. The interpretations of landscape hitherto published reflect the absolute reality in various degrees. In this study they have been arranged in a systematic order revealing them as necessary steps on the way to an exact understanding of the whole of the landscape.

5. The widespread opinion that a landscape is an areal unit is fictitious. There are subjective delimitations of landscape only, resulting from a personal, and therefore limited, viewpoint. They are merely units for the sake of interpretation.

6. Several sciences contribute to an understanding of the features of a region. No geographer can do all-round scientific work anymore. He should, however, know all their results that bear upon his subject-line, and be capable of making proper use of them.

7. The task of scientific geography cannot consist in a synopsis of the knowledge other sciences have made accessible. Its highest achievement is a synthesis which requires the gift of the scientist combined with that of the artist.

8. Real science is at once analytical and synthetical. Systematic analysis makes the primary step; synthesis connects the individual results and arranges them in proper order. In this way scientific geography is to examine the tectonic-normative interrelations characterizing the landscape. These interrelations rank above the individual phenomena of a region; to penetrate them implies familiarity with the relevant results of the special branches of science. In the tectonic-normative interrelations the true nature of the landscape reveals itself. 